\title{
The effects of a randomized four-week dynamic balance training program on individuals with chronic ankle instability
}

\author{
Benjamin M. Anguish \\ West Virginia University
}

Follow this and additional works at: https://researchrepository.wvu.edu/etd

\section{Recommended Citation}

Anguish, Benjamin M., "The effects of a randomized four-week dynamic balance training program on individuals with chronic ankle instability" (2010). Graduate Theses, Dissertations, and Problem Reports. 4560.

https://researchrepository.wvu.edu/etd/4560

This Thesis is protected by copyright and/or related rights. It has been brought to you by the The Research Repository @ WVU with permission from the rights-holder(s). You are free to use this Thesis in any way that is permitted by the copyright and related rights legislation that applies to your use. For other uses you must obtain permission from the rights-holder(s) directly, unless additional rights are indicated by a Creative Commons license in the record and/ or on the work itself. This Thesis has been accepted for inclusion in WVU Graduate Theses, Dissertations, and Problem Reports collection by an authorized administrator of The Research Repository @ WVU. For more information, please contact researchrepository@mail.wvu.edu. 
The Effects of a Randomized Four-Week Dynamic Balance Training Program on Individuals with Chronic Ankle Instability

Benjamin M. Anguish, ATC

Thesis to be submitted to

College of Physical Activity and Sport Sciences

at West Virginia University

in partial fulfillment of the requirements for the degree of

Master of Science in Athletic Training

Michelle A. Sandrey, PhD, ATC, Chair

Benjamin Moorehead, MD

Greg Dahmer, MA, ATC, CO

Sean Bulger, Ed.D

Morgantown, West Virginia

2010

Keywords: Chronic Ankle Instability, Dynamic Balance Training, Star Excursion Balance Test, Joint Position Sense, Foot and Ankle Ability Measure and FAAM sport 


\begin{abstract}
The Effects of a Randomized Four-Week Dynamic Balance Training Program on Individuals with Chronic Ankle Instability
\end{abstract}

\title{
Benjamin M. Anguish
}

Context: Rehabilitation for chronic ankle instability is constantly evolving in an attempt to determine the correct course to reduce the deficits associated with chronic ankle instability. Research has shown that balance training over a 4 week period was beneficial in improving selfreported function, dynamic postural control and static postural control. With results still unclear on whether balance and coordination training will increase dynamic postural control or joint position sense, dynamic balance training program may be beneficial in decreasing the deficits associated with chronic ankle instability. Objective: The present study aims to investigate the affects of a dynamic balance training program compared to traditional balance rehabilitation on dynamic postural control, joint position sense and self reported function with subjects who experience chronic ankle instability. Design: A 2x3 factorial design (time x group), time being pre-post measures and group including control, traditional rehab, and dynamic balance rehab, was used for all independent variables (FAAM, FAAM Sport, SEBT A, PM, PL, and JPS DF, PF, IV, and EV). Setting: A AAA High School in North Central West Virginia. Patients or Other Participants: Twenty-six subjects ( 3 female, 23 male; Age 19.65 \pm 2.91 yrs; Height $175.56 \pm 7.27 \mathrm{~cm}$ ) with a history of chronic ankle instability as determined by an instability questionnaire and orthopedic special tests volunteered for this study. Interventions: Subjects were randomly assigned to the Dynamic Balance-Training program (DBTP), Traditional Rehabilitation Program(TRP) or control group. The DBTP and TRP groups participated in two different 4 wk programs $3 x$ a week. The DBTP group performed a battery of dynamic hop to stabilization exercises $3 x$ a week over a 4 week period. The 4 -week TRP group performed a series of single leg balance exercises three times a week, with exercises being advanced throughout the 4 week period for both groups. Pre- and Post-test measurements were taken using the Foot and Ankle Ability Measures (FAAM), FAAM Sport, the SEBT in three directions, and weight bearing JPS. Main Outcomes Measures: A significant improvement in dynamic postural control and joint position sense in both groups with the DBTP group having a greater improvement. Also a significant increase in self reported function with DBTP group having a greater improvement. Results: There was a significant interaction for time by group with FAAM $\left(\mathrm{F}_{2,23}=7.17, \mathrm{P}=.003, \mathrm{y}^{2}=.402,1-\beta=.918\right)$, SEBT A $\left(\mathrm{F}_{2,23}=24.469, \mathrm{P}<.001, \mathrm{y}^{2}=.680,1-\beta=1.00\right)$, $\operatorname{SEBT} P M\left(\mathrm{~F}_{2,23}=19.461, \mathrm{P}<.001, \mathrm{\eta}^{2}=.629,1-\beta=1.00\right)$, and SEBT PL $\left(\mathrm{F}_{2,23}=25.764, \mathrm{P}<.001\right.$, $\left.\eta^{2}=.691,1-\beta=1.00\right)$ with post test $>$. There was a significant main effect for time with FAAM $\left.\left(\mathrm{F}_{1,23}=31.99, \mathrm{P}<.001, \mathrm{y}^{2}=.582,1-\beta=1.00\right)\right)$, FAAM Sport $\left(\mathrm{F}_{1,23}=31.85, \mathrm{P}<.001, \mathrm{\eta}^{2}=.581,1-\beta=\right.$ 1.0), SEBT A $\left(\mathrm{F}_{1,23}=128.56, \mathrm{P}<.001, \mathrm{\eta}^{2}=.848,1-\beta=1.00\right)$, SEBT PM $\left(\mathrm{F}_{1,23}=108.216, \mathrm{P}<.001\right.$, $\mathrm{y} 2=.825,1-\beta=1.00)$, SEBT PL $\left(\mathrm{F}_{1,23}=149.25, \mathrm{P}<.001, \mathrm{\eta}^{2}=.866,1-\beta=1.00\right)$, JPS DF $\left(\mathrm{F}_{1,23}=12.85\right.$, $\left.\mathrm{P}=.002, \mathrm{\eta}^{2}=.358,1-\beta=.929\right)$, JPS PF $\left.\mathrm{F}_{1,23}=12.194, \mathrm{P}=.002, \mathrm{\eta}^{2}=.346,1-\beta=.917\right)$, JPS IV $\left(\mathrm{F}_{1,23}=10.954, \mathrm{P}=.003, \mathrm{\eta}^{2}=.323,1-\beta=.887\right)$ with post test scores $>$ pre test, except for JPS where post test scores were $<$. There was a significant main effect for group was FAAM $\operatorname{Sport}\left(\mathrm{F}_{2,23}=15.65, \mathrm{P}<.001, \mathrm{y}^{2}=.576,1-\beta=.998\right)$. Conclusions: A four week dynamic or traditional balance training program can increase self reported function, dynamic postural control, and joint position sense in athletes who are experiencing chronic ankle instability 


\section{ACKNOWLEDGMENTS}

I would like to thank my family, especially my mom and dad, for encouraging me to continue my educations and always giving me extra support through tough times.

I would like to thank Dr. Michelle Sandrey for all of her hard work in helping me complete everything on time. You have a true passion for research and it was reflected in your passion to help me complete this study.

I would like to thank Michael Dolan MA, ATC, for opening the realm of research to me throughout my 4 years as a student at Canisus College. Completing this study would have been much more difficult without your early guidance.

I would like to thank the University High School athlete, parents, coaches and administration for volunteering, and creating a wonderful working environment for me to work in for the past two years.

I like to thank Greg Dahmer MS, ATC, CO, Dr. Benjamin Moorehead MD, and Dr. Sean Bulger Ed. D for taking time out of your very busy schedules and being a part of my committee as well as the feedback you have provided, it is very much appreciated. 


\section{TABLE OF CONTENTS}

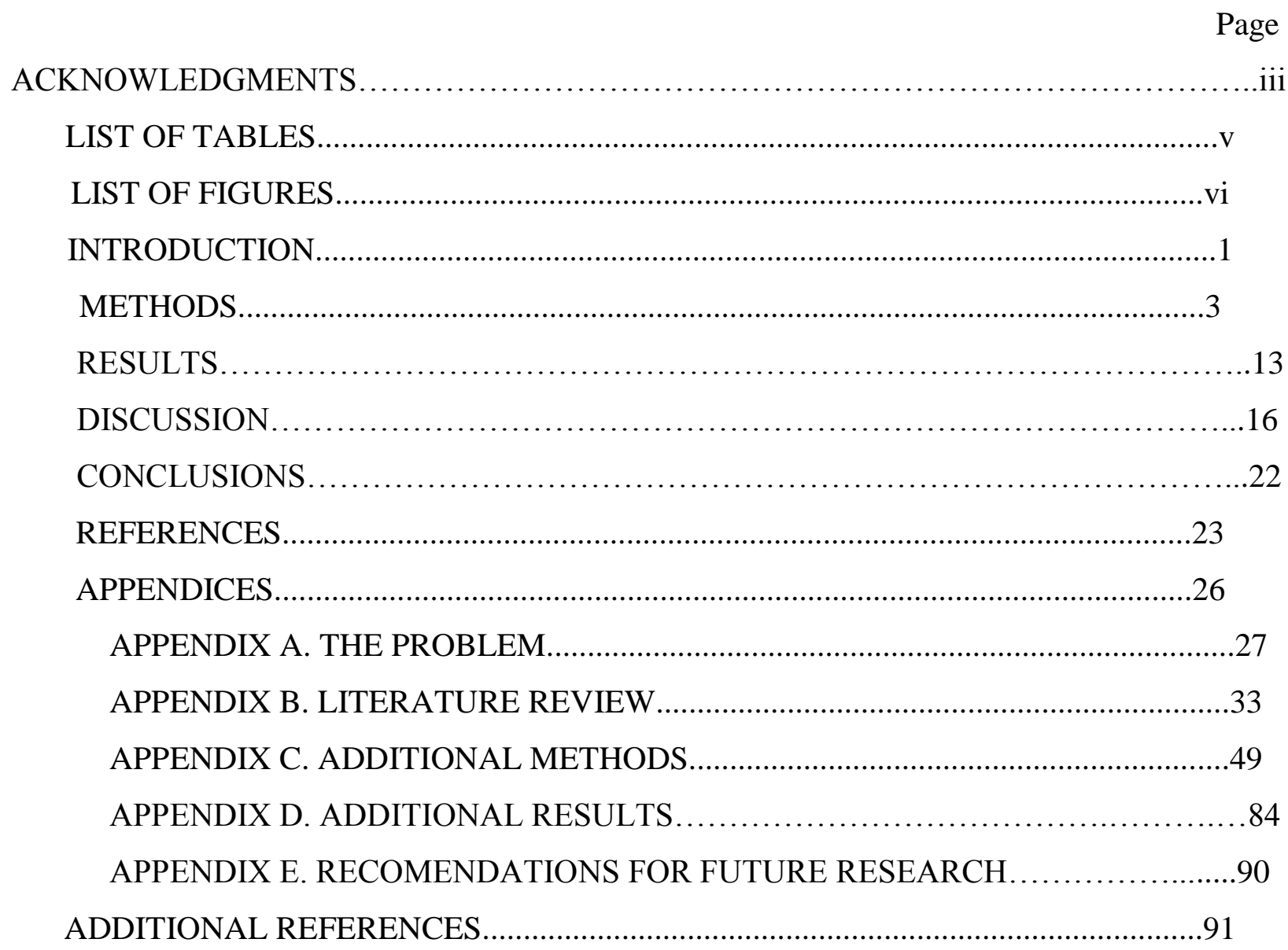




\section{LIST OF TABLES}

TABLES Page

B1. Anatomical Locations of Talocrural Joint Ligaments...................... 36

B2. Subtalar Ligaments of the Ankle........................................... 36

B3. Talocrural Joint Muscles............................................. 37

B4. Ankle Complex Muscles of the Subtalar Joint................................ 38

C1. Parental Consent Form.................................................. 49

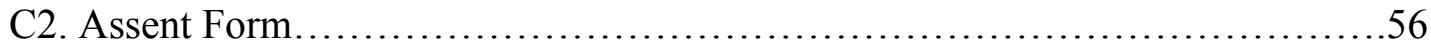

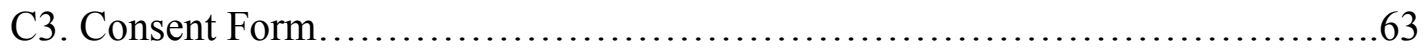

C4. Demographics Questionnaire........................................ 70

C5. FAAM and FAAM Sport............................................. 71

D1. Descriptive statistics.......................................... 84

D2. FAAM and FAAM Sport ANOVA..................................... 84

D3. Percent Change Scores for FAAM and FAAM Sport.......................84

D4. Two way Repeated Measures ANOVA Results for SEBT A, PM, and PL.....84

D5: Percent Change Scores for SEBT- A, PM, PL............................. 85

D6. Two-way Repeated Measures ANOVA Results for JPS DF, PF,IV, EV.......85

D7. Percent Change Scores for JPS- DF, PF, IV, EV ......................... 85

D8: Confidence Intervals for Dependent Variables........................... 86 


\section{LIST OF FIGURES}

FIGURE $\quad$ Page

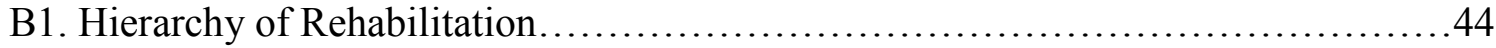

C1. Star Excursion Balance Test............................................... 74

C2. Joint Position Sense Blocks........................................... 75

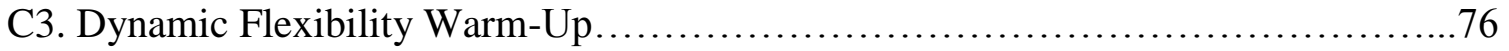

C4. Dynamic Balance Training Program.......................................... 79

C5. Traditional Rehabilitation Program....................................... 83

D1. FAAM and FAAM Sport Means and Standard Deviations........................87

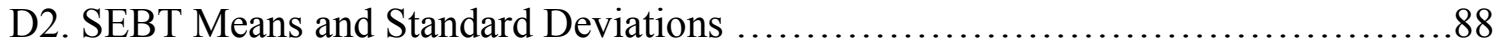

D3. Joint Position Sense Means and Standard Deviations...........................89 


\section{INTRODUCTION}

Lateral ankle sprains are among the most common injuries found in athletes and physically active individuals. 1, 2, 3, 4, 5,6,7 The injury rates for ankle sprains fall somewhere between 75 and $85 \%$ of all ankle injuries. ${ }^{5,7,8,9,10}$ It is estimated that everyday in the United States more than 25,000 ankle sprains occur, leading to an increase in health care costs due to the time loss related to symptoms associated with lateral ankle sprains. ${ }^{7}$ Once an initial ankle sprain occurs the individual is now pre-disposed to further an kle sprains, 5, 3, 7, 6, 10,11 thus potentially developing into chronic ankle instability. Individuals with chronic ankle instability have the subjective feeling, after the initial sprain, of their ankle giving way with continuous instances of instability which eventually lead to reoccurring ankle sprains. $5,3,7,6,10,11$

Recently, research has linked chronic ankle instability with deficits in neuromuscular control, proprioception, strength and postural control. ${ }^{4,6,11}$ Neuromuscular control refers to an unconscious activation of dynamic restraints occurring for and in response to joint motion and loading for the purpose of maintaining and restoring functional joint stability. $11,12,13,14$ Proprioception is the result of neural input to the CNS, from mechanoreceptors in the joint capsules and ligaments, as well as the surrounding muscles and overlying skin. ${ }^{11,15}$ Proprioception is divided into two components, kinesthesia and joint position sense. Ankle joint kinesthesia is assessed using the threshold to detection of passive motion, while joint position sense is assessed using both active and passive joint reproduction. ${ }^{11}$ Postural control is the ability to stabilize ones self while stationary or during movement on a flat or alternate surface. ${ }^{11,6}$ In most cases postural control deficits are secondary or as a result of decreases in neuromuscular control and proprioception. Eventually, loss of strength becomes a concern with chronic ankle instability because the surrounding muscles act as dynamic stabilizers. If the muscles are unable to properly stabilize the joint due to weakness, a decrease in stabilization may become evident. ${ }^{11,16,17}$ Deficits in all or even just one of these areas can lead to an individual suffering from chronic ankle instability. ${ }^{11}$

Joint position sense, a contributor to proprioception, is a main concern that needs further attention when addressing chronic ankle instability. ${ }^{2,3,11,17}$ Joint position sense is the body's ability to determine a static position in space. ${ }^{6,2,3,11,17,18}$ If there is a deficit in joint position sense, the potential for ankle injuries is greater and further contributes to chronic ankle 
instability. Therefore, a need to increase joint position sense is apparent and has been thought to improve using therapeutic exercise. ${ }^{11,1,6,4}$

Rehabilitation for chronic ankle instability is constantly evolving by attempting to determine the deficits that are associated with chronic ankle instability. Research, despite being controversial at times, has shown that balance training over a four week period was beneficial in improving self-reported function, dynamic postural control and static postural control. 5 According to Mckeon et al, ${ }^{5}$ mixed results reported in the literature cannot definitively lead to the conclusion that balance and coordination training increases dynamic postural control with individuals who suffer from chronic ankle instability. ${ }^{5}$ By evaluating the effects of a four week balance training program that emphasized dynamic balance stabilization in a single leg stance, on ankle kinematics during walking and jogging, balance training significantly changed the relationship between shank rotation and inversion/eversion of the rearfoot after the balance training. ${ }^{1}$

Rozzi et al $^{19}$ reported similar positive results in balance ability and perceived function following four week balance training program that involved single leg balance activities for subjects with functionally unstable ankles. ${ }^{19}$ The results of this study further justify that balance training is an effective way of improving joint proprioception and single leg standing in subjects with functionally unstable ankles. ${ }^{19}$

McKeon et al. ${ }^{6}$ used the same four-week progressive dynamic balance-training program in those with chronic ankle instability as reported in a previous study. ${ }^{1} \mathrm{He}$ incorporated singlelimb hops to stabilization, hop to stabilization and reach, unanticipated hop to stabilization, and single-limb stance activities, all through various progressions, into a rehabilitation program. All the exercises were designed to challenge the subjects' ability to maintain a single-limb stance while performing various balance activities. A balance training program that emphasizes dynamic stabilization after landing from a hop in multiple directions and conditions significantly improves self-reported function, static postural control, and dynamic postural control in subjects with chronic ankle instability. ${ }^{6}$ Most of these positive results are attributed to a decrease in constraints placed on the sensimotor system as a result of balance training.

Mckeon ${ }^{6}$ stated that in further research it is important to understand the difference and benefits of a dynamic stabilization balance training and a traditional rehabilitation program. He felt it would be beneficial to compare various programs, especially for chronic ankle instability. 
This would help determine the most effective components of rehabilitation in increasing ones self reported function and postural control. ${ }^{6}$ By using Mckeon's ${ }^{6}$ dynamic balance training program previously discussed and comparing it to a more traditional form of rehabilitation, conclusions may be drawn to the most beneficial aspects of rehabilitation for those with chronic ankle instability. Therefore, the present aim of this study is to compare the affect of rehabilitation programs and their influence on dynamic postural control, self reported function, and joint position sense in individuals experiencing chronic ankle instability.

\section{METHODS}

This study was a $2 \times 3$ factorial design for all dependent variables. The independent variables in this study were time and group. The time variable occurred on two levels (pre and post). There was three levels for group; dynamic balance training program(DBTP), traditional balance rehabilitation (TBR), and control. The dependent variables were reach distances, absolute angle measurements and the score for the FAAM and FAAM Sport disability questionnaires. For the Star Excursion Balance Test(SEBT) the normalized reach distances for anterior, posteriormedial, and posteriolateral directions were used. For ankle joint position sense, the absolute angle measurements were determined for dorsiflexion, plantarflexion, inversion, and eversion.

Subjects

Twenty-Six subjects ( $\mathrm{n}=26 ; 3$ female, 23 male; age 19.65 \pm 2.91 years; $\mathrm{ht}=175.56 \pm 7.27 \mathrm{~cm}$ ) completed the study. Subjects were randomly placed into the Dynamic Balance training group $(\mathrm{n}=9)$, Traditional Balance training group $(\mathrm{n}=9)$, and the control group $(\mathrm{n}=8)$.

Subjects were from a High School in North Central West Virginia, and a DI Mid-Atlantic University. Subjects completed an ankle instability questionnaire that included criteria for chronic ankle instability classification. Inclusion criteria for this study included a history of more than one ankle sprain and residual symptoms, frequent giving way of the ankle (at least within one month ago) as quantified by four or more "yes" responses on the subject demographic questionnaire, pain, feeling of instability, and decreased function. There was no history of lowerextremity surgery, no balance disorders, neuropathies, diabetes, or other conditions known to affect balance. If a subject reported bilateral ankle instability, the self-reported worse limb was used for analysis and training. Subjects were excluded with an acute ankle sprain within six 
weeks of participation, a history of surgery or fracture to either lower extremity or diagnosed with a grade III ankle sprain. This study was approved by the Office of Research Compliance at West Virginia University.

Instrumentation

Demographic questionnaire: The demographic questionnaire included questions used by Hubbard et $\mathrm{al}^{10}$ as a criteria for functional ankle instability and Docherty et $\mathrm{al}^{20}$ used in the Ankle Instability Instrument. The questions will be used to determine inclusion or exclusion into the study.

The Foot and Ankle Ability Measures Questionnaire (FAAM): provided a subjective measure for those with musculoskeletal lower leg, ankle and foot disorders. ${ }^{21,22}$ The FAAM ADL and FAAM Sport were designed to be a self-reported evaluative instrument to assess physical function of these individuals. ${ }^{21,22}$ The FAAM ADL contains 21 items related to activities of daily living and the FAAM Sport includes eight more items that evaluate perceived disability due to ankle injuries in activities associated with physical activity and sport. ${ }^{21,22}$

The FAAM ADL and FAAM Sport are reliable, and valid responsive measures of selfreported physical function. ${ }^{21}$ Validity evidence was provided for test content, internal structure, score stability, and responsiveness. Test retest reliability was 0.89 and 0.87 for the ADL and Sports subscales, respectively. ${ }^{21}$ The minimal detectable change based on a 95 percent confidence interval was \pm 5.7 and \pm 12.3 points for the ADL and Sports subscales, respectively.

Following direction, every question was answered with one response that is the closest in describing their condition within the past week. ${ }^{21,22}$ If for some reason the activity is limited due to another body part than the question was answered n/a. Activity was rated by points 4,3,2,1,0, N/A; ranging from no difficulty at all, slight difficulty, moderate difficulty, extreme difficulty, unable to do, and not applicable, respectively. ${ }^{21,22}$ Pain was rated in a similar fashion 4,3,2,1,0; ranging from no pain, mild, moderate, severe or unbearable, respectively. ${ }^{21,22}$ FAAM scores are a percentage of a total of 84 points, while the FAAM Sport is a percentage of 32 points. $^{21,22}$ Finally the patient rated the current level of function during ADL's and sport from 0-100 percent. These numbers give a measurable value to the subjective feelings of the subject involved. ${ }^{21,22}$

Star excursion balance test (SEBT):Star excursion balance test (SEBT) evaluates dynamic postural control. ${ }^{23}$ The SEBT, first introduced by Gary Gray in 1995, is a functional balance test that uses a unilateral stance on the center of an asterisk (star) and a maximal reach 
down each of the asterisk's eight lines. ${ }^{23,24,25,26}$ The SEBT offers a simple, reliable, low-cost alternative to more expensive, refined instruments available today. ${ }^{27}$ An asterisk is made with lines extended out from the center at 45 degree increments on a grid. Each line has a specific name in relation to which leg is being tested (the leg the subject is standing on is the leg being tested). The eight directions are named anterolateral (AL), anterior (A), anteromedial (AM), medial (M), posteromedial (PM), posterior (P), posterolateral (PL), and lateral (L) respective to the foot that is weight-bearing. ${ }^{23,25,28,26,27,29}$ For research and testing procedures in the clinic, only the anterior (A), posteromedial (PM), and posterolateral (PL) directions were used. These three directions have been found to assess unique aspects of dynamic postural control. ${ }^{6,29}$

The SEBT was placed directly on a non-slick floor using tape, three tape measures, and a protractor. The subject unilaterally standed in the center of the asterisk and maximally reaches with the contralateral leg down each line. ${ }^{27}$ The test required three practice reaches in each of the three directions and three recorded test reaches. Each reach, or trial, was held for one second for recording of measurements. Each trial was measured from the center of the asterisk and the three trials were averaged and normalized to the subject's height or true leg length. The further the reach, the greater the demand is on the dynamic postural control of the weight-bearing leg. ${ }^{23,242,28,26}$ The subject returned to the static unilateral stance position following each trial and remains there for 10-15 seconds before the next trial. During the SEBT, the individual's dynamic postural control constantly corrects as the center of mass migrates from over the base of support in all directions. ${ }^{30}$ Some factors to be considered when testing an individual using the SEBT are balance disorders, foot type, past injuries/surgeries, flexibility, and shoe condition. ${ }^{30,31}$

The star excursion balance test (SEBT) has been reported to have high reliability for testing dynamic postural control of those with and without functional ankle instability. ${ }^{24,26,28}$ Hertel et al. ${ }^{32}$ found intratester reliability of the SEBT between 0.78 and 0.96 . Olmsted et al. ${ }^{27}$ and McKeon et al. ${ }^{6}$ have both found the SEBT to be sensitive in detecting reach deficits between athletes with chronic ankle instability and healthy athletes. Validity for SEBT was also determined from Olmstead et al. ${ }^{27}$ and McKeon ${ }^{6}$. Kinzey ${ }^{26}$ determined that the SEBT has moderate reliability for assessing dynamic balance with an Intraclass Correlation Coefficient (ICC) of 0.86 to 0.98 for assessing dynamic balance.

Joint position sense blocks: This method used 2 slope surface boards, connected by a hinge to allow freedom of motion, that are $30 \mathrm{~cm}(\mathrm{~L}) \times 30 \mathrm{~cm}(\mathrm{~W}) \times 1.5 \mathrm{~cm}(\mathrm{H})$ and a set of blocks 
that have sloped surfaces at angles between $0^{0}$ and $25^{\circ}$ with increments of $2.5^{\circ}$, giving a total of 11 different angles. ${ }^{33}$ The blocks were created via trigonometry tangent function and a protractor to obtain and exact angles for the block specs. ${ }^{33}$ The subject stood on the slope board with a specific angle wedge sandwiched between the two slope boards, changing the angle of the foot through all 4 motions of the ankle; plantarflexion, dorsiflexion, inversion, eversion depending on the direction that the subject faced. ${ }^{33}$ All auditory and visual interference was removed in order prevent addition feedback or distraction. ${ }^{33}$ Subjects were given reference values of $0^{0}, 12.5^{0}$, and $25^{\circ}$ for plantarflexion, dorsiflexion, and inversion, and $5^{0}$ and $10^{0}$ for eversion. Sekizawa et al ${ }^{33}$ used this assessment method to measure joint positions sense while looking at the effects of shoe sole thickness on joint position sense. Through the use of the block method Sekizawa et $\mathrm{al}^{33}$ found a significant difference in joint position sense in dorsiflexion of the ankle with different shoe thicknesses. The study ${ }^{33}$ also noted a greater estimation error within plantarflexion than other angles involves, The study ${ }^{33}$ also found plantarflexion and inversion being underestimated more than dorsiflexion and eversion in both thickness of shoe. ${ }^{33}$ This is an important finding and supports the usage of the block method, being that the most errors were found in the position where ankle sprains are most common. ${ }^{33}$ Robbins et al ${ }^{34}$ used this method to measure joint position sense and found that foot position sense decreases with age and footwear can also decrease foot position sense.

Procedures

Subjects were contacted and asked to attend a meeting where they will be provided with a Parental Consent Form (Table C1) and Assent Form (Table C2) if under age 18, a Consent Form (Table C3), an Authorization to Use or Disclose Protected Health Information Form that is included in the informed consent forms and a subject Demographic Questionnaire (Table C4). The study was described to the potential subjects to make an informed decision about whether to participate or not. Any questions from the potential subject pool were answered and explained. The potential subjects were then asked to fill out the Parental Consent Form (Table C1), Assent Form (Table C2), or Consent Form (Table C3) with Authorization to Use or Disclose Protected Health Information in the consent or assent form and Subject Demographic Questionnaire truthfully and to the best of their ability. The demographic questionnaire demonstrated the subjects' eligibility in the study by assessing chronic ankle instability. The subjects then answered several questions concerning injury background past and present with the involved 
ankle. The researcher reviewed the forms for completeness to note if the subject has met the inclusion criteria, and not the exclusion criteria. Subjects were excluded if answering "yes" to the following questions: have you had any fractures in either of your ankles, have you had any surgeries in either of your lower extremities, and are you currently involved in a "formal", rehabilitation program for the affected ankle. The use of orthopedic special tests (Talar Tilt, Anterior Drawer, and Subtalar Glide) were used to determine subjects with a grade III ankle sprain and if a grade III is found subject were eliminated from the study. If the subjects met the inclusion criteria, they were contacted by the researcher to schedule a time to complete the pretest FAAM ADL and FAAM Sport questionnaire (Table C5), the SEBT pre-test (Figure C1), and the pre-test with the joint position sense blocks (Figure C2).

Times were established for subjects to meet with the researcher three times a week over a four week period for approximately 30 minutes per session where the subject were involved in either the dynamic balance-training program, or the traditional balance training program. The injured ankle was used for the training sessions. All exercises were performed at a High School in North Central WV to serve as an environmental control. The primary researcher supervised or administered all testing and exercising sessions. At the conclusion of the last exercise session, post-test measurements for the FAAM ADL, FAAM Sport, joint position sense blocks, and SEBT tests were obtained. The post-test was performed to the exact specifications as the pre-test, and was completed within the week following the final training session of the fourth week. Pre-Post testing

FAAM ADL and FAAM Sport: The subject completed the FAAM ADL and FAAM Sport. The subjects were asked to answer the FAAM ADL 21-item questionnaire with one response that most clearly described their condition within the past week. If the activity in question was limited by something other than the foot/ankle, N/A was marked. The current level of functional activity during ADLs was rated from 0-100 percent. Upon completion, the subjects answered the FAAM Sport 8-item questionnaire with one response that most clearly described the condition within the past week as well. If the activity in question was limited by something other than the foot/ankle, N/A is marked. The current level of functional activity during sports was rated from 0-100 percent. The primary researcher recorded the FAAM ADL scores as a percentage of 84 points and function percentage and the FAAM Sport scores as a percentage of 32 points and function percentage. 
Star excursion balance test (SEBT): The subjects' true leg length was measured and recorded to normalize the data. The SEBT (Figure C1) was performed with the subjects standing in the middle of a grid formed by eight lines extending out at $45^{\circ}$ from each other. The participant was asked to reach as far as possible along the anterior (A), posteromedial (PM), and posterolateral (PL) lines, make a light touch on the line, not transferring weight, and return the reaching leg back to the center, while maintaining a single-leg stance with the other leg in the center of the grid. Subjects were instructed to make a light touch on the ground with the most distal part of the reaching foot and return to a double-leg stance without allowing the contact to affect overall balance. When reaching in the posterolateral direction, subjects reached behind the stance leg to complete the task. Subjects were allowed to practice reaching in each of the three directions three times to minimize the learning effect. Following a five-min rest period, subjects performed three trials in each of the three directions. The subjects randomly drew one of three index cards, to determine the starting direction. All subjects began with the involved stance leg in the center of the grid depending on the functionally unstable ankle. Each reach distance was measured from a mark on the tape as the distance from the center of the grid to point of maximum excursion by the reach leg. The trial was discarded and repeated if the primary researcher felt the subject was using the reach leg for a substantial amount of support at any time, has removed the foot from the center of the grid, or was unable to maintain balance on the support leg throughout the trial.

Joint position sense blocks: Joint position sense (Figure C2) was measured in the involved leg by the sloped surface block methods. These measurements were taken with the subject wearing goggles and headphones to block out audio and visual interference. Barefooted subjects were asked to step onto the surface of the box, which was positioned against a rigid wall. Prior to testing subjects were given reference angles of $0^{\circ}, 12.5^{\circ}$ and $25^{\circ}$ for plantarflexion, dorsiflexion, and inversion as well as $5^{\circ}$ and $10^{\circ}$ for eversion. These reference angles were also given again at the half way point of each trial. The subject stood on the surface for 5 seconds then was tapped on the leg then they estimated the angle. The angles involved with plantarflexion, dorsiflexion, and inversion were $0,2.5,5,7.5,10,12.5,15,17.5,20,22.5,25$, and for eversion, 0,2.5,5,7.5,10. After the subject estimated the angle, the subject was tapped to remove leg from the surface, and the block was changed and then steps were repeated. The angles used began at $2.5^{\circ}$ and increase up to $25^{\circ}$ in $2.5^{\circ}$ increments. There was a total of 36 trials, with 21 in 
the sagital plane and 15 in the frontal plane; 10 for plantarflexion, 10 for dosiflexion, 10 for inversion, 5 for eversion and two for neutral $0^{\circ}$, one measure in each plane.

Interventions

Dynamic Flex Band flexibility warm-up routine: The dynamic flex bed warm-up routine (Figure C3) was incorporate the lower extremity as a whole, due to the movements of the dynamic balance-training program. The dynamic warm-up was approximately ten minutes. The warm-up started with the ankles (inversion/eversion), gastrocnemius, achilles, hamstring, groin, I-T Band, and concluded with the quadriceps/hip flexor stretches. The routine was specific in that the ankles (inversion/eversion), gastrocnemius and achilles stretches will be in sequence on one foot initially then completed on the opposite foot. After the Ankle warm-up for both legs was concluded, the subject moveed onto the hamstring, groin, I-T Band, and quadriceps/hip flexor stretches. Once again one leg was completed before subsequently moving to the other leg.

Dynamic Balance Rehabilitation Program: McKeon et al. ${ }^{6}$ developed a four week progressive dynamic balance-training program (Figure $\mathrm{C} 4$ ) for those with chronic ankle instability. He incorporated single-limb hops to stabilization, hop to stabilization and reach, unanticipated hop to stabilization, and single-limb stance activities into a rehabilitation program designed to challenge the subjects' ability to maintain a single-limb stance while performing various balance activities. ${ }^{6}$ More specifically, the program challenges recovery of single-limb balance efficiently after a disturbance and effectively develops natural execution to accomplish movement goals. ${ }^{6}$ These innovative activities promotes the restoration of functional variability within the sensorimotor system with environmental constraints. ${ }^{6}$

The first of four exercises was a single-limb hops to stabilization. Subjects performed ten repetitions per direction, anterior/posterior, medial/lateral, anterolateral/posteromedial, and anteromedial/posterolateral. Each repetition consisted of a hop from the starting position to the target position at 18, 27, or 36 inches. After stabilizing balance in a single-limb stance, subject hopped in the opposite direction back to the starting position and stabilized in a single-limb stance. Subjects did not advance to the next level until the ten repetitions were error-free. Errors were determined on the basis of the following: touching down with the opposite limb, excessive trunk motion ( $>30^{\circ}$ lateral flexion), removal of hands from hips during hands on hips activities, bracing the nonstance limb against the stance limb, and missing the target. 
The five-repetition hop to stabilization and reach exercise was a combination of the previously mentioned exercise. However, after stabilization in the single-limb stance, the subject reached back to the starting position with the opposite foot. Subjects hopped, stabilized, and then reached back to the starting position, then hopped back to the starting position and reached to the targeted position with the opposite foot. A subjects' advancement to the next level occued when there is five error-free repetitions. Errors were determined by all errors associated with hop to stabilization and by using the reaching leg for substantial amount of support during the reaching component.

Both the hop to stabilization and hop to stabilization and reach have seven levels of difficulty. The progression will begin with an 18, 27 or 36-inch hop using the arms to aid in stabilizing balance after landing, to an 18, 27, or 36-inch hop with hands on hips while stabilizing balance after landing. The seventh and final level will consist of a 36-inch hop from a 6-inch platform.

The third exercise will be an unanticipated hop to stabilization with the subjects standing in the middle of a nine-marker grid. A randomized, sequence of numbers was displayed on a computer screen in front of the subjects. Each number corresponded to a hop target position. As the progression of numbers change, subjects hopped to the new target position. The hop to stabilization rules applied for this activity; however, in this case, subjects were allowed to use any combination of hops (AP, ML, AM/PL, or AL/PM) to accomplish the goal of moving through the sequence error-free. As subjects advance, the amount of time per move was reduced. In each session, subjects will perform three sequences of numbers.

The unanticipated hop to stabilization also has seven levels of progression. As previously stated advancement did not occur until error-free. The subject were given five, three, or one second(s) per move, with each level of progression. As the subject progressed to completion of all moves within one second without error, a foam pad would have been placed on one of the numbers during the sequence. The subject then continued the progression at the same level of intensity. If the course is not completed error-free, the error-free time constraint was increased to the level below, for example, if the subject could not complete at the 1 second interval, then drop back to the 3 second interval. For the fifth level, a step would be added to an additional number. At level six, an additional foam pad would be added to one of the numbers, resulting in two foam pads and one step. An additional step would have included in level seven, resulting in two foam 
pads and two steps. Errors were determined as touching down with the opposite limb, excessive trunk motion ( $>30^{\circ}$ lateral flexion), removal of hands from hips during hand on hips activities, bracing the nonstance limb against the stance limb, and missing the target.

The fourth and final exercise was the single-limb stance. Subjects performed three repetitions of a single-limb stance. Each activity (eyes open and eyes closed) consists of seven levels of difficulty. In the single-limb eyes opened stance, arms were be across the chest while standing on a hard floor (60 seconds). The next progression included the arms across the chest while standing on a foam pad (30, 60, or 90 seconds). The subject then advanced to a ball toss on a foam pad with the arms across the chest. The progression continued with 20 throws with a 6-lb medicine ball for 30 seconds. Time was then increased to 60 seconds and finally 90 seconds. The final advancement will be was a single-limb stance with eyes closed and arms out while standing on a hard floor (30 seconds), to arms across the chest while standing on a hard floor (30 and 60 seconds). The exercise then progressed to the arms out on a foam pad (30 seconds), and finally the arms across the chest on a foam pad for 30,60, and 90 seconds. As previously stated advancement would not be allowed until error free. Errors were determined by subjects touching down with opposite limb, excessive trunk motion ( $>30^{\circ}$ lateral flexion), removal of arms from across the chest during specified activities, and bracing the non stance limb against the stance limb.

Traditional Balance Rehabilitation: Hale et $\mathrm{al}^{34}$ designed a rehabilitation program for patients with chronic ankle instability that involves stretching, strengthening, functional tasks, and neuromuscular control exercises. ${ }^{34}$ This was a four week training study that used a total of 6 supervised sessions, while all of the other sessions were assigned for home exercise. ${ }^{34}$ Home exercises were to be completed 5 times a week, compliance showed that home exercises were completed on an average of 3.5 times per week. ${ }^{34}$ The results from this study suggested that a progressive, comprehensive rehabilitation may serve to minimize lower extremity reach deficits and perceived deficits with ADL's and sport specific activity. ${ }^{34}$ Hale also stated that the exact mechanism that underlies the benefits of rehabilitation is not clear, ${ }^{34}$ specifically it is unclear as to which component of the rehabilitation program contributes the most to the improvements in dynamic postural control.

For the purpose of this study only the neuromuscular control component of Hale's ${ }^{34}$ rehabilitation program (Figure C5) was used. The first component was single-limb stance for 60 
seconds with two repetitions. Progressions for the first components included eyes open to eyes closed, then perturbations. The advancement in the progression was allowed after the subject completes the exercise set without error. Errors were determined by subjects touching down with opposite limb, excessive trunk motion ( $>30^{\circ}$ lateral flexion), removal of arms from across the chest during specified activities, and bracing the non stance limb against the stance limb.

The next exercise was a single-limb stance with a ball toss 3 times with 10 tosses each time. The progression for this exercise included increasing number of tosses or changing the surface (adding a foam pad). The advancement in the progression was allowed after the subject completes the exercise set without error. Errors were determined by subjects touching down with opposite limb, excessive trunk motion ( $>30^{\circ}$ lateral flexion), and bracing the non stance limb against the stance limb.

The next exercise was a single-limb stance while kicking against resistance in four directions three times with 5 kicks each direction with green surgical tubing. This exercise was progressed by increasing resistance (blue surgical tubing) and then increasing repetitions. The advancement in the progression was allowed after the subject completes the exercise set without error. Errors were determined by subjects touching down with the opposite limb, excessive trunk motion ( $>30^{\circ}$ lateral flexion), removal of arms from across the chest during specified activities, and bracing the non stance limb against the stance limb.

The final exercise was a step-downs with single-limb in three-directions including two sets of five repetitions in each direction on a six inch step. The progression that was used changes the surface (adding a foam pad) and then the height of the step (10 inches). The advancement in the progression was allowed after the subject completes the exercise set without error. Errors were determined by subjects touching down with opposite limb, excessive trunk motion ( $>30^{\circ}$ lateral flexion), removal of arms from across the chest during specified activities, and bracing the non stance limb against the stance limb.

\section{Data Analysis}

Data for the SEBT was analyzed by the mean and normalized by leg length. The means of reach distance from the 3 trials of each performance of the SEBT were calculated and used for statistical analysis. Reach distances were then divided by the measured leg length and multiplied 
by 100 to calculate a dependent variable that represents reach distance as a percentage of leg length. Data for Joint Position sense was reduced by taking the estimated angle minus the actual slope angle to equal the estimated angle error. A positive value represents dorsiflexion and inversion and a negative value representing plantarflexion and eversion. A positive value for a dorsiflexion measurement correlates to an overestimation while a negative correlates to a underestimation of angle. Conversely, a positive value for plantarflexion correlates to underestimation, and a negative value correlates to overestimation. This same format occurs for inversion and eversion positive value for eversion and negative for inversion.

Descriptive statistics included means and standard deviations. Two separate $2 \times 3$ repeated measures ANOVA (time $x$ group) were used for the FAAM-ADL and the FAAM-Sport. Three separate $2 \times 3$ repeated measures ANOVA (time $\mathrm{x}$ group), one for each direction, were used to for the SEBT measurements. For the Joint Position Sense blocks four separate $2 \times 3$ repeated measures ANOVA(time $\mathrm{x}$ group) were used, one for each direction. Alpha level used a priori of $\mathrm{p}=0.05$ with a Bonferroni correction of $\mathrm{p}=0.01$ for all analysis. The strength of effect sizes will be determined as small $(<0.04)$, moderate $(0.41-0.7)$, and large effects $(>0.71)$. Percent change scores will also be evaluated to examine the amount of change that occurred within groups. Alpha level used a priori of $\mathrm{p}=0.05$ with a Bonferroni correction of $\mathrm{p}=0.004$ for all analyses. SPSS 17.0 (Chicago, IL) will be used to analyze data.

\section{RESULTS}

\section{Disability Questionnaire}

Descriptive statistics for the pre-test and post-test data by group including the Foot and Ankle Ability Measure (FAAM) and FAAM Sport can be found in Table D1 and Figures D1-3. For the FAAM (Table D2) there was a significant interaction for time $\mathrm{x}$ group $\left(\mathrm{F}_{2,23}=7.17\right.$, $\left.\mathrm{P}=.003, \mathrm{y}^{2}=.402,1-\beta=.918\right)$ and the main effect of time $\left(\mathrm{F}_{1,23}=31.99, \mathrm{P}<.001, \mathrm{y}^{2}=.582,1-\beta=1.00\right)$ with post-test score higher than pre-test scores (Table D2). There was no significant change for the main effect of group $\left(\mathrm{F}_{2,23}=4.35, \mathrm{P}=.025, \mathrm{y}^{2}=.274,1-\beta=.695\right)$. However the Control, Traditional, and Dynamic groups percent change scores all increased .5, 3.14, 6.14 percent, respectively. The Dynamic group improved more than the control or traditional group (Table D3). 
The FAAM Sport (Table D2) had a significant difference for the main effect of time $\left(\mathrm{F}_{1,23}=31.85, \mathrm{P}<.001, \mathrm{y}^{2}=.581,1-\beta=1.0\right)$ with the post test scores higher than the pre test scores(TableD2). There was also a significant difference for the main effect of group $\left(F_{2,23}=15.65, \mathrm{P}<.001, \mathrm{y}^{2}=.576,1-\beta=.998\right)$. The Dynamic group performed significantly better than the traditional and control group $(5.743,99 \% \mathrm{CI}, 1.958-9.528, \mathrm{P}<.001)$. There was no significant interaction for time by group $\left(\mathrm{F}_{2,23}=6.515, \mathrm{P}=.006, \mathrm{y}^{2}=.362,1-\beta=.865\right)$. The Control, Traditional, and Dynamic groups percent change scores all increased .43, 9.17, and 9.0 percent, respectively. The Traditional and Dynamic group improved more than the Control (Table D3). Star Excursion Balance Test (SEBT)

Descriptive Statistics for pre test and post test data including SEBT directions Anterior (A), Posteriormedial (PM), and Posteriorlateral (PL) can be found in Table D1 and Figures D1-3. There was a significant interaction for all directions A, PM, and PL for the main effect of time and time by group (Table D4).

There was a significant interaction between time $\mathrm{x}$ group $\left(\mathrm{F}_{2,23}=24.469, \mathrm{P}<.001, \mathrm{y}^{2}=.680\right.$, $1-\beta=1.00)$ for anterior with post test scores higher than pre test scores for the traditional and dynamic group. There was also a significant main effect for time $\left(\mathrm{F}_{1,23}=128.56, \mathrm{P}<.001\right.$, $\left.\eta^{2}=.848,1-\beta=1.00\right)$ with post test scores higher than pre test scores for the dynamic and traditional group. There was no significant interaction for the main effect of group $\left(\mathrm{F}_{2,23}=2.80\right.$, $\left.\mathrm{P}=.082, \mathrm{y}^{2}=1.96,1-\beta=.496\right)$. The Dynamic group's percent change score increased the greatest (Table D5) when compared to the Control group with 5.71\%.

There was a significant interaction between time $\mathrm{x}$ group $\left(\mathrm{F}_{2,23}=19.461, \mathrm{P}<.001, \mathrm{y}^{2}=.629\right.$, $1-\beta=1.00)$ for posteriomedial with post test scores higher than pre test scores for the traditional and dynamic group. There was also a significant main effect for time $\left(\mathrm{F}_{1,23}=108.216, \mathrm{P}<.001\right.$, $\mathrm{y} 2=.825,1-\beta=1.00)$ with post test scores higher than pre test scores. There was no significance evident for group $\left(\mathrm{F}_{2,23}=.301, \mathrm{P}=.743, \mathrm{\eta}^{2}=.025,1-\beta=.092\right)$. The Traditional group's percent change score increased the greatest (Table D5) when compared to the Control group with $4.31 \%$.

There was a significant interaction between time $\mathrm{x}$ group $\left(\mathrm{F}_{2,23}=25.764, \mathrm{P}<.001, \mathrm{y}^{2}=.691\right.$, $1-\beta=1.00$ ) for posteriolateral with post test scores higher than pre test scores for the traditional and dynamic group. There was also a significant main effect for time $\left(\mathrm{F}_{1,23}=149.25, \mathrm{P}<.001\right.$, $\left.\eta^{2}=.866,1-\beta=1.00\right)$ with post test scores higher than pre test scores. There was no significant interaction for the main effect of group $\left(\mathrm{F}_{2,23}=1.65, \mathrm{P}=.215, \mathrm{y}^{2}=1.25,1-\beta=.311\right)$. The Traditional 
group's percent change score increased the greatest (Table D5) when compared to the Control group with $5.68 \%$.

Joint Position Sense (JPS)

Descriptive Statistics for pre test and post test data including JPS directions Dorsiflexion (DF), Plantatflexion (PF), Inversion (IV), Eversion (EV) can be found in Table D1 and Figures D1-3. There were significant differences for the main effect of time for DF, PF, and IV (Table D6). Percent change scores are shown in Table D7.

For Dorsiflexion there was a significant difference for the main effect of time $\left(\mathrm{F}_{1,23}=12.85, \mathrm{P}=.002, \mathrm{y}^{2}=.358,1-\beta=.929\right)$ with post test absolute error less than pre test. There was no significant difference for the main effect of group $\left(\mathrm{F}_{2,23}=1.116, \mathrm{P}=.345, \mathrm{\eta}^{2}=.088,1\right.$ $\beta=.222)$, or an interaction between time and group $\left(F_{2,23}=2.334, P=.119, \eta^{2}=.169,1-\beta=.424\right)$. The Traditional group showed the greatest increase in percent change scores over the control group with $15.51 \%$.

For Plantarflexion there was a significant difference for the main effect of time $\left(\mathrm{F}_{1,23}=12.194, \mathrm{P}=.002, \mathrm{y}^{2}=.346,1-\beta=.917\right)$ with post test absolute error less than pre test. There was no significant difference for the main effect of group $\left(\mathrm{F}_{2,23}=.096, \mathrm{P}=.889, \mathrm{\eta}^{2}=.01,1-\beta=.066\right)$, or an interaction between time and group $\left(\mathrm{F}_{2,23}=2.661, \mathrm{P}=.091, \mathrm{\eta}^{2}=.188,1-\beta=.475\right)$. The Traditional group showed the greatest increase in percent change scores over the control group with $24.43 \%$.

For Inversion there was a significant difference for the main effect of time $\left(F_{1,23}=10.954\right.$, $\mathrm{P}=.003, \mathrm{y}^{2}=.323,1-\beta=.887$ ) with post test absolute error less than pre test. There was no significant difference for the main effect of group $\left(\mathrm{F}_{2,23}=.729, \mathrm{P}=.493, \mathrm{\eta}^{2}=.06,1-\beta=.158\right)$. or an interaction between time and group $\left(\mathrm{F}_{2,23}=2.659, \mathrm{P}=.091, \mathrm{\eta}^{2}=.188,1-\beta=.475\right)$. The Dynamic showed the greatest increase in percent change scores over the control group with $18.54 \%$.

There was a significant difference for the main effect of time $\left(\mathrm{F}_{1,23}=2.584, \mathrm{P}=.122\right.$, $\left.\mathrm{y}^{2}=.101,1-\beta=.338\right)$ with post test absolute error scores less than pre test. There was no significant difference for the main effect of group $\left(\mathrm{F}_{2,23}=1.253, \mathrm{P}=.304, \mathrm{y}^{2}=.098,1-\beta=.254\right)$, or an interaction between time and group $\left(\mathrm{F}_{2,23}=.207, \mathrm{P}=.814, \mathrm{y}^{2}=.018,1-\beta=.079\right)$. The Traditional showed the greatest increase in percent change scores over the control group with $13.13 \%$ 


\section{DISCUSSION}

This present study found that a four week dynamic balance training program and a traditional balance rehabilitation program improved self reported function (FAAM and FAAM Sport) and dynamic postural control (Star Excursion Balance Test (SEBT)) in individuals who experience chronic ankle instability. There were significant interactions found with pre test and post test results for FAAM, FAAM Sport and all three directions of the SEBT. All significant results were found over time, between groups, or between group by time; depending on the variable. Significant results were found with Joint Position Sense (JPS) over time but not between groups or between groups by time. While there was some significant change between experimental groups, a decrease was evident in all pre to post test results for both experimental groups for either the Traditional or Dynamic Group demonstrating an decrease depending on the variable. With this study being one of the first studies to compare the dynamic balance training program designed by Mckeon et $\mathrm{al}^{6}$ to a traditional balance training program used by Hale et $\mathrm{al}^{34}$ for chronic ankle instability, it is difficult to draw direct conclusions with comparisons to other known studies in this area.

It was hypothesized that there would be a significant increase in FAAM, FAAM Sport, SEBT, and JPS for both the Traditional and Dynamic Group, with the Dynamic Group performing better than the Traditional Group. This hypothesis is not supported by these results; the only variable that had a significant increase due to the main effect of group is FAAM Sport. There was however, a significant change over time for FAAM, FAAM Sport, all SEBT directions, and JPS DF, PF and IV. There were significant interactions between time and group for FAAM, and all SEBT directions. All variables showed an increase in percent change other than JPS EV where the Traditional group and the Control Group changed equally over time, and the Dynamic Group changed 7\% less. It was clear that both the Traditional and Dynamic Groups increased in relation to the Control group but the change between Traditional and Dynamic groups were minor for FAAM, all SEBT directions, and JPS DF, PF, and IV. The only significant change between groups was for FAAM Sport between the dynamic and control group. The Traditional group showed a greater increase in percent change over the Dynamic group for FAAM Sport, SEBT PM, PL, JPS DF, PF, and EV. The Dynamic group showed a greater increase in percent change over the Traditional group for FAAM, SEBT A, and JPS IV. 
However none of these results were statistically significant between the groups as even the control group improved.

Despite the lack of significant differences between the experimental groups overall, the results of this study are still promising. Although the Traditional and Dynamic programs in this study have yet be evaluated in the literature using athletes experiencing chronic ankle instability, improvement in self reported function, dynamic postural control, and joint position sense over time were noted. Within a brief treatment period of four weeks, the Traditional and Dynamic groups showed improvement over the control group but neither group performed any better than the other overall. While no optimal treatment program length has been recommended in the literature, it seems reasonable to conclude that a longer treatment period may have resulted in additional changes. However with some improvement for either groups perhaps over a Four week period both the traditional and dynamic balance training programs could be beneficial for those with chronic ankle instability.

Foot and Ankle Ability Measures Questionnaire

The Foot and Ankle Ability Measures Questionnaire( FAAM) provides subjective measure for those with musculskeletal lower leg, ankle and foot disorders. ${ }^{21,22}$ The FAAM ADL and FAAM Sport are designed to be a self-reported evaluative instrument that assesses physical function of these individuals. ${ }^{21,22}$ The FAAM ADL contains 21 items related to activities of daily living and the FAAM Sport includes eight more items that evaluate perceived disability due to ankle injuries, in activities associated with physical activity and sport. ${ }^{21,22}$ A similar questionnaire, the Foot and Ankle Disability Index (FADI) and (FADI Sport) evaluated the change in disability following the same dynamic balance training program for those with chronic ankle instability. ${ }^{6}$ Mckeon et al $^{6}$ found no significance between groups for pre test measurements, however they were significant increases in post test measures for the balance group compared to the control group.

In this study there was an increase of FAAM ADL scores over time and an increase in post test scores based on group membership, but there was no difference between groups. Over the course of the four weeks, treatment had an impact on the self-reported scores, however neither experimental group had improved more than the other. Self reported function can be improved over a four week balance training period whether a traditional or dynamic program is used. 
The FAAM Sport showed a significant increase in scores over time and between groups. In the case of the FAAM Sport, scores increased over time for both experimental groups but the dynamic group improved over the control group regardless of the time variable. The Dynamic balance training program is more beneficial to improve self-reported function when referring to sport activities. This finding is more consistent to what Mckeon et $\mathrm{al}^{6}$ found as hop to stabilization is a skill used in all sport activity.

One reason that the FAAM sport may have seen a greater improvement with the dynamic group is because the nature of the dynamic balance training program is more sport specific than the traditional balance training program. Also the subjects in this study were determined to have mainly grade I and a few grade II sprains previously, which made the subject population very homogeneous as all groups were similar at baseline. Therefore with everyday activity and sport activities such as running, jumping, starting and stopping quickly there would be no problems in being able to participate in sport.

In this study the control group did not significantly change over time but the dynamic group scores did significantly increase. These results are similar to Rozzi et al. ${ }^{19}$ who reported improvements on the Ankle Joint Functional Assessment Tool when comparing a group with CAI to a group of healthy controls who underwent balance training. They found that individuals who underwent a four week training program on the Biodex Stability System had improvements in self-reported function, regardless of group membership. ${ }^{19}$ Based on the findings for the FAAM and FAAM Sport it would be beneficial for a subject with chronic ankle instability to be involved in either the dynamic or traditional balance training program for 4 weeks to improve $t$ self reported function. A longer duration of training may produce differences between groups and perhaps a greater clinical change over time.

Dynamic Postural Control

Using the DBT protocol, McKeon et al. ${ }^{6}$ noted that the PM and the PL reach components of the SEBT were greater for those in the balance training group at the end of the study. In both directions, the balance-training group had greater reach distances in the post-test measures compared with the pre-test measures. ${ }^{6}$ Moreover, the balance training group reached farther than the control group on the posttest measures but not on the pre-test measures. ${ }^{6}$ There were no changes in the Anterior reach direction between pre test and post-test measures for either group. ${ }^{6}$ 
These findings were also evident in the current study as the dynamic group improved more at post test, however the traditional group improved as well.

A four-week rehabilitation program, designed by Hale et al. ${ }^{34}$ found subjects with chronic ankle instability demonstrated deficits in postural control and SEBT reach tasks of the involved limb compared to the uninvolved limb and reported functional deficits of the involved limb compared to healthy subjects. Following rehabilitation, the chronic ankle instability rehabilitation group had greater SEBT reach improvements on the involved limb than the other groups. The current study, in comparison with Mckeon et $\mathrm{al}^{6}$ and Hale et al., ${ }^{34}$ used chronic ankle instability subjects that followed a four week rehabilitation program. Furthermore the rehabilitation programs were similar in that the dynamic rehabilitation program was developed by McKeon et al. ${ }^{6}$ and the traditional rehabilitation program had components adopted from Hale et al. ${ }^{34}$ However, the current study did not use healthy subjects as a control group.

The present study found an increase from pre to post test distances in all directions, the post test distances increased for the experimental groups. Though no significant was found specifically for an expermental group, percent change scores showed minor differences between the groups. Essentially over time distances improved when compared to the control but neither group increased more than the other. Dynamic postural control is improved during a four week balance training program whether using a dynamic or traditional balance training approach. This statement is similar to the findings in Hale et $\mathrm{al}^{34}$ and Mckeon et $\mathrm{al}^{6}$, Both studies showed an improvement with SEBT reach distances improved following a four week rehabilitation program with chronic ankle instability subjects.

One reason why these there was no difference between groups is the use of a homogeneous subject population consisting mainly of off season football and basketball athletes with chronic grade I instability. Because of this, all subjects were similar at baseline and at the end of the study, allowing for little group differences. The nature of the balance training programs may have resulted in improvements as both programs incorporated single leg stance, especially the dynamic program which included an exercise which involved a hop to stabilization and then a reach back to the starting point. This specific exercise mimics a reach task from the SEBT. The subjects in this study, for the most part, were also participating in their off-season strength and conditioning programs. While none were involved in additional balance training they were doing total body strength training and core stability training. Kahle et al. ${ }^{35}$ found that 
maximal reach distances improved for SEBT, compared to a control group, after a 6 week core stability training program. ${ }^{35}$ These results of improved reach scores after a core training program could possibly explain why this study had a difference over time but not between specific groups. Potentially the core stability could be a factor for increasing the reach tasks as both groups increased over the course of the four weeks. When testing the involved limb the dominant limb was used for baseline and post testing. The uninvolved limb was not tested and no baseline data from pre-injury status was available, making it difficult to truly understand the influence of the training programs on the affected limb.

\section{Joint Position Sense}

Sekizawa et $\mathrm{al}^{33}$ used this assessment method to measure joint positions sense while evaluating at the effects of shoe sole thickness on joint position sense. Through the use of the block method Sekizawa et $\mathrm{al}^{33}$ found a significant difference in joint position sense in dorsiflexion of the ankle with different shoe thicknesses. Also noted were more estimation errors with plantarflexion than other angles, including plantar flexion and inversion being underestimated more than dorsiflexion and eversion in both thickness of shoe. This is an important finding as being that most errors were found in the position where ankle sprains are most common. Robbins et $\mathrm{al}^{34}$ using a similar technique found that foot position sense decreases with age and footwear. Although not evaluating type of footwear, this study adopted the block technique to observe if absolute error would occur in the four directions for those with chronic ankle instability. It has been noted with previous studies that with chronic ankle instability there are disruptions with mechanoreceptors within the articular surfaces, lateral ankle ligaments, and joint capsules of the talocrural and subtalar joints. ${ }^{10}$ Joint position sense is thought to decrease when these receptors are damaged in the event of an injury. ${ }^{10}$ This reduction of joint position sense can lead to an over or underestimation in position sense which can then lead to further injury. ${ }^{33}$ No study has evaluated joint position sense by the standing weight bearing block method with subjects with chronic ankle instability following balance training.

The only significant findings were pre-test to post test with the directions of Dorsiflexion, PlantarFlexion, and Inversion. Over the course of the 4 week training period the absolute error decreased indicating better awareness of the differences between actual angle and estimated angle. Despite the improvement for thee of the four angles there was no difference between 
groups, but the dynamic group improved more in Inversion while the traditional group improved more in dorsiflexion and plantarflexion.

Using a Homogeneous subject population perhaps again limited the ability for difference to occur between groups. The reduction of joint position sense is partially due to damaged mechanoreceptors sending corrupt signals. With mainly grade I injuries there is a possibility that the subjects are not transferring corrupt signals from mechanoreceptors, does not occur and the system will not be affected. Since the system is intact, the window of improvement will be very minimal. In this study there was a decrease in angle error for plantatflexion and inversion, this is important clinically because the most common position for the foot and ankle to be in when a lateral ligament is sprained is plantarflexion and inversion. With a decrease in absolute angle error subjects are not underestimating the position of the foot and ankle. If an athlete jumps in the air and receives feedback from the mechanoreceptors that the foot and ankle are in a neutral position; but really the foot and ankle is in a plantarflexed and inverted position, then when the athlete lands the potential for a lateral ankle sprain may exist. With the reduction of absolute angle error, potentially the athlete may be in a better position upon landing. Even though the difference between pre test and post test was minimal even a small change may be beneficial

In conclusion a Four week balance training program can be beneficial to those with chronic ankle instability to improve joint position sense. Either mode, dynamic or traditional style balance training was shown to improve joint position sense.

Clinical Implications and Limitations

Despite no clear significant difference between groups the subjects showed beneficial improvements after the four week training period with either the traditional or dynamic balance training group. The usage of a balance training program can improve self reported function, dynamic postural control, and joint position sense for those with chronic ankle instability. Rehabilitation programs could also be used for a longer duration and if given an appropriate rate of progression, one might expect to see further training adaptation. Furthermore, these training adaptations could be monitored using the tests employed in this study. The FAAM, FAAM Sport, and SEBT tests were easy to administer and required no specialized equipment/facilities. The joint position sense block method can be easily crafted but involves trigometric calculations, however it is an easy test to administer and takes little time or space. Even though in some cases 
statistical significance wasn't found, clinical significance may be found in some cases due to an increase in percent change.

The primary limitations of the present study included a small sample size, limited generalizability of results, and the use of a relatively brief dynamic balance-training program. This study used a sample of convenience at a North Central high school and Mid-Atlantic University of only injured physically active individuals. While the sample was of convenience, scheduling sessions was challenging due to snow days and bad-road conditions which disabled the subjects from making their scheduled time. Due to weather conditions a week of school closures filled the time between the completion of pre-testing and the beginning of the balance training programs. There was a delay between pre testing and the initiation of the balance training programs due $t$ weather, which may have made an impact on the results. While the sample was of convenience, the small sample size prevented the results from being generalized to a broader population. If used with other participants, traditional and dynamic balance-training program adaptations might vary depending on a number of additional factors that contribute to individual variability including previous injury, rehabilitation history and current fitness level. While a length of the traditional and dynamic balance training program was similar to previous studies a longer duration may be necessary to show the differences between groups.

\section{CONCLUSION}

There is a significant difference between Foot and Ankle Ability Measure (FAAM), FAAM Sport, and Star Excursion Balance Test (SEBT), with post test scores higher than pre test and a significant increase in Joint Position Sense (JPS) with post test scores lower than pre-test scores. While there were no significant differences between groups, except FAAM Sport, there were increases in pre test to post test scores showing an increase in percent change scores for both the traditional and dynamic groups. A four week dynamic or traditional balance training program can increase self reported function, dynamic postural control, and joint position sense in athletes who are experiencing chronic ankle instability. These results support the usage of a dynamic or traditional style balance training program in clinical practice for those with chronic ankle instability 


\section{REFERENCES}

1. Mckeon PO, Paolini G, Ingersoll CD, Kerrigan DC. Effects of balance training on gait parameters in patients with chronic ankle instability: a randomized control trial. Clin Rehab. 2009; 23: 609-621

2. Hartsell, HD. The effects of external bracing on joint position sense awareness for the chronic unstable ankle. J Sport Rehabil. 2000;9:279-289

3. Brown C, Ross S, Mynark R, Guskiewicz K. Assessing functional ankle instability with joint position sense, time to stabilization, and electromyography. J Sports Rehabil. 2004; 13: $122-134$

4. Mckeon PO, Hertel J. The Dynamic-Systems approach to studying athletic injury. Athl Ther Today. 2006; 11(1); 31-33

5. Mckeon PO, Hertel J. Systematic review of postural control and lateral ankle instability, Part II: Is balance training clinically effective? J Athl Train. 2008;43(3):305-315

6. Mckeon PO, Ingersoll CD, Kerrigan DC, Saliba E, Bennett B, Hertel J. Balance training improves function and postural control in those with chronic ankle instability. Med Sci Sport Exerc. 2008; 40(10):1810-1819

7. Olmstead-Kramer LC, Hertel J. Preventing recurrent lateral ankle sprains: an evidence based approach. Athl Ther Today. 2004;9(6):19-22, 34-35, 68.

8. Lynch SA, Assessment of the injured ankle in the athlete. J Athl Train. 2002;200:457-465

9. Pollard H, Sim P, McHardy A. Lateral ankle injury: literature review and report of two cases. Australas Chiropr Osteopathy. 2002; 10(1):21-30.

10. Hubbard TJ, Kaminski TW. Kinesthesia is not affected by functional ankle instability status. J Athl Train. 2002;37(4):481-486

11. Holmes A, Delahunt E. Treatment of common deficits associated with chronic ankle instability. Sports Med. 2009;39(3):207-224

12. Coughlin G, Caulfield B. A 4-week neuromuscular training program and gait patterns at the ankle joint. J Athl Train. 2007; 42(1):51-59

13. Lephart SM, Pincivero DM, Giraldo JL, Fu FH. The role of proprioception in the management and rehabilitation of athletic injuries. Am J Sports Med. 1997;25(1):130-137

14. Delahunt E, Monaghan K, Caulfield B. Altered neuromuscular control and ankle joint kinematics during walking walking in subjects with functional instability of the ankle joint. Am J Sports Med. 2006;34(12):1970-1976 
15. Gribble PA, Hertel J, Denegar CR, Buckley WE. The effects of fatigue and chronic ankle instability on dynamic postural control. J Athl Train. 2004;39(4): 321-329

16. Powers M, Buckley B, Kaminski T, Hubbard T, Ortiz C. Six Weeks of Strength and Proprioception Training Does Not Affect Muscle Fatigue and Static Balance in Functional Ankle Instability. J of Sport Rehabil. August 2004;13(3):201-227.

17. Kaminski TW, Perrin DH, Gansneder BM. Eversion strength analysis of uninjured and functionally unstable ankles. J Athl Train. 1999. 34(3): 239-245

18. Sandrey M, Kent TE. The effects of eversion fatigue on frontal plane joint position sense in the ankle. J of Sports Rehabil. 2008, 17, 257-268

19. Rozzi SL et al. Balance training for persons with functionally unstable ankles. J Orthop Sports Phys Ther. 1999;29(8):478-486

20. Docherty CL, Gansneder BM, Arnold BL, Hurwitz SR. Development and reliability of the ankle instability instrument. J Athl Train. 2006; 41(2):152-158

21. Martin RL et al. Evidence of validity for the foot and ankle ability measure (FAAM). Foot Ankle Int. 2005;26(11):968-983

22. Hale SA, Hertel J. Reliability and sensitivity of the foot and ankle disability index in subjects with chronic ankle instability. J Athl Train. 2005; 40(1):35-40

23. Earl JE, Hertel J. Lower-extremity muscle activation during the star excursion balance tests. J Sports Rehabil. 2001; 10(2):93-104

24. Gribble PA, Hertel J. Considerations for normalizing measures of the star excursion balance test. Measure Phys Ed Exer Sci. 2003;7(2): 89-100

25. Gribble P, Kaminski TW. Research Digest. The Star excursion balance test as a measurement tool. Athl Ther Today. 2003;8(2):89-100

26. Kinzey SJ. The reliability of the star excursion test in assessing dynamic balance. $J$ Orthop Sports Phys Ther. 1998;27(5):356-360

27. Olmstead LC, Carcia CR, Hertel J, Schultz SJ. Efficacy of the star excursion balance tests in detecting reach deficits in subjects with chronic ankle instability. J Athl Train. 2002;37(4): 501-506

28. Gribble P, Hertel J, Denegar C, Buckley W. Reliability and validity of a 2D video digitizing system during a static and dynamic task. J Sport Rehabil. 2005;14:137-149 
29. Hertal J, Braham RA, Hale SA, Olmstead LC. Simplifying the star excursion balance test: factors analyses of subjects with and without ankle instability. J Sport Phys Ther. 2006;36(3):131-7

30. Hertel J, Denegar CR, Buckley WE. The effects of rear-foot orthotics on postural control in healthy subjects. J Sport Rehabil. 2001;10:36-47

31. Cote KP, Brunet ME, Gransneder BM, Schultz SJ. Effects of pronated and supinated foot postures on static and dynamic postural stability. J Athl Train. 2005; 40(1): 41-46

32. Hertal J. Functional instability following lateral ankle sprains. Sports Med. 2000;29(5)361-371

33. Sekizawa K, Sandrey M, Ingersoll CD, Cordova ML. Effects of show thickness on joint position sense. Gait Posture. 2001; 13:221-228

34. Hale S, Hertel J, Olmstead-Kramer L. The effect of a 4-week comprehensive rehabilitation program on postural control, and lower extremity function in individuals with chronic ankle instability. J of Orthop Sports Phys Ther. 2007;37(6) 303-311

35. Kahle N, Gribble P. Core Stability Training in Dynamic Balance Testing Among Young, Healthy Adults. Athletic Training \& Sports Health Care. March 2009;1(2):65-73. 
APPENDICIES 


\section{APPENDIX A}

\section{THE PROBLEM}

\section{Research Question}

Lateral ankle sprains are among the most common injuries found in athletes and physically active individuals. ${ }^{1,2,3,4,5,6,7}$. The injury rates for ankle sprains fall somewhere between 75 and $85 \%$ of all ankle injuries. ${ }^{7,5,8,9,10}$ It is estimated that everyday in the United States more than 25,000 ankle sprains occur daily, these staggering numbers lead to an increase in health care costs due to the time loss related to symptoms associated with lateral ankle sprains.

${ }^{7}$ Once an initial ankle sprain occurs the individual is now pre-disposed to further ankle sprains., 3, 7, 6, 10,11 leading to chronic ankle instability. Individuals with chronic ankle instability, after the initial sprain experience their ankle giving way with continuous instances of instability, which tend to lead to reoccurring ankle sprains. $5,3,7,6,10,3,6,11$

Recently, research has linked chronic ankle instability with deficits in neuromuscular control, proprioception, strength and postural control. ${ }^{11,4,6}$ Neuromuscular control refers to an unconscious activation of dynamic restraints occurring for and in response to joint motion and loading for the purpose of maintaining and restoring functional joint stability. ${ }^{11} 121314$ Proprioception is the result of the neural input to the CNS, from mechanoreceptors in the joint capsules and ligaments, as well as the surrounding muscles and overlying skin. ${ }^{11,15}$ Proprioception is divided into two components, kinesthesia and joint position sense. Ankle joint kinesthesia is usually assessed using the threshold- to-detection of passive motion, while joint position sense is assessed using both active and passive joint reproduction. ${ }^{11}$ Postural control is the ability to stabilize ones self while stationary or during movement on a flat or alternate surface. ${ }^{11,6}$ In most cases postural control deficits are found secondary or as a result to decreases in neuromuscular control and proprioception. Furthermore, loss of strength becomes a concern with chronic ankle instability since surrounding muscles act as dynamic stabilizers, if the muscles cannot properly stabilize the joint due to weakness, a decrease in stabilization may become evident. ${ }^{11,16,17}$ Deficits in all or even just one of these areas can lead to chronic ankle instability. ${ }^{11}$ 
Joint position sense, a contributor to proprioception, is a main concern that needs further attention when addressing chronic ankle instability. 2,3,11,18 Joint position sense is the body's ability to determine a static position in space. ${ }^{6,2,3,11,18,4}$ If there is a deficit in joint position sense further ankle injuries can occur more easily and contribute to the problem of chronic ankle instability. Therefore, a need to increase joint position sense is apparent and has been thought to be enhanced through therapeutic exercise. ${ }^{11,1,6,4}$

Rehabilitation for chronic ankle instability is constantly evolving in an attempt to determine the correct course to reduce apparent deficits that are associated with chronic ankle instability. Research, despite being controversial at times, has shown that balance training over a 4 week period was beneficial in improving self-reported function, dynamic postural control and static postural control. ${ }^{5}$ According to Mckeon et $\mathrm{al}^{5}$ mixed results found in the literature cannot definitively lead to the conclusion that balance and coordination training increased dynamic postural control with individuals who suffer from chronic ankle instability. ${ }^{5}$

With results still unclear on whether balance and coordination training will increase dynamic postural control or joint position sense, further research is needed to determine whether a dynamic balance training program is beneficial in increasing dynamic postural control and decreasing the symptoms of chronic ankle instability.

Therefore the following research question is being proposed: can a balance and dynamic balance training program increase dynamic postural control, and joint position sense in those with chronic ankle instability?

\section{Experimental Hypothesis}

1. There will be a significant improvement of pre-post test SEBT scores in the Dynamic Balance Training Program group compared to the Traditional Rehabilitation Program and Control groups.

2. There will be a significant improvement of pre-post test Joint Position Sense in the Dynamic Balance Training Program group compared to the Traditional Rehabilitation Program and Control groups.

3. There will be a significant increase in pre-post test FAAM and FAAM Sport scores in the Dynamic Balance Training Program group compared to the Traditional Rehabilitation Program and Control groups. 
4. The Traditional Rehabilitation Group will also have significant improvement in pre-post test SEBT, joint position sense, and FAAM/FAAM Sport.

Assumptions

1. All participants in this study will meet all of the inclusion criteria with no participant used if any of the exclusion criteria are met.

2. Participants will answer questionnaires honestly.

3. Participants will give maximum effort and perform to the best of their ability during training periods and pre/post testing.

4. The participants will be compliant with their designated rehabilitative programs and will return for post-testing.

5. Enough patients with chronic ankle instability will volunteer for this study.

\section{Delimitations}

1. The small sample size will not be generalized to the population as a whole.

2. Chronic ankle sprains at one institution will not be generalized to the population as a whole.

Operational Definitions

1. Anterior Talofibular Ligament - A flat, weak band that extends anteriorly and medially from the lateral malleolus to the neck of the talus. ${ }^{35,36}$

2. Anterior Drawer test- Evaluates the integrity of the Anterior Talofibilar ligament. ${ }^{20}$

3. Athlete- Someone with athletic ability. ${ }^{37}$

4. Chronic Ankle Sprain - An injury to the lateral ankle ligaments that has occurred more than once. ${ }^{37}$

5. Collagen - The collagen arrangement in ligamentous tissue that is comprised of structural, fibrous protein found in all connective tissues. ${ }^{3}$

6. Contralateral - Referring to the opposite side of the body. ${ }^{39}$

7. Disability Index - Assesses functional limitations related to foot and ankle conditions. ${ }^{40}$

8. Dominant Leg - Preferred leg used when performing tasks such as kicking a soccer ball. ${ }^{39}$ 
9. Dynamic Balance-Training - Emphasis on the dynamic stabilization after perturbations such as predictable and unpredictable changes in direction, landing, from a hop, and dynamic reaching. ${ }^{6}$

10. Dynamic Postural Control -The ability to stabilize oneself while stationary or during movement on a flat or compromised surface. ${ }^{39}$

11. Functional Instability -Recurrent joint instability and the sensation of joint instability due to the contributions of any neuromuscular deficit. ${ }^{40}$

12. Joint Position Sense - The body's conscious awareness of joint position and movement resulting from the proprioceptive input to the central nervous system. ${ }^{41}$

13. Lateral Ankle Injury - Any harm caused to the distal fibula, tarsal bones, metatarsal bones, or ligaments, muscles, or tendons surrounding these bones when the ankle is placed in extremes of physiological ROM. ${ }^{35,36}$

14. Medial Stress test- Evaluates the integrity of the Deltoid ligament. ${ }^{42}$

15. Posterior Talofibular Ligament - A thick, fairly strong band that runs horizontally medially and slightly posteriorly from the malleolar fossa to the lateral tubercle of the talus. ${ }^{35,36}$

16. Proprioception -The specialized variation of the sensory modality of touch that encompasses the sensation of movement (kinesthesia) and joint position (joint position sense). ${ }^{43}$

17. Range of Motion - The degrees a limb can be moved through a full motion. ${ }^{39}$

18. Rehabilitation - Exercises and modalities used in order to help promote healing and return a person with an injury to pre-injury state. ${ }^{44}$

19. Scar Tissue - A dense, fibrous connective tissue that joins the torn fibers of a ligament or tendon. ${ }^{45}$

20. Subtalar Joint (STJ) - Sits inferiorly to the talocrural joint. The talus is the ceiling of the subtalar joint while the calcaneus is the floor. The STJ allows the foot to move into inversion and eversion. ${ }^{46,47}$

21. Talar Tilt test- Evaluates the integrity of the calcaneofibular ligament. ${ }^{20}$

22. Talocrural Joint (TCJ) -The tibia forms the medial portion of the ankle; the fibula forms the lateral portions of the ankle; and the talus forms the floor of the inferior portion of the TCJ. The TCJ is responsible for dorsiflexion and plantarflexion motions of the foot. ${ }^{46,47}$ 
23. Time to Stabilization- a force-plate measure that is used to evaluate dynamic postural stability. The measurement provides an indication of how quickly individuals stabilize after a jump landing. ${ }^{48}$

24. Treatment - Physically treating an injury with modalities and rehabilitation. ${ }^{49}$

25. Unilateral - Referring to one side of the body only (a unilateral stance is standing on one leg only). ${ }^{39}$

\section{Limitations}

1. Participants will drop out of the study at any time or not return for post-testing due to injury or other reasons.

2. Participants will not be compliant with the rehabilitation programs.

3. Participants will be exposed to unexpected events that occur throughout the course of the study.

4. Patient will be subjected to selection bias.

5. Patients will maturate during the study.

Significance of Study

Though there is a fair amount of research on dynamic postural control and joint position sense, overall most of the results from research studies appear to be inconsistent. With the extremely high incidence of reoccurring ankle sprains this area of research demands attention.

With researching the effects of a dynamic balance training program on chronic ankle instability a better understanding might be found on how to effectively treat athletes with chronic ankle instability. Certified athletic trainers constantly experiments with ankle rehabilitation protocols as the numbers of athletes with chronic ankle instability continues to grow. Therefore, the need to find the most effective treatment for athletes with chronic ankle instability is apparent.

According to recommendations from Mckeon et al, ${ }^{6}$ further research is needed with the focus on a 4week dynamic balance training verses more traditional forms of rehabilitation for chronic ankle instability. This research can help to show which components of rehabilitation are most desirable in improving patients self reported function, dynamic postural control, joint position sense and with the intent to decrease recurrent ankle sprains. 
Results from this study, comparing programs described above, may help Certified Athletic Trainers with the future education on this topic of chronic ankle instability, through publications, presentations, and workshops. These results may help athletic trainers everyday who are treating individuals who have chronic ankle instability. Thus, better understanding and perhaps clearer knowledge on this issue will help clinicians determine rehabilitation protocols and preventative techniques when treating ankle sprains and chronic ankle instability as well as decreasing the re-occurance of injury. 


\section{APPENDIX B}

\section{LITERATURE REVIEW}

Introduction

Lateral ankle sprains are the most common injuries in sport resulting in loss of participation. ${ }^{37}$ Usually an inversion mechanism with an excessive supinated/inverted foot and ankle is the cause. ${ }^{37,47,50}$ The injury rates for ankle sprains fall somewhere between 75 and $85 \%$ of all ankle injuries. ${ }^{5,7,8,9,10}$ It is estimated that everyday in the United States more than 25,000 ankle sprains occur daily, leading to an increase in health care costs due to the time loss related to symptoms associated with lateral ankle sprains. ${ }^{7}$ The two main joints of the ankle are the subtalar and talocrural. ${ }^{51,52}$ The talocrural joint consists of the muscles of the anterior compartment and posterior compartment and the superficial ligaments of the lateral side along with the deltoid ligament medially. ${ }^{50,46,35,53}$ The subtalar joint consists of the muscles of the lateral and deep posterior compartments and the deep ligaments of the lateral side along with the retinacula. ${ }^{50,46,35,53}$ During dorsiflexion and plantarflexion the muscles and ligaments of the talocrural joint are constantly being eccentrically and concentrically contracted. ${ }^{52,53}$ The same can be said for the muscles and ligaments of the subtalar joint that provide inversion and eversion to the ankle joint complex. Supination and pronation occur at the subtalar joint, while plantarflexion and dorsiflexion occur at the talocrural joint. ${ }^{52,53}$

Chronic ankle instability is a common problem that athletes face after a lateral ankle sprain; with this increase the need for an intervention is also evident. Research in the area of ankle rehabilitation is plentiful. However no specific protocol has provided more benifits than another perhaps due to the variations of injury for each individual athlete. ${ }^{54,55}$ Traditional rehabilitation for chronic ankle instability has recently been criticized to not be the optimal intervention as it does not efficiently address or improve the associated symptoms. This has sparked a lot of new interest in the areas of joint position sense and dynamic postural control. ${ }^{11,4}$ Rehabilitation focusing on improving dynamic postural control and joint position sense can be beneficial for athletes with chronic ankle instability. 6,34

In the literature review, anatomy of the subtalar and talocrural joint, biomechanics of the ankle joint, epidemiology, etiology, assessment tools for the ankle, components of traditional 
rehabilitation, components of dynamic rehabilitation, and the foot and ankle ability measures questionnaire will be discussed.

Anatomy

The anatomy of the ankle is comprised of the talocrural joint, subtalar joint and the distal tibofibular syndesmosis. ${ }^{46,50}$ These joints all contribute to motion of the rearfoot through the sagital, frontal and transverse planes. In the event of an ankle sprain the rearfoot may be affected involving the talocrural and subtalar joints.

The talocrural joint is a hinge joint which is responsible for plantarflexion and dorsiflexion movements. ${ }^{50,46,35,53}$ The joint is formed by the articulation of the dome of the talus, the medial malleolus, the tibial plafond, and the lateral malleolus. The shape allows for torque of the leg to be transmitted into the foot. ${ }^{50,46,35,53}$ The talocrural joint receives ligamentous support from a joint capsule and several ligaments, including the anterior talofibular ligament (ATFL), posterior talofibular ligament (PTFL), calcaneofibular ligament (CFL), and deltoid ligament. ${ }^{50,46,35,53}$ Lateral support is provided by the ATFL, PTFL, and CFL, while the deltoid ligament provides medial. ${ }^{50,46,35,53}$ The anatomical locations, origin, insertion, angle and length/width of the ligaments are described in more detail in Table B1. The ATFL restricts excessive plantarflextion, while the PTFL restricts excessive inversion and internal rotation at the talocrural joint and the CFL restricts excessive supination at both talocrural and subtalar joints. $50,46,35,53$

The muscles of the talocrural joint are important to the function of the ankle joint complex in providing the means of movement through concentric and eccentric contractions. ${ }^{56,57}$ The muscles that aid in talocrural joint function are the tibialis anterior, extensor digitorum longus, extensor hallicus longus, peroneus tertius, gastrocnemius and soleus. ${ }^{56,57}$ In Table B3 a detailed look at the location, action and nerve innervation of the muscles in relation to the talocrural joint is provided.

The muscles of the anterior compartment are ankle dorsiflexors and toe extensors. The muscles are active in walking by concentrically contracting to raise the forefoot to clear the ground during the swing phase of the gait cycle and eccentrically contract to lower the forefoot to the ground after heel strike of the stance phase. ${ }^{56,57}$ The posterior compartment muscles are plantarflexors. The gastrocnemius and soleus provide the power of plantarflexion that propels the body when walking and plays a major role in running and jumping via push off. ${ }^{56,57}$ 
The talocrural joint is innervated by the deep fibular nerve in the anterior compartment and accompanied by the anterior tibial artery ${ }^{56}$. The posterior compartment is innervated by the tibial nerve and accompanied by the posterior tibial artery and the fibular artery and accompanying veins. ${ }^{56,57}$

The subtalar joint is formed by articulations between the talus and calcaneus, allowing for pronation and supination of the foot and ankle. ${ }^{53,56,57}$ The Subtalar joint is divided into two joints; anterior and posterior compartments. The anterior subtalar joint is formed from the head of the talus, the anterior-superior-facets, the sustentaculum tali of the calcaneus, and the concave proximal surface of the tarsal navicular. ${ }^{53,56,57}$ The posterior subtalar joint is formed between the inferior posterior facet of the talus and the superior posterior facet of the calcaneus ${ }^{53,56,57}$ The anterior and posterior subtalar joints have separate ligamentous joint capsules and are separated from each other by the sinus tarsi and canalis tarsi. ${ }^{53,56,57}$ A more indepth look at the ligaments is illustrated in Table B2 including origin and insertion.

The ligaments can be divided into deep, peripheral and retinacula. The deep ligaments consist of the cervical and interosseous ligaments. Together theses ligaments stabilize the subtalar joint and form a division between the anterior and posterior joint capsules. ${ }^{53,56,57}$ The cervical ligament lies within the sinus tarsi and provides support to both the anterior and posterior joints. ${ }^{53,56,57}$ The cervical ligament is the strongest subtalar ligament and has been shown to resist supination. The interosseous ligament because of the diagonal orientation and oblique fiber arrangement across the joint, portions of the ligaments are taut throughout pronation and supination. ${ }^{53,56,57}$ In regards to the peripheral ligaments the CFL is crucial in preventing excessive inversion and internal rotation of the calcaneus in relation to the talus. The fibers of the inferior extensor retinacula (IER) have been proposed to provide support to the lateral aspect of the subtalar joint. ${ }^{53,56,57}$

The muscles of the subtalar joint, like the talocrural joint, play major roles in concentric and eccentric functions of the foot and ankle. The peroneus longus and brevis muscles cross the ankle complex which help protect against lateral ankle sprains. ${ }^{56,57}$ In addition to the peroneals, the muscles of the deep posterior compartment of the leg may also contribute to the dynamic stability of the lateral ankle complex by contracting eccentrically during forced supination of the rearfoot. $^{56,57}$ The peroneus longus, peroneus brevis, tibialis posterior, flexor hallicus longus, and flexor digitorum longus muscles are in Table B4 which includes origin, insertion, main action, 
and nerve innervation. The subtalar joint is innervated by the superficial fibular nerve and tibial nerve. ${ }^{56,57}$ The anterior tibial artery and fibular artery are perforating branches since no one artery courses through the lateral compartment of the subtalar joint. ${ }^{56,57}$ The arteries are accompanied by veins. The posterior tibial artery and nutrient artery of the tibia supply the deep posterior compartment along with their accompanying veins. ${ }^{56,57}$

\section{Table B1. Anatomical Location of Talocrural Joint Ligaments $35,46,50,56$}

\begin{tabular}{|c|c|c|c|c|}
\hline$\underline{\text { Ligament }}$ & $\underline{\text { Origin }}$ & $\underline{\text { Insertion }}$ & $\underline{\text { Angle }}$ & Length/Width \\
\hline $\begin{array}{l}\text { Anterior } \\
\text { Talofibular }\end{array}$ & $\begin{array}{l}\text { Anterior Aspect of } \\
\text { Distal Fibula }\end{array}$ & $\begin{array}{l}\text { Body of the talus, } \\
\text { just anterior to the } \\
\text { articular facet }\end{array}$ & $75^{\circ}$ to the floor & $20 \mathrm{~mm} / 10 \mathrm{~mm}$ \\
\hline $\begin{array}{l}\text { Posterior } \\
\text { TaloFibular }\end{array}$ & $\begin{array}{l}\text { Medial surface of } \\
\text { lateral malleolus }\end{array}$ & $\begin{array}{l}\text { Medially and } \\
\text { horizontally to the } \\
\text { posterior talus }\end{array}$ & & $3 \mathrm{~cm}$ \\
\hline Calcaneofibular & $\begin{array}{l}\text { Anterior border of } \\
\text { the distal fibula just } \\
\text { below the orgin of } \\
\text { the ATFL }\end{array}$ & $\begin{array}{l}\text { Small tubercle } \\
\text { posterior/superior } \\
\text { to the peroneal } \\
\text { tubercle of the } \\
\text { calcaneus }\end{array}$ & $104^{\circ}$ with the ATFL & $2 \mathrm{~cm} / 5 \mathrm{~cm}$ \\
\hline Deltoid & Medial malleolus & $\begin{array}{l}\text { Talus, calcaneus, } \\
\text { and navicular bones }\end{array}$ & & \\
\hline
\end{tabular}

Table B2. Subtalar Ligaments of the Ankle ${ }^{46,50,57}$

\begin{tabular}{|c|c|c|}
\hline$\underline{\text { Ligament }}$ & $\underline{\text { Origin }}$ & Insertion \\
\hline \multicolumn{3}{|l|}{ Deep: } \\
\hline Cervical & $\begin{array}{l}\text { Cervical Tubercle of the calcaneus } \\
\text { anteriorly }\end{array}$ & Medially to talar neck \\
\hline Interosseous & $\begin{array}{l}\text { Calcaneus just anterior to the } \\
\text { posterior subtalar joint capsule }\end{array}$ & Superiorly and medial to talar neck \\
\hline \multicolumn{3}{|l|}{ Peripheral : } \\
\hline Calcaneofibular & $\begin{array}{l}\text { Anterior border of the distal fibula } \\
\text { just below the origin of the ATFL }\end{array}$ & $\begin{array}{l}\text { Small tubercle posterior and superior } \\
\text { to the peroneal tubercle of the } \\
\text { calcaneus }\end{array}$ \\
\hline $\begin{array}{l}\text { Lateral Talocalcaneal } \\
\text { Retinacula: }\end{array}$ & Trochlea of the talus & Lateral surface of the calcaneus \\
\hline Inferior Extensor Retinacula & Medial malleolus & Lateral malleolus \\
\hline
\end{tabular}


Table B3. Talocrural Joint Muscles ${ }^{56}$

\begin{tabular}{|c|c|c|c|c|}
\hline Muscle & Origin & Insertion & Innervation & Main Action \\
\hline Tibialis Anterior & $\begin{array}{l}\text { Lateral condyle and } \\
\text { superior } 1 / 2 \text { of lateral } \\
\text { surface of tibia and } \\
\text { interosseous } \\
\text { membrane }\end{array}$ & $\begin{array}{l}\text { Medial and inferior } \\
\text { surfaces of the } \\
\text { medial cuneiform } \\
\text { and base of the first } \\
\text { metatarsal }\end{array}$ & $\begin{array}{l}\text { Deep fibular nerve } \\
\text { (L4,L5) }\end{array}$ & $\begin{array}{l}\text { Dorsiflexion and } \\
\text { inversion of ankle }\end{array}$ \\
\hline $\begin{array}{l}\text { Extensor Digitorum } \\
\text { Longus }\end{array}$ & $\begin{array}{l}\text { Lateral Condyle of } \\
\text { tibia and superior } 3 / 4 \\
\text { of medial surface of } \\
\text { fibula and } \\
\text { interosseous } \\
\text { membrane }\end{array}$ & $\begin{array}{l}\text { Middle and distal } \\
\text { phalanges of the } \\
\text { lateral four digits }\end{array}$ & $\begin{array}{l}\text { Deep fibular nerve } \\
(\mathrm{L} 5, \mathrm{~S} 1)\end{array}$ & $\begin{array}{l}\text { Extends lateral four } \\
\text { digits and } \\
\text { dorsiflexes ankle }\end{array}$ \\
\hline $\begin{array}{l}\text { Extensor Hallicus } \\
\text { Longus }\end{array}$ & $\begin{array}{l}\text { Middle part of the } \\
\text { anterior surface of } \\
\text { fibula and } \\
\text { interosseus } \\
\text { membrane }\end{array}$ & $\begin{array}{l}\text { Dorsal aspect of the } \\
\text { base of the distal } \\
\text { phalanx of the great } \\
\text { toe }\end{array}$ & $\begin{array}{l}\text { Deep fibular nerve } \\
(\mathrm{L} 5, \mathrm{~S} 1)\end{array}$ & $\begin{array}{l}\text { Extends great toe } \\
\text { and dorsiflexes ankle }\end{array}$ \\
\hline Peroneus Tertius & $\begin{array}{l}\text { Inferior } 1 / 3 \text { of } \\
\text { anterior surface of } \\
\text { fibula and } \\
\text { interosseous } \\
\text { membrane }\end{array}$ & $\begin{array}{l}\text { Dorsum of the base } \\
\text { of the } 5^{\text {th }} \text { metatarsal }\end{array}$ & $\begin{array}{l}\text { Deep fibular nerve } \\
(\mathrm{L} 5, \mathrm{~S} 1)\end{array}$ & $\begin{array}{l}\text { Dorsiflexes ankle } \\
\text { and aids in inversion } \\
\text { of foot }\end{array}$ \\
\hline Gastrocnemius & $\begin{array}{l}\text { Lateral Head: lateral } \\
\text { aspect of the lateral } \\
\text { condyle of femur } \\
\text { Medial Head: } \\
\text { popliteal surface of } \\
\text { femur superior to } \\
\text { medial condyle }\end{array}$ & $\begin{array}{l}\text { Posterior surface of } \\
\text { the calcaneus via } \\
\text { calcaneal tendon }\end{array}$ & $\begin{array}{l}\text { Tibial Nerve (S1, } \\
\text { S2) }\end{array}$ & $\begin{array}{l}\text { PlantarFlexes ankle } \\
\text { and flexes leg at } \\
\text { knee joint }\end{array}$ \\
\hline Soleus & $\begin{array}{l}\text { Posterior aspect of } \\
\text { the head of fibula, } \\
\text { superior aspect of } \\
\text { the fibula soleal line, } \\
\text { medial border of the } \\
\text { tibia }\end{array}$ & $\begin{array}{l}\text { Posterior surface of } \\
\text { calcaneus via } \\
\text { calcaneal tendon }\end{array}$ & $\begin{array}{l}\text { Tibial Nerve (S1, } \\
\text { S2) }\end{array}$ & $\begin{array}{l}\text { Plantarflexes ankle } \\
\text { independent of knee } \\
\text { postion }\end{array}$ \\
\hline
\end{tabular}


$\underline{\text { Table B4. Ankle Complex Muscles of the Subtalar Joint }}{ }^{56,57}$

\begin{tabular}{|c|c|c|c|c|}
\hline Muscle & Origin & Insertion & $\underline{\text { Innervations }}$ & Main Action \\
\hline$\overline{\text { Peroneus Longus }}$ & $\begin{array}{l}\text { Head and superior } \\
2 / 3 \text { of lateral surface } \\
\text { of Fibula }\end{array}$ & $\begin{array}{l}\text { Base of the } 1^{\text {st }} \\
\text { metatarsal and } \\
\text { medial cuneiform }\end{array}$ & $\begin{array}{l}\text { Superficial fibular } \\
\text { nerve (L5, S1, S2) }\end{array}$ & $\begin{array}{l}\text { Everts foot and } \\
\text { weakly plantarflexes } \\
\text { ankle }\end{array}$ \\
\hline Peroneus Brevis & $\begin{array}{l}\text { Inferior } 2 / 3 \text { of lateral } \\
\text { surface of fibula }\end{array}$ & $\begin{array}{l}\text { Dorsal surface of } \\
\text { tuberosity on lateral } \\
\text { side of base of } 5^{\text {th }} \\
\text { metatarsal }\end{array}$ & $\begin{array}{l}\text { Superficial fibular } \\
\text { nerve (L5, S1, S2) }\end{array}$ & $\begin{array}{l}\text { Everts foot and } \\
\text { weakly plantarflexes } \\
\text { ankle }\end{array}$ \\
\hline Tibialis Posterior & $\begin{array}{l}\text { Interosseous } \\
\text { membrane posterior } \\
\text { surface of tibia } \\
\text { inferior to soleal line } \\
\text { posterior, posterior } \\
\text { surface of the fibula }\end{array}$ & $\begin{array}{l}\text { Tuberosity of } \\
\text { navicular. } \\
\text { Cuneiform and } \\
\text { cuboid, bases of } 2^{\text {nd }} \text {, } \\
3^{\text {rd }}, 4^{\text {th }} \text {, metatarsals }\end{array}$ & Tibial nerve (L4,L5) & $\begin{array}{l}\text { Plantarflexes ankle, } \\
\text { and inverts foot }\end{array}$ \\
\hline $\begin{array}{l}\text { Flexor hallicus } \\
\text { Longus }\end{array}$ & $\begin{array}{l}\text { Inferior } 2 / 3 \text { of } \\
\text { posterior surface of } \\
\text { fibula, inferior part } \\
\text { of interosseous } \\
\text { membrane }\end{array}$ & $\begin{array}{l}\text { Base of distal } \\
\text { phalanx of great toe }\end{array}$ & Tibial nerve $(\mathrm{S} 2, \mathrm{~S} 3)$ & $\begin{array}{l}\text { Flexes great toe at } \\
\text { all joints, weak } \\
\text { plantar flexor, } \\
\text { supports medial } \\
\text { longitudinal arch of } \\
\text { foot }\end{array}$ \\
\hline $\begin{array}{l}\text { Flexor Digitorum } \\
\text { Longus }\end{array}$ & $\begin{array}{l}\text { Medial part of } \\
\text { posterior surface of } \\
\text { tibia inferior to the } \\
\text { sloeal line }\end{array}$ & $\begin{array}{l}\text { Bases of distal } \\
\text { phalanges of lateral } \\
\text { four digits }\end{array}$ & Tibial nerve (S2, S3) & $\begin{array}{l}\text { Flexes lateral four } \\
\text { digits, plantarflexor, } \\
\text { supports longitudinal } \\
\text { arch of foot. }\end{array}$ \\
\hline
\end{tabular}

\section{Biomechanics}

Lateral ankle sprains, one of the most common injuries in athletics, is often studied because of the high rates of reccurence. ${ }^{10}$ Mechanical instability (MI) and functional ankle instability (FAI) have been purposed to be two of the causes of chronic ankle instability (CAI). ${ }^{10}$ A change in a joint's axis of rotation is due to abnormal ankle mechanics such as hypermobility and hypomobility resulting in MI. ${ }^{10}$ Proprioceptive, neuromuscular control, strength, and impaired postural control deficits are all causes of FAI. ${ }^{10}$ With a strong understanding of normal and abnormal biomechanics of the ankle complex, a better understanding can found between the relationship of the ankle complex and injury.

Kinematics: Ankle motion can be described as the planes in which the motion occurs and the axes around which that movement takes place. During ankle dorsiflexion, the talus glides posteriorly and externally rotates in relation to the mortise. ${ }^{10,50}$ With plantarflexion, the talus glides anteriorly and internally rotates. ${ }^{10,50}$ These motions of the talus in relation to the mortise produce a superior-posterior glide and lateral displacement of the distal fibula in relation to the 
tibia. ${ }^{10,50}$ The axis of rotation of the talocrural joint passes through the medial and lateral malleoli. ${ }^{10,50}$ In neutral, the axis is slightly anterior to the frontal plane passing through the tibia but slightly posterior to the frontal plane passing through the fibula. Isolated movement occurs primarily in the sagittal plane, with a small amount of transverse and frontal plane motion occurring around the oblique axis of rotation (anteroposterior axis). ${ }^{10,50}$ Subtalar joint motion is complex as a result of triplanar motion of the talus around a single oblique axis. ${ }^{10,50}$ The subtalar joint has one degree of freedom for pronation and supination. Pronation primarily incorporates the cardinal plane motions of eversion and external rotation, while supination primarily involves inversion and internal rotation. ${ }^{10,50}$ Ankle range of motion will differ between individuals, but in general; 10 to 20 degrees of dorsiflexion and 20 to 50 degrees of plantarflexion from neutral is considered normal. ${ }^{10,50}$ Inversion and eversion values usually range between 25 to 35 and 5 to 10 degrees, respectively. ${ }^{10,50}$

Kinetics: Ankle sprains commonly occur during walking and running, lateral cutting and side-shuffle movements and when landing from a jump. ${ }^{12,43}$ Individuals who have functional ankle instability have been shown to have different kinetic and kinematic patterns during jump landings compared with those who do not have FAI. Those with functional ankle instability used more knee flexion range of motion during landing than non-FAI individuals and reach peak ground reaction forces more quickly after landing than non-FAI individuals. ${ }^{58}$ Individuals with functional ankle instability demonstrated significantly less peroneal EMG activity and were in a more inverted position before initial contact. ${ }^{58}$ Also, those with functional ankle instability who exhibited greater angles of ankle inversion during a drop landing were found to use greater cocontraction of the ankle dorsiflexor and plantarflexor muscles, which can be interpreted as a greater impact force at initial contact compared with those without functionally unstable ankles. 58 During landing, the body's weight is decelerated using trunk, hip, and leg musculature, utilizing the entire kinetic chain. A dysfunction at one level of the kinetic chain will have an effect at a proximal or distal level through the kinetic chain. ${ }^{59}$

Anatomically, the dorsiflexed ankle is more stable due to the skeletal construction of the joint, contraction of the plantarflexors, and the pre-stretched gastrocnemius and soleus. ${ }^{14,30,60}$ This stability allows the ankle joint to be resistant to collapse upon ground contact. ${ }^{14,30,60}$ Stability of the ankle is of the utmost importance in acceleration, sprinting, and jumping. A stable ankle provides a solid base through which the hip and knee joints may apply force to the 
ground. During acceleration, touchdown occurs on the ball of the foot, and excessive collapse in the ankle joint means force will be absorbed rather than transmitted to the ground. ${ }^{14,30,60}$ On the other hand, a plantar flexed ankle position results in joint instability and creates longer contact times, delaying toe-off and disrupting the location of the base of support. ${ }^{14,30,60}$ Because of this instability, some collapse of the ankle joint upon contact is inevitable, and a compensatory plantar flexion occurs as a substitute force producer. ${ }^{14,30,60}$

Structural foot type may affect postural sway during static and dynamic postural control. ${ }^{30}$ Hyperpronated and hypersupinated subtalar joints may be less able to control postural sway. ${ }^{30}$ Orthotics have shown to significantly reduce postural sway in those with a lateral ankle sprain. An increased structural support to both the medial and lateral sides of the foot occurs with wearing orthotics. ${ }^{30}$ This support does not allow the increased subtalar joint movement that occurs in lateral ankle sprains. ${ }^{30}$

Epidemiology

The lateral ankle sprain is the most common injury in competitive and recreational athletics. An estimated 23,000 to 27,000 ankle sprains occur per day in the United States, which equals approximately one ankle sprain per 10,000 people everyday.$^{50,61,8}$ Seven to 10 percent of ankle sprains result in emergency room visits, where as an estimated 55 percent of individuals who experience a lateral ankle sprain do not seek medical treatment. ${ }^{50}$ Studies have shown that approximately 10 percent to 25 percent of all sports injuries are ankle sprains. Ankle sprains account for 75 percent of all ankle injuries with 85 percent due to inversion trauma, which involves the lateral ligaments. ${ }^{9,20}$ After suffering one ankle sprain, an individual is predisposed to chronic ankle instability. The reoccurrence rate of ankle sprains varies in the literature from 20 percent to as high as 80 percent. ${ }^{53,35,37,61}$

In regards to time loss of participation, lateral ankle sprains have shown to cause more loss than any other injury. Time loss due to ankle injuries is estimated to account for one sixth of all time lost from sport. Safran et al. ${ }^{37,62}$ stated that approximately 25 percent of time loss in football, basketball, and cross country is due to ankle injuries.

Beginning in 1998, the NCAA used the Injury Surveillance System to understand the epidemiology of injuries by sport and gender. ${ }^{63}$ Eight men's teams in the NCAA participated in the study including baseball, basketball, football, ice hockey, lacrosse, soccer, wrestling, and spring football. ${ }^{63}$ For ankle ligament sprains, men's basketball accounted for 26.6 percent of all 
injuries, soccer 17.2 percent, spring football 14.9, lacrosse 14.4 percent, football 13.6 percent, Baseball 7.9 percent , wrestling 7.4 percent, and finally ice hockey 4.5 percent. $^{63}$

Eight Woman's teams also participated in this study including, basketball, field hockey, gymnastics, ice hockey, lacrosse, soccer, softball and volleyball. ${ }^{63}$ For the ankle ligament sprains women's basketball accounted for 24 percent all injuries, volleyball 23.8 percent, lacrosse 17.7 percent, soccer 16.7 percent, gymnastics 15.4 percent, ice hockey field hockey 10 percent, softball 9.9 percent and ice hockey at 2.8 percent. ${ }^{63}$ Women showed to have a lower frequency compared to males with 7,861 and 19,256 respectively.

Etiology

Ankle sprains commonly occur during walking and running, lateral cutting and sideshuffle movements and when landing from a jump. ${ }^{12,43}$ Usually an inversion mechanism with an excessive supinated/inverted foot and ankle is the cause. ${ }^{50,7,47}$ Lateral ankle sprains and reoccurring lateral ankle sprains are the most frequent injury in athletics. Recurrent lateral ankle sprains have been thought to be caused by mechanical instability (MI) and functional instability (FAI). Mechanical instability involves laxity of ligaments and functional instability refers to neuromuscular and proprioceptive deficits. ${ }^{50,10,64}$

When a lateral ankle sprain occurs, damage is not only evident at the ligaments but the nervous and musculotendinous tissue surrounding the ankle complex are also involved. ${ }^{50,10,64}$ Mechanoreceptors have been shown to innervate the lateral ankle ligaments, and joint capsules of the talocrural and subtalar joints. ${ }^{50,10,64}$ Joint position sense is thought to be decreased when these receptors are damaged in the event of an injury. ${ }^{50,10,64}$ Mechanoreceptors sense increased tension in the ligaments and send an afferent message to the spinal cord. In response, an efferent response is sent to the muscles; which can slow or reverse the direction of joint movement. ${ }^{50,10,64}$

While injury to the ligaments may result in laxity of the joints of the ankle complex, neuromuscular deficits are also likely to occur due to the injury to the nervous and musculotendinous tissue. ${ }^{50,10,64}$ These associated neuromuscular deficits may be described as impaired balance, reduced joint position sense, slower firing of the peroneal muscles to inversion perturbation of the ankle, slowed nerve conduction velocity, impaired cutaneous sensation, strength deficits and decreased dorsiflexion range of motion. ${ }^{50,10,64}$

Many acute lateral ankle sprains occur when performing a lateral cutting movement, or landing on an irregular surface, such as the foot of another player, however recurrent lateral 
ankle sprains are liable to suffer the same mechanism due to the neuromuscular deficits of the ankle complex. ${ }^{10,32}$ When landing on an irregular surface or poorly executing a cut, a large supination torque that supinates and inverts the rearfoot excessively results in overloading and damage to the lateral ankle ligaments. ${ }^{10,32}$ If the strain in any of the ligaments exceeds the tensile strength of the tissues, ligamentous damage occurs.

Some intrinsic characteristics that may lead to ankle sprains include; demographics gender, height and weight, limb dominance, previous sprain, ligamentous stability, range of motion, muscular strength. Other intrinsic factors are foot size, anatomic foot and ankle alignment, postural sway, gait mechanics, and muscle reaction time. ${ }^{65,66}$ Some extrinsic risk factors include ankle bracing and taping, shoe type, duration and intensity of competition, sport, and player position. ${ }^{65,66}$

Lateral ankle sprains occur in sports with a high level of jumping, running, and cutting and in which involve optimal neuromuscular development and control, balance, and quick stopstart movements. With the high-intensity nature of sports many factors may predispose an athlete or individual to ankle sprains, more specifically lateral ankle sprains. Assessment Tools

Many studies suggest performing clinical stability tests for ligamentous laxity/damage between four and seven days after the injury as the most beneficial time to receive a good positive result. ${ }^{67,68,69}$ The theory behind this is that the acute pain and swelling will be decreased and the patient will be able to relax during the examination. ${ }^{67,68,69}$ However, delaying the grading of the severity of an ankle sprain might prevent diagnosis. ${ }^{67,68,69}$ The anterior drawer test (AD), the Talar Tilt(TT) inversion, and the medial subtalar glide (MSG) are stability tests for the lateral ankle ligaments.

The ATFL is the most commonly injured ligament of the ankle. The anterior drawer test evaluates the integrity of the ATFL by the amount of anterior-talar displacement that can be produced in the sagittal plane. ${ }^{67,68,69}$ To perform the test, the patient is seated with the knee flexed to 90 degrees and the involved foot relaxed in slight plantarflexion. The examiner stabilizes the tibia and fibula with one hand and grasps the calcaneus with the other. ${ }^{67,68,69}$ This may also be performed with the patient in a prone position. While the examiner assures stabilization of the distal tibia and fibula, an anterior force is applied to the calcaneus and talus. ${ }^{67,68,69} \mathrm{~A}$ positive sign for a possible ATFL sprain is anterior translation of the talus away from the ankle mortise that is 
greater on the involved side, in relation to the noninvolved side. ${ }^{67,68,69}$ The sensitivity of the test can be improved by placing the ankle in 10 degrees of plantarflexion. ${ }^{67,68,69}$

It has been stated that the anterior drawer test has been shown been has to have a sensitivity ranging from 32 percent to 80 percent without discrimination of the lateral ligaments affected by injury. ${ }^{67,68,69}$ However, research has shown for isolated tears of the ATFL, the anterior drawer test to have a sensitivity of 60 percent and a specificity of 74 percent. ${ }^{67,68,69}$ Like many other special tests examiner inter-reliability is based on experience of examiner.

The talar tilt inversion test evaluates the integrity of the CFL. The talar tilt inversion test is performed by having the patient lie on the uninvolved side on a table with the involved foot relaxed and the knee flexed to 90 degrees ${ }^{67,68,69}$ The examiner stabilizes the distal tibia with one hand while grasping the talus with the other. The examiner first places the foot in the anatomical position (neutral). ${ }^{67,68,69}$ The examiner then tilts the talus into an adducted position. ${ }^{67,68,69}$

A positive test reveals range of motion in the adducted position on the involved foot greater than that of the noninvolved foot. ${ }^{67,68,69}$ This may be indicative of a tear of the CFL of the ankle. A general rule is more than ten degrees of difference from the noninvolved side is considered abnormal. ${ }^{67,68,69}$ The greatest CFL strain is shown when the talar tilt test is performed with the foot in ten degrees of dorsiflexion.

The medial subtalar-glide test is reported to test the laxity of the subtalar joint. ${ }^{8,69}$ The test is performed with the patient in the same position as the anterior drawer, seated and knee flexed to 90 degrees. The examiner stabilizes the tibia and fibula with one hand and grasps the plantar surface of the foot with the other hand. ${ }^{8,69}$ The examiner translates the calcaneus medially (inversion) on the talus in the transverse plane. ${ }^{8,69}$ A positive sign is increased laxity on the involved limb compared to the uninvolved limb. ${ }^{8,69}$ However, Vela et al. ${ }^{69}$ reported that Hertel et al. ${ }^{53}$ found good agreement between the results of the medial subtalar-glide test and those of subtalar stress images in patients. The sensitivity and specificity of this test is unknown. ${ }^{8,69}$

Traditional Rehabilitation

Throughout the literature different variations of rehabilitation for CAI have been reported. ${ }^{6,70}$ Guidelines can be used to establish a rehabilitation program; however it is important not to use a cookbook approach. Rehabilitation is often more beneficial when created for an individual based on the injury. This is largely due to the many factors that enter into each 
athlete's situation to be able to apply a standard treatment regimen for all. Once a complete understanding of the injury, including knowledge of mechanism, major anatomical structures affected, severity, and injury healing phases, then guidelines for a rehabilitation program can be established.

Hertel and Denegar ${ }^{71}$ described a hierarchy of rehabilitation goals including the neuromuscular control paradigm. ${ }^{71}$ The hierarchy of rehabilitation goals is a pyramid incorporating the phases of healing from the initial phase up to return to full participation. ${ }^{71}$ (Figure B1)

Figure B1. Hierarchy of Rehabilitation ${ }^{71}$

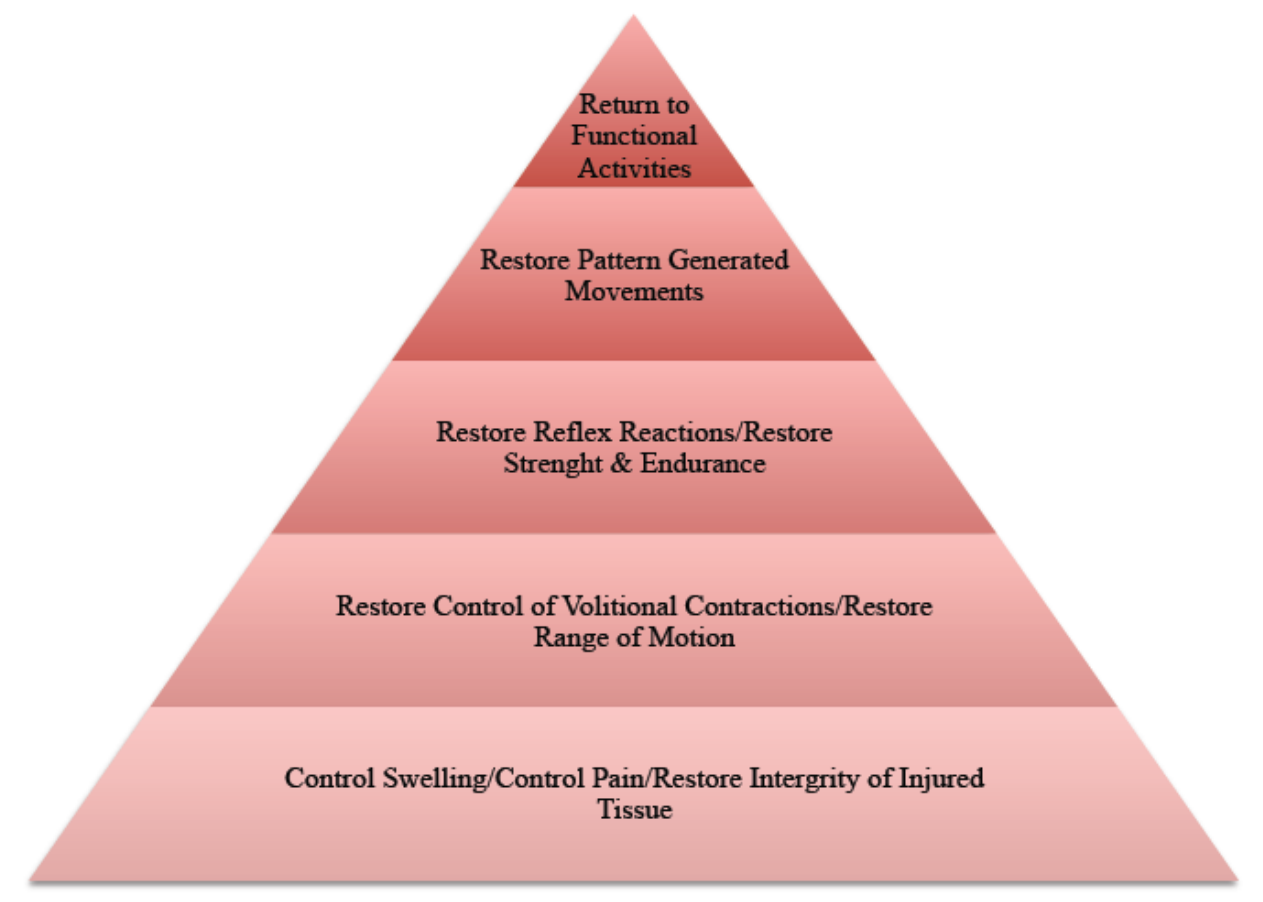

The base of the pyramid has goals of controlling swelling, pain, and to restore integrity of injured tissue hence, the primary focus of rehabilitation during this phase is to control swelling and to modulate pain by protection of the injured tissues. Cryotherapy, compression, and elevation along with medication and modalities such as transcutaneous electrical nerve stimulation are used in various combinations to achieve these goals. ${ }^{72,73,54,55}$ Strategies to control pain and swelling must be minimized and managed before a rehabilitation program can progress beyond the restoration of volitional muscle control. 
The next goal of rehabilitation should be the restoration of volitional muscle contractions and restoration of range of motion. ${ }^{74,71}$ Though not all athletic injuries result in a loss of the ability to contract muscles, it is still important to asses ones ability before progressing to the next phase. ${ }^{71}$ As part of this tier of rehabilitation the following exercises can be used to restore volitional muscle contractions and restore ROM; towel stretches, slant board, alphabet drawing, wobble board, and BAPS board. ${ }^{71}$

The next tier involves restoring reflex reactions and restoring strength and endurance. The main focus in this section of the rehabilitation program involves improving reflex responses and strengthening. Closed kinetic chain activities that maximize input from joint mechanoreceptors are ideal for retraining reflex responses and sensorimotor facilitation in the lower extremity. ${ }^{58,12,19}$ Some exercises that help achieve reflex response are single- and doubleleg; wobble board, BAPS board, Dyna Disk, Airex, and Star Excursion Balance Test. Having eyes opened and closed, uncompromised surfaces, object toss, and adding rhythmic stabilization or perturbations, can increase the difficulty of the exercise. ${ }^{58,12,19}$

There are several ways in which strength training can be accomplished. Usually, for rehabilitation purposes, high-repetition/low resistance exercises should precede high-resistance exercises and power work. ${ }^{71}$ Restoration of muscular endurance is necessary for returning to unrestricted sports performance. Isometric, isotonic, isokinetic, and plyometric exercises can be beneficial if used throughout rehabilitation. ${ }^{71}$ A functional rehabilitation-strengthening plan should involve exercises in all three planes of motion, concentrate on a combination of concentric, eccentric, and isometric exercises designed to increase strength through a full multiplanar range of motion. ${ }^{71}$ Some strengthening exercises that are often used during rehabilitation are as follows; isometric 4-way ankle, isotonic 4-way ankle (adding tubing, bands, cuff weights), toe raises, toe walks, toe curls, heel walks, marble pickup, PNF, and box jumping all function to provide resistance to a particular muscle, or group of muscles. ${ }^{71,70}$

The next tier is restoring pattern generated movements; this phase involves functional activity as a progression to sport specific exercises. The restoration of pattern generated movements should be individualized to the athlete and their specific needs for sport. ${ }^{71,74}$ An example is a running progression starting with walking, then moving to jogging, jog/run, running, double to single leg hop, figure eight's, running and hopping, stair running and skipping. ${ }^{71,74}$ Sport specific exercises should also be incorporated and performed at various 
speeds and intensities ${ }^{7}$; such as rebounding, kicking a ball, changing directions, running routes, lay-ups, and/or swinging a bat. ${ }^{71,74}$

The final tier is return to activity, the main long term goal in most athletes rehabilitation. Requirements for a athlete to enter this stage safely include pain ROM, minimum of 80-90 percent of pre-injury strength, and can perform all functional tests and practice without reaggravating the injured part; if all of these requirements are met the athlete may return to competition. ${ }^{7,54,55}$

Rozzi et al ${ }^{19}$ found significant results in balance ability and perceived function through 4 week balance training program that involved single leg balance activities for subjects with functionally unstable ankles. ${ }^{19}$ The results of this study explain that balance training is an effective way of improving joint proprioception and single leg standing in subjects with functionally unstable ankles. ${ }^{19}$

Hale et al ${ }^{34}$ found through a 4 -week rehabilitation program that subjects with CAI demonstrated deficits in postural control and SEBT reach tasks of the involved limb compared to the uninvolved limb and reported functional deficits of the involved limb compared to healthy subjects. ${ }^{34}$ This rehabilitation program encompassed, stretching, strengthening, single leg balance activities, and functional tasks. The strengthening that was used encompassed all planes of ankle movement using a thera-band as well as calf raises. The single leg balance activities varied from single leg balance, single limb stance with ball toss, single leg with kicking of opposite leg against resistance and then single leg step downs. After rehabilitation, the CAI rehabilitation group showed an improved SEBT reach than other groups. The article concluded that postural control and functional limitations exist in individuals with CAI, and that rehabilitation can improve these deficits. ${ }^{34}$ The article also concludes that the SEBT may be a good functional measure to monitor changes after rehabilitation in subjects with CAI. ${ }^{34}$ Though this article Hale et $\mathrm{al}^{34}$ found that a comprehensive rehabilitation program may serve to minimize lower extremity deficits and perceived deficits, however the components of rehabilitation that are most beneficial to minimize these deficits are still unclear. ${ }^{34}$

Mckeon et $\mathrm{al}^{6}$ tested a 4-week progressive balance training program that emphasized dynamic stabilization after hop in multiple directions and conditions, on subjects with CAI. ${ }^{6}$ The results showed a significant improvement in self reported function, static postural control, and dynamic postural control assessed by the SEBT. ${ }^{6}$ These results are similar to the Hale article 
previously discussed in that rehabilitation can be beneficial for those with CAI. Mckeon et al ${ }^{6}$ recommends to test their program against traditional rehabilitation programs for chronic ankle instability in an attempt to find the most beneficial components of the rehabilitation programs. Foot and Ankle Ability Measures Questionnaire

The Foot and Ankle Ability Measures Questionnaire( FAAM) provides subjective measure for those with musculskeletal lower leg, ankle and foot disorders. ${ }^{21,22}$ The FAAM ADL and FAAM Sport are designed to be a self-reported evaluative instrument that assesses physical function of these individuals. ${ }^{21,22}$ The FAAM ADL contains 21 items related to activities of daily living and the FAAM Sport includes eight more items that evaluate perceived disability due to ankle injuries, in activities associated with physical activity and sport. ${ }^{21,22}$

The FAAM ADL and FAAM Sport are reliable, valid, and a responsive measure of selfreported physical function. ${ }^{21}$ Validity evidence was provided for test content, internal structure, score stability, and responsiveness. Test retest reliability was 0.89 and 0.87 for the ADL and Sports subscales, respectively. ${ }^{21}$ The minimal detectable change based on a 95 percent confidence interval was $\underline{ \pm}$.7 and \pm-12.3 points for the ADL and Sports subscales, respectively.

By direction, one would answer every question with one response that is the closest in describing their condition within the past week. ${ }^{21,22}$ If for some reason the activity is limited due to another body part than the question should be answered n/a. Activity is rated by points 4,3,2,1,0, N/A; no difficulty at all, slight difficulty, moderate difficulty, extreme difficulty, unable to do, and not applicable, respectively. ${ }^{21,22}$ Pain is rated in a similar fashion 4,3,2,1,0; no pain, mild, moderate, severe or unbearable, respectively. ${ }^{21,22}$ FAAM scores are a percentage of a total 84 points, while the FAAM Sport is a percentage of 32 points. ${ }^{21,22}$ Finally the patient is to rate their current level of function during ADL's and sport from 0-100 percent. These numbers give a measurable value to the subjective feelings of the subject involved. ${ }^{21,22}$ Summary

Ankle sprains are extremely common among physically active individuals, with recurrent ankle sprains being a main concern. Lateral ankle sprains are the most common injuries in sport resulting in loss of participation. ${ }^{7}$ Usually an inversion mechanism with an excessive supinated/inverted foot and ankle is the cause. ${ }^{50,7,47}$ The injury rates for ankle sprains fall somewhere between 75 and $85 \%$ of all ankle injuries. ${ }^{5,7,8,9,10}$ It is estimated that everyday in the United States more than 25,000 ankle sprains occur daily, leading to an increase in health care 
costs due to the time loss related to symptoms associated with lateral ankle sprains. ${ }^{7}$ The two main joints of the ankle are the subtalar and talocrural. ${ }^{52,53}$ A very detailed anatomy that includes ligaments, muscles tendons, nerves, and articulations of the talocrural and subtalar joints creates a complex joint which deserves much attention. Mechanics of the foot and ankle create an understanding of mechanical and functional instability. Understanding why the injury occurs and the prevalence can lead to preventative measures against CAI. Properly understanding the assessment techniques are required to make a clinical diagnosis and drive rehabilitation. The Anterior Drawer test, talar tilt test, and the medial subtalar glide test are specific to ankle ligament sprains and instability. Rehabilitations should be individualized, all encompassing, and address deficits that are associated with CAI, such as, joint position sense and dynamic postural control. The FAAM ADL and FAAM Sport provide a measurable subjective report for the patient to express their disabilities with their foot and ankle. All of these topics addressed play a major role in assessing, diagnosing, and treating chronic ankle instability. 


\section{Study Title:}

The Effects of a Randomized Four-Week Dynamic Balance Training Program on Individuals with Chronic Ankle Instability

\section{Co-Investigator(s):}

Benjamin M. Anguish, ATC

In the event your child experiences any side effects or injury related to his research, you should contact Benjamin M. Anguish, ATC at (315) 415-2222 or at banguish@ mix.wvu.edu. If you have any questions, concerns, or complaints about this research you can contact Dr. Michelle A. Sandrey, PhD, ATC at (304) 293-0870 or at msandrey@ mail.wvu.edu.

For information regarding my rights as a research subject, I may contact the Executive Secretary of the Review Board at (304) 293-7073.

\section{Introduction:}

You, , have been asked to allow your child,

to participate in this research study, which has been explained to you and your child by Benjamin M. Anguish, ATC. This study is being conducted by principle investigator Michelle A. Sandrey $\mathrm{PhD}$., ATC and the co-investigator Benjamin M. Anguish, ATC. This research is being conducted to fulfill the requirements for a thesis in athletic training in the College of Physical Activity and Sport Sciences at West Virginia University, under the supervision of Dr. Michelle A. Sandrey PhD., ATC.

\section{Purpose of Study:}

The purpose of this study is to investigate the affects of a dynamic balance training program and a traditional rehabilitation program and its influence on improving self reported function, dynamic postural control and joint position sense with subjects experiencing chronic ankle instability. WVU expects to enroll approximately 60 subjects; a total of approximately 60 subjects at all sites are expected to participate in this study.

\section{Description of Procedures}

Procedures

This study will be conducted at University High School, 131 Bakers Ridge Rd, Morgantown, WV 26508 or West Virginia University Athletic Training Research Lab, PO Box 6116, 
Morgantown, WV 26505. All testing and training procedures will be done in the athletic training room and gymnasium so that subjects may hear and understand all directions in a quiet atmosphere that is free from any distractions. At the orientation meeting the purpose of this study will be explained to you. You will be given a demographic questionnaire (gender, height, weight, past and current medical history) and have ankle movement tests (movement of the ankle back and forth and side to side to determine looseness) done to determine inclusion/exclusion into the study. You do not have to answer all the questions. You will have the opportunity to see the questionnaire before signing this consent form and Authorization to Use or Disclose Protected Health Information section. All completed forms will be confidential. If you are an eligible subject, you will be contacted by the research team in order to schedule a meeting time for pre testing. Pre-testing will involve completion of the Foot and Ankle Ability Measure (FAAM ADL) and FAAM Sport questionnaires performance of the Star Excursion Balance Test (SEBT), measurement of leg length, and performance of the Joint Position Sense Blocks.

Your child will have a one in three chance of being randomly assigned to either the dynamic balance training program, traditional rehabilitation or the control group. Your child will then be asked for his/her full cooperation and to work to the best of their ability three times a week for forty-five minutes over a four-week period. Your child will complete a final sixty minute posttesting session for the FAAM and FAAM Sport, SEBT, and joint position sense blocks which will conclude his/her participation. The post-test will be performed to the exact specifications as the pre-test, and will be completed within the week following the final balancing training session of the fourth week.

After your child's level of functional ankle instability is determined by the demographic questionnaire. The special tests will be the final inclusion or exclusion criteria into the study. If your child has a grade III sprain determined by a special tests he/she will be excluded from the study.

Your child will be asked to answer the FAAM-22 item questionnaire with one response that will most clearly describe his/her condition within the past week. Upon completion, your child will answer the FAAM Sport 8-item questionnaire with one response that will most clearly describe his/her condition within the past week.

Your child's true leg length will be measured using a tape measure to normalize data. Instructions will be given to your child to stand in the middle of a grid formed by three lines extending out at $135^{\circ}$ from each other. Your child will be asked to reach as far as possible along the three lines (forward, backward and to the side, and backward to the opposite side) lines, make a light touch on the line, and return the reaching leg back to the center, while maintaining a single-leg stance with the other leg in the center of the grid.

Your child will be allowed to practice reaching in each of the three directions three times. Following a 5-min rest period, your child will perform three trials in each of the three directions. The reach distance will be recorded from the center of the grid to the point of maximum distance by the reach leg. 
Joint position sense will be measured in the involved leg by the sloped surface block methods. This measurement will be taken with the subject wearing goggles and headphones to block out distractions. Your child will be asked to step onto the surface of the box, which will be positioned against a wall. Prior to testing your child will be given reference angles for each motion of the ankle; toe pointing down, toe pointing up, toe pointing in and toe pointing out. These reference angles will also be given again at the half way point of each trial. Your child will stand on the surface for 5 seconds and estimate the angle. After your child estimates the angle, the leg will be removed from the surface, and the block will changed and then steps are repeated.

\section{Interventions}

Your child will perform a ten-minute dynamic Flex Band flexibility warm-up routine regardless of the experimental he/she is randomly assigned. If your child is randomly assigned to the control group he/she will only do the pre and post testing. The dynamic warm-up will consist of ankle, calf, achilles, hamstring, groin, I-T Band, and concludes with quadriceps/hip flexor stretches on both legs.

The dynamic balancing-training program is a four-week progressive program for those with chronic ankle instability. He/she will perform single-limb hops to stabilization, hop to stabilization and reach, unanticipated hop to stabilization, and single-limb stance activities into a rehabilitation program.

The first exercise will require your child to hop in four directions ten times. Each repetition will consist of a hop from the starting position to the target position at 18, 27, or 36 inches. After your child stabilizes his/her balance in a single-limb stance, he/she will hop in the exact opposite direction back to the starting position and stabilize in the single-limb stance.

The second exercise will be a five-repetition hop to stabilization and reach exercise with a combination of the previously mentioned exercise. Your child will hop, stabilize, and reach back to the starting position, then hop back to the starting position and reach to the targeted position.

The third exercise will be an unanticipated hop to stabilization with your child standing in the middle of a nine-marker grid. A randomized, sequence of numbers will be displayed on a computer screen in front of your child. Each number will correspond to a hop target position. As the progression of numbers change, your child will hop to the new target position. Your child will do three repetitions.

The fourth and final exercise is the single-limb stance. Your child will perform three repetitions of a single-limb stance. The exercise is made more difficult by the environment and conditions, such as eyes open, eyes closed, standing on foam, and throwing a ball.

The four-week dynamic balancing-training program has several levels of difficulty. Your child will be progressed accordingly. At the end of the fourth week FAAM and FAAM Sport, SEBT, and joint position sense measurements will be taken again. Your child will now complete the study and will be released from this study. 
The Traditional Rehabilitation program is a four-week progressive program for those with chronic ankle instability. The program involves all single-limb balance activities with multiple variations of activities.

The first exercise is single-limb stance for 60 seconds with two repetitions. Your child will stand on one leg for 60 seconds with their eyes open, attempting to balance on one leg without assistance. Your child may progress to performing this activity with their eyes closed and then with eyes closed and the researcher causing an unbalanced situation.

The second exercise is a single-limb stance with a ball toss 3 times with 10 tosses each time. Your child will balance on one leg with eyes open, and toss a ball back and forth with the researcher 10 times and repeat 3 times, attempting to balance without assistance. Your child may progress to more tosses and then adding a foam pad underneath their foot they are balancing on.

The next exercise is a single-limb stance while kicking against resistance in 4 directions 3 times with 5 kicks each direction with green surgical tubing. Your child will balance on one leg with a green resistance band tied around their other ankle and perform kicks with a straight leg in the forward, backward, right and left directions. Your child will attempt to balance without assistance. Your child may progress to a blue resistance band (more resistance) or increasing the amount of kicks that he/she performs.

The final exercise is step-downs with single-limb in 3-directions including 2 sets of 5 repetitions in each direction on a 6 inch step. Your child will stand on one leg on top of a 6 inch box and lower their opposite foot to the ground until their heel touches. He/she will perform this movement in the forward, backward and side direction attempting to balance without assistance. Your child may progress to adding a foam pad under their balancing limb and then increasing the step height to 10 inches.

\section{Risks and Discomfort}

You understand there are no known or expected risks for my child from participation in this study. You understand that your child's participation in this study is expected to result in only minor muscle soreness or discomfort from performance of dynamic balance training program or traditional rehabilitation program exercises. The treatment will only occur every other day. After completion of the dynamic balance training program or traditional rehabilitation program, ice will be applied to the tested extremity to aid in prevention of muscle soreness. While performing any testing or exercise which requires the eyes to be open, loss of balance should be minimal. However, balance may be lost in exercises requiring the eyes to be closed, but instructions will be given to touch down with the non-injured foot during single-limb balancing exercises if balance is lost. A member of the research team will stand next to the subject if additional support is needed.

You understand that every precaution has been taken to prevent my child from being injured in this study. If an adverse physical or psychological reaction were to occur during any point of the study, appropriate care or referral will be made available. Should any injury occur to my child, I 
understand that Benjamin M. Anguish, ATC will provide first aid and make any necessary medical referrals at your expense.

\section{Alternative}

The Alternatives to this study include physical therapy or strength training to the involved extremity. These therapies are used every day and therefore, they may be used as an alternative to participation in this research study.

\section{Benefits}

You may receive direct benefits from this study if you are in one of the experimental groups. Benefits may include: gaining a better understanding of the severity of your ankle injury, learning safe exercises, and improving your function. Additionally, the knowledge gained from this study may eventually benefit others with chronic ankle instability.

\section{Financial Considerations}

There will be no cost as a result of participation in this study. You understand that you will not receive any monetary compensation for participation in this study.

\section{Confidentiality}

Subjects Name:

ID Number:

We know that information about your child and your child's health is private. We are dedicated to protecting the privacy of that information. Because of this promise, we must get your written authorization (permission) before we may use or disclose your child's protected health information or share it with others for research purposes. This form gives that permission. It also helps us make sure that you are correctly told how this information will be used or disclosed. Please read the information below carefully before signing this form. Please ask any questions you may have about this form or its uses. You can decide to sign or not to sign this authorization form. However, if you choose not to sign this authorization form, your child will not be able to take part in the research study. Whatever choice you make about this research study, it will not have an effect on you access to medical care.

\section{USE AND DISCLOSURE COVERED BY THIS AUTHORIZATION. DO NOT SIGN A} BLANK FORM. You or your authorized representative should thoroughly read the information below before signing this form. This form will authorize the following person(s), class(es) of persons, and/or organization (s) to disclose, use, and receive the information: WVU, Michelle A. Sandrey, PhD., ATC, Benjamin M. Anguish, ATC. The research site(s) carrying out this study includes WVU and University High School. It also includes each site's research staff and medical staff. Health care providers who provide services to you as part of this research study include Benjamin M. Anguish, ATC. If, during the course of the research, the institution listed 
above merges with, or is purchased by, another company or institution, this authorization to use or disclose protected health information in the research will extend to the successor company or institution. A self-report demographic history that includes information on height, weight, and past medical history of any lower limb injury is included in this study.

SPECIFIC UNDERSTANDINGS: By signing this research authorization form, you give permission for the use and/or disclosure of your protected health information described above. The purpose for the uses and disclosures you are authorizing is to carry out the research study explained to you during the informed consent process. It is also to ensure that the information relating to the research is available to all parties who may need it for research purposes. Your protected health information may be used as necessary for your research-related treatment. This information may be re-disclosed or used for other purposes if a recipient described in this form is not required by law to protect the privacy of the information. You have a right to refuse to sign this authorization. Your health care outside the study, the payment for your health care, and your health care benefits will NOT be affected if you do not sign this form. However you will NOT be able to take part in the research study described in this authorization if you do not sign this form. If you sign this authorization, you will have the right to cancel it at any time, except to the extent that WVU has already taken action based upon your authorization or needs the information to complete analysis and reports of data for this research study. To cancel this authorization, please write to the Principal Investigator, Michelle A. Sandrey, Ph.D, at: West Virginia University, PO Box 6116, Morgantown, WV 26506. You will NOT be allowed to see or copy the information described on this form as long as the research is in progress, but you have a right to see and copy the information upon completion of the research in accordance with hospital policies. You have a right to receive a copy of this form after you have signed it. Expiration Date: NONE

In any publications that result from this research, neither your name nor any information from which you might be identified will be published without your consent.

\section{THE SUBJECT OR HIS/HER AUTHORIZED REPRESENTATIVE MUST BE PROVIDED} WITH A COPY OF THIS FORM AFTER IT HAS BEEN SIGNED.

\section{SIGNATURE}

I have read this form and all of my questions about this form have been answered. By signing below, I acknowledge that I have read and accept all of the above.

Signature of Subject or Authorized

Representative

Date

Print Name of Subject or Authorized

Representative

Print Name of Individual Explaining this Research Authorization Form 
CONTACT INFORMATION: The contact information of the subject or authorized representative who signed this form should be filled in below.

Address

Telephone:

(daytime)

(evening)

E-mail Address(optional):

\section{Voluntary Participation}

Participation in this study is voluntary. You are free to withdraw your consent to participate in this study at any time. Refusal to participate or withdrawal will not affect your future care, your class standing, or your grades and will involve no penalty to you. In the event that new information becomes available that may affect your willingness to participate in this study, this information will be given to you so that you can make an informed decision about whether or not to continue your participation. You have been given the opportunity to ask questions about the research, and you have received answers concerning areas you did not understand.

Upon signing this form you will receive a copy.

I willingly consent for my child to participate in this research.

Signature of Subject or

Printed Name

Date

Time

Subjects Legal Representative

The participant has had the opportunity to have questions addressed. The participant willingly agrees to be in the study.

Signature of Investigator or

Co-Investigator

Printed Name

Date

Time 
Table C2. Assent Form

\section{Study Title:}

The Effects of a Randomized Four-Week Dynamic Balance Training Program on Individuals with Chronic Ankle Instability

\section{Co-Investigator(s):}

Benjamin M. Anguish, ATC

In the event you experiences any side effects or injury related to his research, you should contact Benjamin M. Anguish, ATC at (315) 415-2222 or at banguish@mix.wvu.edu. If you have any questions, concerns, or complaints about this research you can contact Dr. Michelle A. Sandrey, $\mathrm{PhD}$, ATC at (304) 293-0870 or at msandrey@ mail.wvu.edu.

For information regarding my rights as a research subject, I may contact the Executive Secretary of the Review Board at (304) 293-7073.

\section{Introduction:}

You, , have been asked to participate in this research study, which has been explained to you and by Benjamin M. Anguish, ATC. This study is being conducted by principle investigator Michelle A. Sandrey PhD., ATC and the co-investigator Benjamin M. Anguish, ATC. This research is being conducted to fulfill the requirements for a thesis in athletic training in the College of Physical Activity and Sport Sciences at West Virginia University, under the supervision of Dr. Michelle A. Sandrey PhD., ATC.

\section{Purpose of Study:}

The purpose of this study is to investigate the affects of a dynamic balance training program and a traditional rehabilitation program and its influence on improving self reported function, dynamic postural control and joint position sense with subjects experiencing chronic ankle instability. WVU expects to enroll approximately 60 subjects; a total of approximately 60 subjects at all sites are expected to participate in this study.

\section{Description of Procedures}

Procedures

This study will be conducted at University High School, 131 Bakers Ridge Rd, Morgantown, WV 26508 or West Virginia University Athletic Training Research Lab, PO Box 6116, Morgantown, WV 26505. All testing and training procedures will be done in the athletic training room and gymnasium so that subjects may hear and understand all directions in a quiet atmosphere that is free from any distractions. At the orientation meeting the purpose of this study will be explained to you. You will be given a demographic questionnaire (gender, height, weight, past and current medical history) and have ankle movement tests (movement of the ankle back 
and forth and side to side to determine looseness) done to determine inclusion/exclusion into the study. You do not have to answer all the questions. You will have the opportunity to see the questionnaire before signing this consent form and Authorization to Use or Disclose Protected Health Information section. All completed forms will be confidential. If you are an eligible subject, you will be contacted by the research team in order to schedule a meeting time for pre testing. Pre-testing will involve completion of the Foot and Ankle Ability Measure (FAAM ADL) and FAAM Sport questionnaires performance of the Star Excursion Balance Test (SEBT), measurement of leg length, and performance of the Joint Position Sense Blocks.

You will have a one in three chance of being randomly assigned to either the dynamic balance training program, traditional rehabilitation or the control group. You will then be asked for your full cooperation and to work to the best of your ability three times a week for forty-five minutes over a four-week period. You will complete a final sixty minute post-testing session for the FAAM and FAAM Sport, SEBT, and joint position sense blocks which will conclude your participation. The post-test will be performed to the exact specifications as the pre-test, and will be completed within the week following the final balancing training session of the fourth week.

After your level of functional ankle instability is determined by the demographic questionnaire. The special tests will be the final inclusion or exclusion criteria into the study. If you have a grade III sprain determined by special tests you will be excluded from the study.

You will be asked to answer the FAAM-22 item questionnaire with one response that will most clearly describe condition within the past week. Upon completion, you will answer the FAAM Sport 8-item questionnaire with one response that will most clearly describe condition within the past week.

Your true leg length will be measured using a tape measure to normalize data. Instructions will be given to you to stand in the middle of a grid formed by three lines extending out at $135^{\circ}$ from each other. You will be asked to reach as far as possible along the three lines (forward, backward and to the side, and backward to the opposite side) lines, make a light touch on the line, and return the reaching leg back to the center, while maintaining a single-leg stance with the other leg in the center of the grid.

Your will be allowed to practice reaching in each of the three directions three times. Following a 5-min rest period, you will perform three trials in each of the three directions. The reach distance will be recorded from the center of the grid to the point of maximum distance by the reach leg.

Joint position sense will be measured in the involved leg by the sloped surface block methods. This measurement will be taken with the subject wearing goggles and headphones to block out distractions. You will be asked to step onto the surface of the box, which will be positioned against a wall. Prior to testing you will be given reference angles for each motion of the ankle; toe pointing down, toe pointing up, toe pointing in and toe pointing out. These reference angles will also be given again at the half way point of each trial. You will stand on the surface for 5 seconds and estimate the angle. After you estimate the angle, the leg will be removed from the surface, and the block will be changed and then steps will be repeated. 
Interventions

You will perform a ten-minute dynamic Flex Band flexibility warm-up routine regardless of the experimental group you are randomly assigned. If you are assigned to the control group then you will just participate in pre-post testing. The dynamic warm-up will consist of ankle, calf, achilles, hamstring, groin, I-T Band, and concludes with quadriceps/hip flexor stretches on both legs.

The dynamic balancing-training program is a four-week progressive program for those with chronic ankle instability. You will perform single-limb hops to stabilization, hop to stabilization and reach, unanticipated hop to stabilization, and single-limb stance activities into a rehabilitation program.

The first exercise will require you to hop in four directions ten times. Each repetition will consist of a hop from the starting position to the target position at 18, 27, or 36 inches. After you stabilize your balance in a single-limb stance, you will hop in the exact opposite direction back to the starting position and stabilize in the single-limb stance.

The second exercise will be a five-repetition hop to stabilization and reach exercise with a combination of the previously mentioned exercise. You will hop, stabilize, and reach back to the starting position, then hop back to the starting position and reach to the targeted position.

The third exercise will be an unanticipated hop to stabilization with you standing in the middle of a nine-marker grid. A randomized, sequence of numbers will be displayed on a computer screen in front of you. Each number will correspond to a hop target position. As the progression of numbers change, you will hop to the new target position. You will do three repetitions.

The fourth and final exercise is the single-limb stance. You will perform three repetitions of a single-limb stance. The exercise is made more difficult by the environment and conditions, such as eyes open, eyes closed, standing on foam, and throwing a ball.

The four-week dynamic balancing-training program has several levels of difficulty. You will be progressed accordingly. At the end of the fourth week FAAM and FAAM Sport, SEBT, and joint position sense measurements will be taken again. You will now complete the study and will be released from this study.

The Traditional Rehabilitation program is a four-week progressive program for those with chronic ankle instability. The program involves all single-limb balance activities with multiple variations of activities.

The first exercise is single-limb stance for 60 seconds with two repetitions. You will stand on one leg for 60 seconds with your eyes open, attempting to balance on one leg without assistance. You may progress to performing this activity with their eyes closed and then with eyes closed and the researcher causing an unbalanced condition.

The second exercise is a single-limb stance with a ball toss 3 times with 10 tosses each time. You will balance on one leg with eyes open, and toss a ball back and forth with the researcher 10 
times and repeat 3 times, attempting to balance without assistance. You may progress to more tosses and then adding a foam pad underneath the foot you are balancing on.

The next exercise is a single-limb stance while kicking against resistance in 4 directions 3 times with 5 kicks each direction with green surgical tubing. You will balance on one leg with a green resistance band tied around you other ankle and perform kicks with a straight leg in the forward, backward, right and left directions. You will attempt to balance without assistance. You may progress to a blue resistance band (more resistance) or increasing the amount of kicks that you perform.

The final exercise is step-downs with single-limb in 3-directions including 2 sets of 5 repetitions in each direction on a 6 inch step. You will stand on one leg on top of a 6 inch box and lower your opposite foot to the ground until your heel touches. You will perform this movement in the forward, backward and side direction attempting to balance without assistance. You may progress to adding a foam pad under their balancing limb and then increasing the step height to 10 inches.

\section{Risks and Discomfort}

You understand there are no known or expected risks from participation in this study. You understand that your participation in this study is expected to result in only minor muscle soreness or discomfort from performance of dynamic balance training program or traditional rehabilitation program exercises. The treatment will only occur every other day. After completion of the dynamic balance training program or traditional rehabilitation program, ice will be applied to the tested extremity to aid in prevention of muscle soreness. While performing any testing or exercise which requires the eyes to be open, loss of balance should be minimal. However, balance may be lost in exercises requiring the eyes to be closed, but instructions will be given to touch down with the non-injured foot during single-limb balancing exercises if balance is lost. A member of the research team will stand next to the subject if additional support is needed.

You understand that every precaution has been taken to prevent you from being injured in this study. If an adverse physical or psychological reaction were to occur during any point of the study, appropriate care or referral will be made available. Should any injury occur to you, I understand that Benjamin M. Anguish, ATC will provide first aid and make any necessary medical referrals at your expense.

\section{Alternative}

The Alternatives to this study include physical therapy or strength training to the involved extremity. These therapies are used every day and therefore, they may be used as an alternative to participation in this research study. 


\section{Benefits}

You may receive direct benefits from this study if you are in one of the experimental groups. Benefits may include: gaining a better understanding of the severity of your ankle injury, learning safe exercises, and improving your function. Additionally, the knowledge gained from this study may eventually benefit others with chronic ankle instability.

\section{Financial Considerations}

There will be no cost as a result of participation in this study. You understand that you will not receive any monetary compensation for participation in this study.

\section{Confidentiality}

Subjects Name:

ID Number:

We know that information about you and your health is private. We are dedicated to protecting the privacy of that information. Because of this promise, we must get your written authorization (permission) before we may use or disclose your protected health information or share it with others for research purposes. This form gives that permission. It also helps us make sure that you are correctly told how this information will be used or disclosed. Please read the information below carefully before signing this form. Please ask any questions you may have about this form or its uses. You can decide to sign or not to sign this authorization form. However, if you choose not to sign this authorization form, you will not be able to take part in the research study. Whatever choice you make about this research study, it will not have an effect on you access to medical care.

\section{USE AND DISCLOSURE COVERED BY THIS AUTHORIZATION. DO NOT SIGN A} BLANK FORM. You or your authorized representative should thoroughly read the information below before signing this form. This form will authorize the following person(s), class(es) of persons, and/or organization (s) to disclose, use, and receive the information: WVU, Michelle A. Sandrey, PhD., ATC, Benjamin M. Anguish, ATC. The research site(s) carrying out this study includes WVU and University High School. It also includes each site's research staff and medical staff. Health care providers who provide services to you as part of this research study include Benjamin M. Anguish, ATC. If, during the course of the research, the institution listed above merges with, or is purchased by, another company or institution, this authorization to use or disclose protected health information in the research will extend to the successor company or institution. A self-report demographic history that includes information on height, weight, and past medical history of any lower limb injury is included in this study.

SPECIFIC UNDERSTANDINGS: By signing this research authorization form, you give permission for the use and/or disclosure of your protected health information described above. The purpose for the uses and disclosures you are authorizing is to carry out the research study explained to you during the informed consent process. It is also to ensure that the information 
relating to the research is available to all parties who may need it for research purposes. Your protected health information may be used as necessary for your research-related treatment. This information may be re-disclosed or used for other purposes if a recipient described in this form is not required by law to protect the privacy of the information. You have a right to refuse to sign this authorization. Your health care outside the study, the payment for your health care, and your health care benefits will NOT be affected if you do not sign this form. However you will NOT be able to take part in the research study described in this authorization if you do not sign this form. If you sign this authorization, you will have the right to cancel it at any time, except to the extent that WVU has already taken action based upon your authorization or needs the information to complete analysis and reports of data for this research study. To cancel this authorization, please write to the Principal Investigator, Michelle A. Sandrey, Ph.D, at: West Virginia University, PO Box 6116, Morgantown, WV 26506. You will NOT be allowed to see or copy the information described on this form as long as the research is in progress, but you have a right to see and copy the information upon completion of the research in accordance with hospital policies. You have a right to receive a copy of this form after you have signed it. Expiration Date: NONE

In any publications that result from this research, neither your name nor any information from which you might be identified will be published without your consent.

\section{THE SUBJECT OR HIS/HER AUTHORIZED REPRESENTATIVE MUST BE PROVIDED WITH A COPY OF THIS FORM AFTER IT HAS BEEN SIGNED.}

\section{SIGNATURE}

I have read this form and all of my questions about this form have been answered. By signing below, I acknowledge that I have read and accept all of the above.

Signature of Subject or Authorized

Representative

Date

Print Name of Subject or Authorized

Representative

Print Name of Individual Explaining this Research Authorization Form

CONTACT INFORMATION: The contact information of the subject or authorized representative who signed this form should be filled in below.

Address

Telephone: (daytime) (evening) 
E-mail Address(optional):

\section{Voluntary Participation}

Participation in this study is voluntary. You are free to withdraw your consent to participate in this study at any time. Refusal to participate or withdrawal will not affect your future care, your class standing, or your grades and will involve no penalty to you. In the event that new information becomes available that may affect your willingness to participate in this study, this information will be given to you so that you can make an informed decision about whether or not to continue your participation. You have been given the opportunity to ask questions about the research, and you have received answers concerning areas you did not understand.

Upon signing this form you will receive a copy.

I willingly consent to participate in this research.

Signature of Subject or

Subjects Legal Representative

Printed Name

Date

Time

The participant has had the opportunity to have questions addressed. The participant willingly agrees to be in the study.

Signature of Investigator or

Printed Name

Date

Time 
Table C3. Consent Form

\section{Study Title:}

The Effects of a Randomized Four-Week Dynamic Balance Training Program on Individuals with Chronic Ankle Instability

\section{Co-Investigator(s):}

Benjamin M. Anguish, ATC

In the event you experiences any side effects or injury related to his research, you should contact Benjamin M. Anguish, ATC at (315) 415-2222 or at banguish@mix.wvu.edu. If you have any questions, concerns, or complaints about this research you can contact Dr. Michelle A. Sandrey, $\mathrm{PhD}$, ATC at (304) 293-0870 or at msandrey@ mail.wvu.edu.

For information regarding my rights as a research subject, I may contact the Executive Secretary of the Review Board at (304) 293-7073.

\section{Introduction:}

You, , have been asked to participate in this research study, which has been explained to you and by Benjamin M. Anguish, ATC. This study is being conducted by principle investigator Michelle A. Sandrey PhD., ATC and the co-investigator Benjamin M. Anguish, ATC. This research is being conducted to fulfill the requirements for a thesis in athletic training in the College of Physical Activity and Sport Sciences at West Virginia University, under the supervision of Dr. Michelle A. Sandrey PhD., ATC.

\section{Purpose of Study:}

The purpose of this study is to investigate the affects of a dynamic balance training program and a traditional rehabilitation program and its influence on improving self reported function, dynamic postural control and joint position sense with subjects experiencing chronic ankle instability. WVU expects to enroll approximately 60 subjects; a total of approximately 60 subjects at all sites are expected to participate in this study.

\section{Description of Procedures}

Procedures

This study will be conducted at University High School, 131 Bakers Ridge Rd, Morgantown, WV 26508 or West Virginia University Athletic Training Research Lab, PO Box 6116, Morgantown, WV 26505. All testing and training procedures will be done in the athletic training room and gymnasium so that subjects may hear and understand all directions in a quiet atmosphere that is free from any distractions. At the orientation meeting the purpose of this study will be explained to you. You will be given a demographic questionnaire (gender, height, weight, past and current medical history) and have ankle movement tests (movement of the ankle back 
and forth and side to side to determine looseness) done to determine inclusion/exclusion into the study. You do not have to answer all the questions. You will have the opportunity to see the questionnaire before signing this consent form and Authorization to Use or Disclose Protected Health Information section. All completed forms will be confidential. If you are an eligible subject, you will be contacted by the research team in order to schedule a meeting time for pre testing. Pre-testing will involve completion of the Foot and Ankle Ability Measure (FAAM ADL) and FAAM Sport questionnaires performance of the Star Excursion Balance Test (SEBT), measurement of leg length, and performance of the Joint Position Sense Blocks.

You will have a one in three chance of being randomly assigned to either the dynamic balance training program, traditional rehabilitation or the control group. You will then be asked for your full cooperation and to work to the best of your ability three times a week for forty-five minutes over a four-week period. You will complete a final sixty minute post-testing session for the FAAM and FAAM Sport, SEBT, and joint position sense blocks which will conclude your participation. The post-test will be performed to the exact specifications as the pre-test, and will be completed within the week following the final balancing training session of the fourth week.

After your level of functional ankle instability is determined by the demographic questionnaire. The special tests will be the final inclusion or exclusion criteria into the study. If you have a grade III sprain determined by special tests you will be excluded from the study.

You will be asked to answer the FAAM-22 item questionnaire with one response that will most clearly describe condition within the past week. Upon completion, you will answer the FAAM Sport 8-item questionnaire with one response that will most clearly describe condition within the past week.

Your true leg length will be measured using a tape measure to normalize data. Instructions will be given to you to stand in the middle of a grid formed by three lines extending out at $135^{\circ}$ from each other. You will be asked to reach as far as possible along the three lines (forward, backward and to the side, and backward to the opposite side) lines, make a light touch on the line, and return the reaching leg back to the center, while maintaining a single-leg stance with the other leg in the center of the grid.

Your will be allowed to practice reaching in each of the three directions three times. Following a 5-min rest period, you will perform three trials in each of the three directions. The reach distance will be recorded from the center of the grid to the point of maximum distance by the reach leg.

Joint position sense will be measured in the involved leg by the sloped surface block methods. This measurement will be taken with the subject wearing goggles and headphones to block out distractions. You will be asked to step onto the surface of the box, which will be positioned against a wall. Prior to testing you will be given reference angles for each motion of the ankle; toe pointing down, toe pointing up, toe pointing in and toe pointing out. These reference angles will also be given again at the half way point of each trial. You will stand on the surface for 5 seconds and estimate the angle. After you estimate the angle, the leg will be removed from the surface, and the block will be changed and then steps will be repeated. 
Interventions

You will perform a ten-minute dynamic Flex Band flexibility warm-up routine regardless of the experimental you are randomly assigned. If you are assigned to the control group you will only participate in pre and post testing. The dynamic warm-up will consist of ankle, calf, achilles, hamstring, groin, I-T Band, and concludes with quadriceps/hip flexor stretches on both legs.

The dynamic balancing-training program is a four-week progressive program for those with chronic ankle instability. You will perform single-limb hops to stabilization, hop to stabilization and reach, unanticipated hop to stabilization, and single-limb stance activities into a rehabilitation program.

The first exercise will require you to hop in four directions ten times. Each repetition will consist of a hop from the starting position to the target position at 18, 27, or 36 inches. After you stabilize your balance in a single-limb stance, you will hop in the exact opposite direction back to the starting position and stabilize in the single-limb stance.

The second exercise will be a five-repetition hop to stabilization and reach exercise with a combination of the previously mentioned exercise. You will hop, stabilize, and reach back to the starting position, then hop back to the starting position and reach to the targeted position.

The third exercise will be an unanticipated hop to stabilization with you standing in the middle of a nine-marker grid. A randomized, sequence of numbers will be displayed on a computer screen in front of you. Each number will correspond to a hop target position. As the progression of numbers change, you will hop to the new target position. You will do three repetitions.

The fourth and final exercise is the single-limb stance. You will perform three repetitions of a single-limb stance. The exercise is made more difficult by the environment and conditions, such as eyes open, eyes closed, standing on foam, and throwing a ball.

The four-week dynamic balancing-training program has several levels of difficulty. You will be progressed accordingly. At the end of the fourth week FAAM and FAAM Sport, SEBT, and joint position sense measurements will be taken again. You will now complete the study and will be released from this study.

The Traditional Rehabilitation program is a four-week progressive program for those with chronic ankle instability. The program involves all single-limb balance activities with multiple variations of activities.

The first exercise is single-limb stance for 60 seconds with two repetitions. You will stand on one leg for 60 seconds with your eyes open, attempting to balance on one leg without assistance. You may progress to performing this activity with their eyes closed and then with eyes closed and the researcher performing perturbations.

The second exercise is a single-limb stance with a ball toss 3 times with 10 tosses each time. You will balance on one leg with eyes open, and toss a ball back and forth with the researcher 10 
times and repeat 3 times, attempting to balance without assistance. You may progress to more tosses and then adding a foam pad underneath the foot you are balancing on.

The next exercise is a single-limb stance while kicking against resistance in 4 directions 3 times with 5 kicks each direction with green surgical tubing. You will balance on one leg with a green resistance band tied around their other ankle and perform kicks with a straight leg in the forward, backward, right and left directions. You will attempt to balance without assistance. You may progress to a blue resistance band (more resistance) or increasing the amount of kicks that he/she performs.

The final exercise is step-downs with single-limb in 3-directions including 2 sets of 5 repetitions in each direction on a 6 inch step. You will stand on one leg on top of a 6 inch box and lower their opposite foot to the ground until their heel touches. You will perform this movement in the forward, backward and side direction attempting to balance without assistance. You may progress to adding a foam pad under their balancing limb and then increasing the step height to 10 inches.

\section{Risks and Discomfort}

You understand there are no known or expected risks from participation in this study. You understand that your participation in this study is expected to result in only minor muscle soreness or discomfort from performance of dynamic balance training program or traditional rehabilitation program exercises. The treatment will only occur every other day. After completion of the dynamic balance training program or traditional rehabilitation program, ice will be applied to the tested extremity to aid in prevention of muscle soreness. While performing any testing or exercise which requires the eyes to be open, loss of balance should be minimal. However, balance may be lost in exercises requiring the eyes to be closed, but instructions will be given to touch down with the non-injured foot during single-limb balancing exercises if balance is lost. A member of the research team will stand next to the subject if additional support is needed.

You understand that every precaution has been taken to prevent you from being injured in this study. If an adverse physical or psychological reaction were to occur during any point of the study, appropriate care or referral will be made available. Should any injury occur to you, I understand that Benjamin M. Anguish, ATC will provide first aid and make any necessary medical referrals at your expense.

\section{Alternative}

The Alternatives to this study include physical therapy or strength training to the involved extremity. These therapies are used every day and therefore, they may be used as an alternative to participation in this research study. 


\section{Benefits}

You may receive direct benefits from this study if you are in one of the experimental groups. Benefits may include: gaining a better understanding of the severity of your ankle injury, learning safe exercises, and improving your function. Additionally, the knowledge gained from this study may eventually benefit others with chronic ankle instability.

\section{Financial Considerations}

There will be no cost as a result of participation in this study. You understand that you will not receive any monetary compensation for participation in this study.

\section{Confidentiality}

Subjects Name:

ID Number:

We know that information about you and your health is private. We are dedicated to protecting the privacy of that information. Because of this promise, we must get your written authorization (permission) before we may use or disclose your protected health information or share it with others for research purposes. This form gives that permission. It also helps us make sure that you are correctly told how this information will be used or disclosed. Please read the information below carefully before signing this form. Please ask any questions you may have about this form or its uses. You can decide to sign or not to sign this authorization form. However, if you choose not to sign this authorization form, you will not be able to take part in the research study. Whatever choice you make about this research study, it will not have an effect on you access to medical care.

\section{USE AND DISCLOSURE COVERED BY THIS AUTHORIZATION. DO NOT SIGN A} BLANK FORM. You or your authorized representative should thoroughly read the information below before signing this form. This form will authorize the following person(s), class(es) of persons, and/or organization (s) to disclose, use, and receive the information: WVU, Michelle A. Sandrey, PhD., ATC, Benjamin M. Anguish, ATC. The research site(s) carrying out this study includes WVU and University High School. It also includes each site's research staff and medical staff. Health care providers who provide services to you as part of this research study include Benjamin M. Anguish, ATC. If, during the course of the research, the institution listed above merges with, or is purchased by, another company or institution, this authorization to use or disclose protected health information in the research will extend to the successor company or institution. A self-report demographic history that includes information on height, weight, and past medical history of any lower limb injury is included in this study.

SPECIFIC UNDERSTANDINGS: By signing this research authorization form, you give permission for the use and/or disclosure of your protected health information described above. The purpose for the uses and disclosures you are authorizing is to carry out the research study explained to you during the informed consent process. It is also to ensure that the information 
relating to the research is available to all parties who may need it for research purposes. Your protected health information may be used as necessary for your research-related treatment. This information may be re-disclosed or used for other purposes if a recipient described in this form is not required by law to protect the privacy of the information. You have a right to refuse to sign this authorization. Your health care outside the study, the payment for your health care, and your health care benefits will NOT be affected if you do not sign this form. However you will NOT be able to take part in the research study described in this authorization if you do not sign this form. If you sign this authorization, you will have the right to cancel it at any time, except to the extent that WVU has already taken action based upon your authorization or needs the information to complete analysis and reports of data for this research study. To cancel this authorization, please write to the Principal Investigator, Michelle A. Sandrey, Ph.D, at: West Virginia University, PO Box 6116, Morgantown, WV 26506. You will NOT be allowed to see or copy the information described on this form as long as the research is in progress, but you have a right to see and copy the information upon completion of the research in accordance with hospital policies. You have a right to receive a copy of this form after you have signed it. Expiration Date: NONE

In any publications that result from this research, neither your name nor any information from which you might be identified will be published without your consent.

\section{THE SUBJECT OR HIS/HER AUTHORIZED REPRESENTATIVE MUST BE PROVIDED WITH A COPY OF THIS FORM AFTER IT HAS BEEN SIGNED.}

\section{SIGNATURE}

I have read this form and all of my questions about this form have been answered. By signing below, I acknowledge that I have read and accept all of the above.

Signature of Subject or Authorized

Representative

Date

Print Name of Subject or Authorized

Representative

Print Name of Individual Explaining this Research Authorization Form

CONTACT INFORMATION: The contact information of the subject or authorized representative who signed this form should be filled in below.

Address

Telephone: (daytime) (evening) 
E-mail Address(optional):

\section{Voluntary Participation}

Participation in this study is voluntary. You are free to withdraw your consent to participate in this study at any time. Refusal to participate or withdrawal will not affect your future care, your class standing, or your grades and will involve no penalty to you. In the event that new information becomes available that may affect your willingness to participate in this study, this information will be given to you so that you can make an informed decision about whether or not to continue your participation. You have been given the opportunity to ask questions about the research, and you have received answers concerning areas you did not understand.

Upon signing this form you will receive a copy.

I willingly consent to participate in this research.

Signature of Subject or

Subjects Legal Representative

Printed Name Date

Time

The participant has had the opportunity to have questions addressed. The participant willingly agrees to be in the study.

Signature of Investigator or

Printed Name

Date

Time 
Table C4. Demographic Questionnaire ${ }^{10,20}$

\section{Instructions}

This form will be used to categorize your ankle instability. A separate form should be used for the right and left ankles. Please fill out the form completely. If you have any question, please ask the administrator of the survey. Thank you for your participation.

Male / Female

Height:

Weight:

Ankle (circle): Right or Left

1. Have you ever sprained an ankle?

If yes, did the initial episode involve your ankle "rolling inward"?

$\mathrm{YN}$

If no, do not continue to fill out this questionnaire.

2. Have you ever seen a doctor for an ankle sprain?

If yes, How did the doctor categorize your most serious ankle sprain?

Mild (grade 1)

Moderate (grade II)

Y N

3. Did you ever use a devise (such as crutches) because you could not bear weight due to an ankle sprain?

If yes, In the most serious case, how long did you need to use the device?

$\begin{array}{lllll}\text { 1-3 days } & 4-7 \text { days } & 1-2 \text { weeks } & 2-3 \text { weeks } & \text { >3weeks }\end{array}$

4. Did the injury to your ankle require immobilization of any form (cast, braces, tape, etc)?

5. Have you been walking around unassisted without a "limp," for at least the past 3 months? Y N

$\begin{array}{lc}\text { 6. Have you had any fractures (breaks) in either of your ankles? } & \text { Y N }\end{array}$

$\begin{array}{lc}\text { 7. Have you had any surgeries in either of your lower extremities? } & \text { Y N }\end{array}$

8. Is the injured/unstable ankle functionally weaker, more painful, "looser," and less functional than your uninvolved ankle?

Y N

9. Have you ever experienced a sensation of your ankle "giving way"?

If yes, When was the last time your ankle "gave way"?

$\begin{array}{llll}<3 \text { weeks } & 3-6 \text { weeks } & \text { 1-3 months } & \text { 4 }\end{array}$

10. Does your ankle ever feel unstable while walking on a flat surface? $\quad$ Y N

11. Does your ankle ever feel unstable while walking on uneven ground? $\quad$ Y N

$\begin{array}{ll}\text { 12. Does your ankle ever feel unstable during recreational or sport activity? } & \text { Y N N/A }\end{array}$

$\begin{array}{ll}\text { 13. Does your ankle ever feel unstable while going up stairs? } & \text { Y N }\end{array}$

14. Do you attribute your current instability to past injuries to the affected ankle?

15. Are you currently involved in a "formal" rehabilitation program for the affected ankle? Y N

If you answered yes, please describe here.

Printed Name

Date

Signature

Administrator Use $\underline{\mathrm{ONLY}}$

Participant ID \# 


\section{Foot and Ankle Ability Measure (FAAM)}

Please answer every question with one response that most closely describes to your condition within the past week.If the activity in question is limited by something other than your foot or ankle mark notapplicable (N/A).

$\begin{array}{llllll}\text { No } & \text { Slight } & \begin{array}{l}\text { Moderate } \\ \text { diffficulticulty }\end{array} & \begin{array}{l}\text { Extreme } \\ \text { difficulty }\end{array} & \begin{array}{l}\text { Unable } \\ \text { do do }\end{array} & \text { N/A }\end{array}$

Standing

Walking on even ground

Walking on even ground without shoes

Walking up hills

Walking down hills

Going up stairs

Going down stairs

Walking on uneven ground

Stepping up and down curbs

Squatting

Coming up on your toes

Walking initially

Walking 5 minutes or less

Walking approximately 10 minutes

Walking 15 minutes or greater 
FAAM ADL Scale

Because of your foot and ankle how much difficulty do you have with:

$\begin{array}{lllll}\text { No } & \text { Slight } & \begin{array}{l}\text { Moderate } \\ \text { Difficulty }\end{array} & \begin{array}{l}\text { Extreme } \\ \text { difficulty }\end{array} & \text { Unable } \\ \text { difficulty }\end{array} \quad$ N/A

Home Responsibilities

Activities of daily living

Personal care

Light to moderate work (standing, walking)

Heavy work (push/pulling, climbing, carrying)

Recreational activities

How would you rate your current level of function during your usual activities of daily living from 0 to 100 with 100 being your level of function prior to your foot or ankle problem and 0 being the inability to perform any of your usual daily activities?

$\square \square \square .0 \%$ 


\section{FAAM Sports Scale}

Because of your foot and ankle how much difficulty do you have with:

$\begin{array}{lllll}\text { No } & \text { Slight } & \begin{array}{l}\text { Moderate } \\ \text { Difficulty }\end{array} & \begin{array}{l}\text { Extreme } \\ \text { difficulty }\end{array} & \text { Unable } \\ \text { difficulty }\end{array} \quad$ N/A

Running

Jumping

Landing

Starting and stopping

quickly

Cutting/lateral movements

Low impact activities

Ability to perform activity with your normal technique

Ability to participate in your desired sport as long as you would like

How would you rate your current level of function during your sports related activities from 0 to 100 with 100 being your level of function prior to your foot or ankle problem and 0 being the inability to perform any of your usual daily activities?

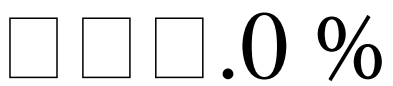

Overall, how would you rate your current level of function?

$\square$ Normal $\square$ Nearly normal $\square$ Abnormal $\square$ Severely abnormal 
Figure C1. Star Excursion Balance Test

1. Subjects' leg length will be measured, with a tape measure from the ASIS to the Medial Malleolus of the ankle on the involved side, in centimeters and recorded to normalize distances to height.

2. Warm-up session of five minutes on a stationary bicycle at 120 revolutions per minute.

3. The subjects will take a five-minute break after the practice trials.

4. Subjects will select an index card to randomly determine in which direction they start.

5. Subjects will be instructed to stand in the center of the star grid and maintain a single leg stance while reaching with the opposite leg to touch as far as possible along the randomly chosen reach direction.

6. Subjects will be instructed to touch the farthest point possible as light as possible along a chosen reach direction with the most distal part of the reach foot.

7. Subjects whose reaching leg will be the right went around the star grid in a counterclockwise fashion while subjects whose reaching leg will be the left went around the star grid in a clockwise fashion.

8. Subjects will be instructed to perform three practice trials in each of the three directions with a 15 -second rest between each excursion.

9. After a five-minute rest following the last practice trial, testing will begin.

10. Three trials will be performed in each of the three directions (anterior, posteromedial, and posterolateral) with a 15 -second rest between each reach.

11. Trials will be discarded and repeated if the reach foot will be used to provide considerable support when touching the ground, if the subjects' stance foot is lifted from the center of the star grid, or if the subjects are not able to maintain balance at any point in the trial.

12. The average for the three trails for each reach distance will be calculated and recorded.

13. The average excursions for the three-reach direction will be divided by leg length and multiplied by 100 to determine each subject's dynamic balance score in each of the three reach directions. 
1. Subjects will stand on adjustable board placed against a rigid wall with involved leg, and opposite leg will be on a box to even out stance.

2. Researcher will then tell subject that joint position is 0 degrees

3. For Dorsiflexion the researcher will place the 12.5 and 25 degree wedge and notify the subject of the angle for reference.

4. The order of directions tested will be dorsiflexion, plantarflexion, inversion then inversion. Sequence of angles tested will be randomized and pulled out of a hat.

5. Subject will then be given goggles with tape on the bottom and headphones to block out distraction

6. Subjects will then be given random wedge angles ranging from $0,2.5,5,7.5,10,12.5$, $15,17.5,20,22.5$, and 25 degrees, and be tapped on the leg to report the angle after 5 seconds (timed by a metronome). Subjects will step off between each wedge change and replace the leg for the next trial. Responses will be recorded

7. Steps 3,4,5 will be repeated for plantarflexion and inversion.

8. For eversion the researcher will place a 5 and 10 degree wedge and notify the subject of the angle for reference.

9. Repeat step 5

10. Subjects will then be given random wedge angles(out of a hat) ranging from $0,2.5,5,7.5$, and 10 degrees, and be tapped on the leg to report the angle after 5 seconds. Subjects will step off between each wedge change and replace its leg for the next trial. Responses recorded

11. There will be a total of 36 trials, data from each plane of motion will be reduced to create the estimate angle error. Estimate angle - Actual Slope angle $=$ Estimate angle error 
Figure C3. Dynamic Flex Band Flexibility Warm-Up Routine ${ }^{\text {Flex Band website }}$

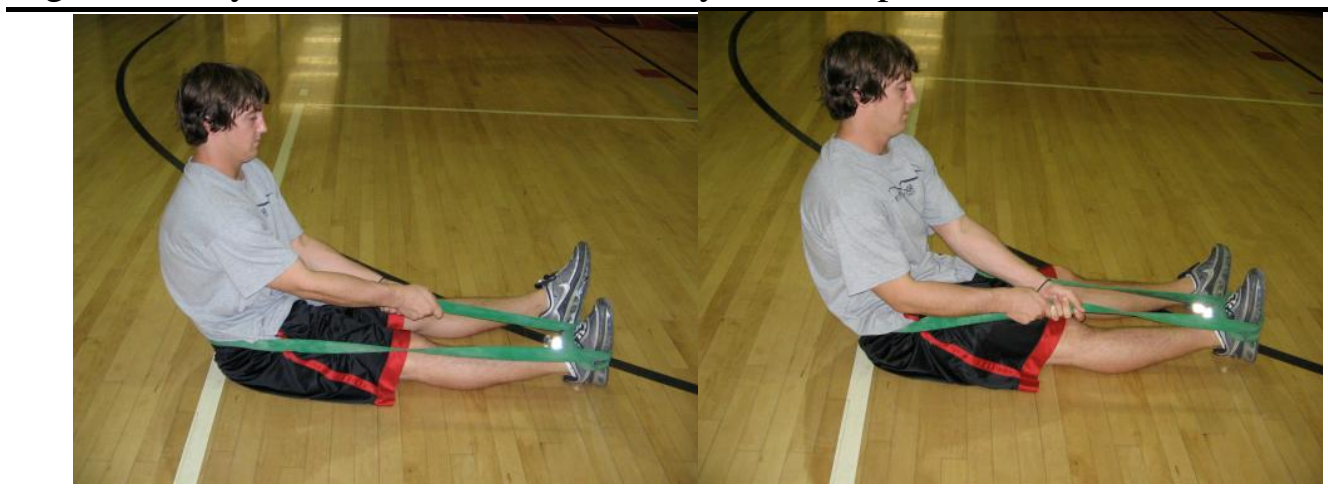

1. Ankles (Inversion/Eversion)

a. Sitting on the floor, position the band around the back at the belt-line.

b. Wrap the end of the band around the arch of the foot, forming a loop.

c. Holding onto the inner side of the band with both hands, turn the ankle in and out as far as it will go 10 times.

d. Then grasp the outer side of the band and turn the ankle out and then in 10 times.

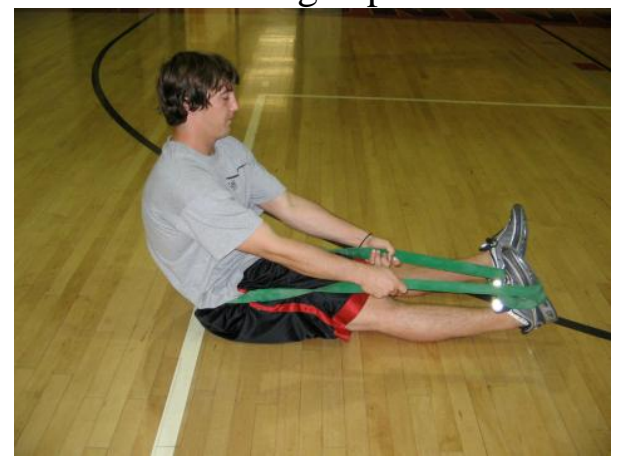

2. Calf Stretch

a. Reach down with both hands and adjust the loop so that it is around the fall of the foot.

b. With one hand on each side of the band below the knee, strech the calf by pulling toward you with the band (dorsiflexion).

c. Then, point the toes away from the body (plantarflexion).

d. Pull back and press out 10 times.

3. Achilles Stretch

a. With the band still positioned around the ball of the foot, plant your heel on the floor close to the body.

b. Stretch out the Achilles by pulling the band toward you.

c. Hold the band against the knee for added resistance and press the toes toward the floor.

d. Repeat 10 times.

4. At this point, grasp the "loop" in both hands and transfer it to the other foot. Repeat the Inversion/Eversion, Calf and Achilles Stretches for the other ankle before proceeding.

5. After completing the Ankle Work for both legs, remove band from around the waist. 


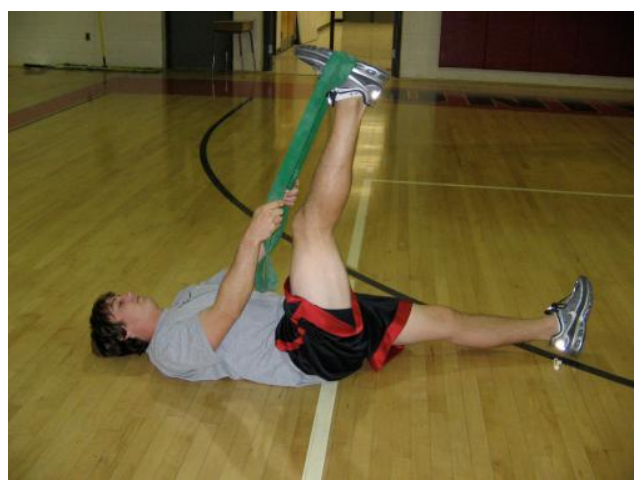

6. Hamstring Stretch

a. Re-wrap the band around the arch of the foot.

b. Lie back on the floor and stretch the hamstring as far as it will go by "walking" your hands up the band.

c. As you return your leg to the floor, let you hands slide down the band while providing resistance

d. Repeat 5 times.

e. Then "walk" up the band to the top and lock out the knee.

f. Hold that position for 5 seconds.

g. Next, give a slight bend to the knee and lock it out again, keeping pressure on the Golgi tendons behind the knee.

h. Bend and lock out 5 times.

i. Then, stretch back and hold again for 5 seconds.

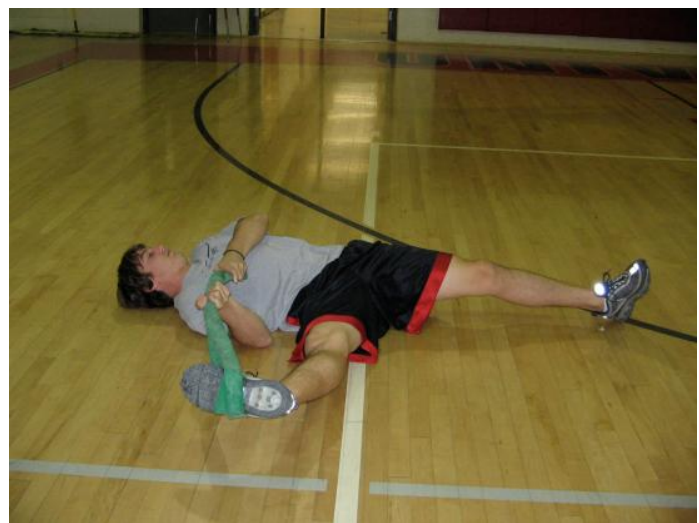

7. Groin Stretch

a. With the loop of the band still around the arch of the foot, grab the end of the band in your opposite hand.

b. With the other hand, grab the middle of the band and take the band behind the head, positioning your elbow on the floor and the leg out to the side as far as it will go.

c. Bend the knee slightly and then lock it out.

d. Repeat 10 times. 


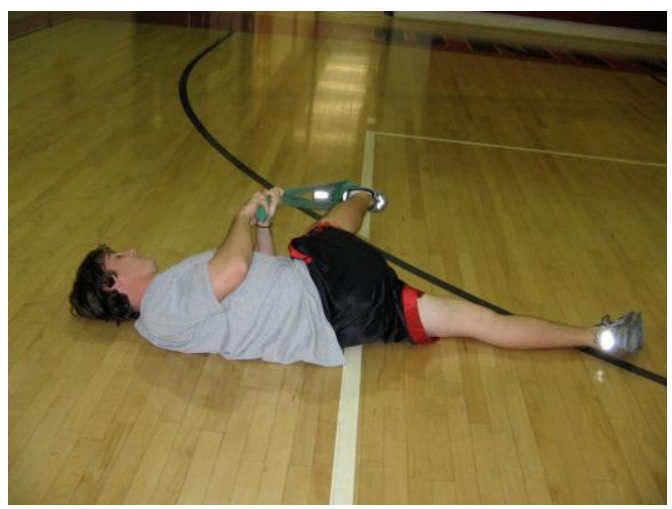

8. I-T Band Stretch

a. With the band still positioned around the arch of the foot, grab the end of the band with the same hand.

b. With your opposite hand, grab the middle of the band and take the band behind your head.

c. Set the elbow down on the floor and read the leg across your body, keeping both shoulders on the ground.

d. Lock the knee and hold for 5 seconds.

e. Next, bend the knee slightly and straighten 10 times.

f. Add more pressure by pulling on the band and hold for 5 seconds.

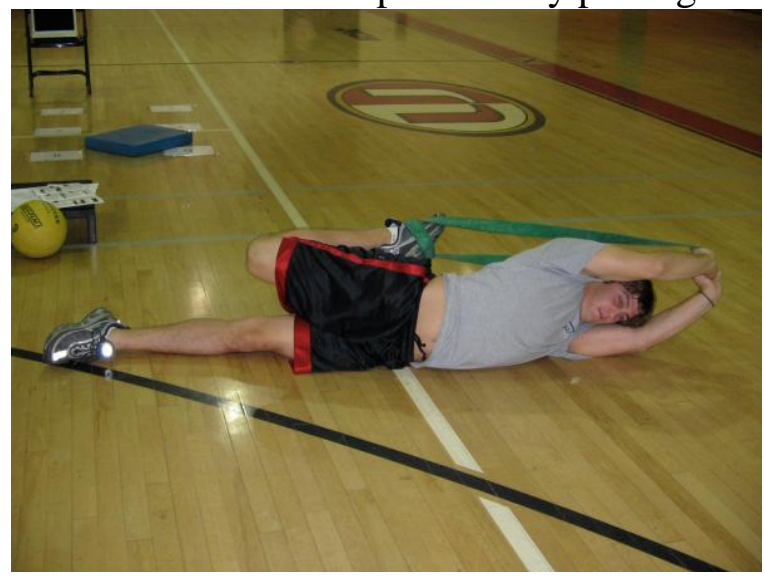

9. Quadriceps \& Hip Flexor Stretch

a. With the band still positioned around the arch of the foot, roll onto your opposite side with the knees bent.

b. Holding the top of the band above the head with both hands, move your leg around to stretch out the hip area.

c. Move your leg in any direction for about 15-30 seconds.

10. Now, sit up and transfer the band to your other foot. Repeat the Hamstring, Groin, I-T Band, and Quadriceps/Hip Flexor Stretches for the other leg. 
Hop to Stabilization

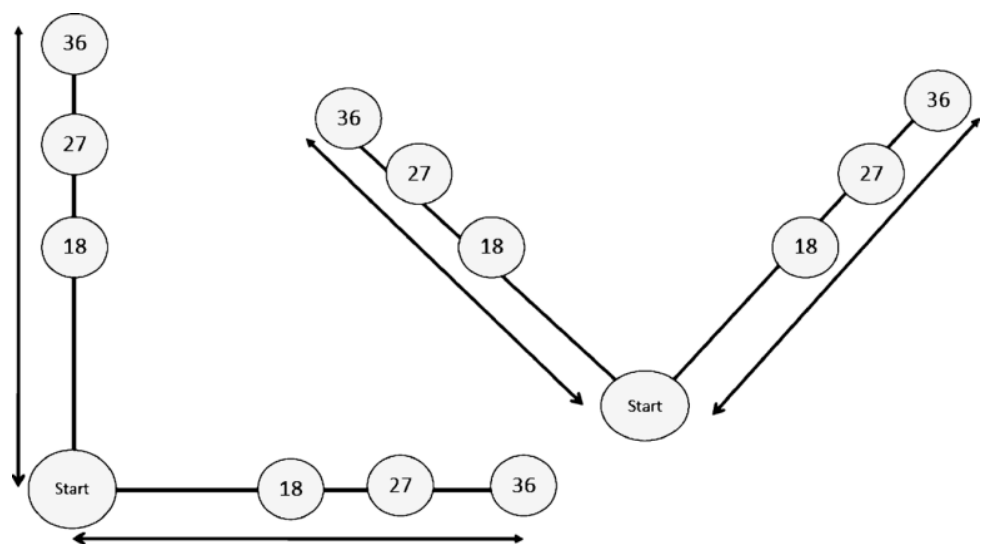

1. Single-limb Hops to Stabilization (10 Repetitions)

a. The subjects will perform ten hops in each of the four directions, anterior/posterior, medial/lateral, anterolateral/posteromedial, and anteromedial/posterolateral.

b. Each repetition will consist of a hop from the starting position to the target position $(18,27$, or 36 inches).

c. After stabilizing balance in a single-limb stance, subjects will hop in the exact opposite direction back to the starting position and stabilize in the single-limb stance.

Errors will be determined on the basis of the following:

1. Touching down with the opposite limb

2. Excessive trunk motion $\left(>30^{\circ}\right.$ lateral flexion)

3. Removal of hands from hips during hands on hips activities

4. Bracing the nonstance limb against the stance limb, and missing the target.

2. Hop to Stabilization and Reach (5 repetitions)

a. A combination of the previously mentioned exercise.

b. However, after stabilization in the single-limb stance, the subject will reach back to the starting position. 
c. Repetitions will be counted in the same manner. Subjects will hop, stabilize, and reach back toe the starting position.

d. Then he/she will hop back to the starting position and reach to the targeted position.

Errors will be determined by:

1. All errors associated with hop to stabilization

2. Using the reaching leg for substantial amount of support during reaching component.

7 progression levels for Hop to Stabilization and Hop to Stabilization and Reach:

1. 18-inch hop; allowed to use arms to aid in stabilizing balance after landing

2. 18-inch hop with hands on hips while stabilizing balance after landing

3. 27-inch hop; allowed to use arms to aid in stabilizing balance after landing

4. 27-inch hop with hands on hips while stabilizing balance after landing

5. 36-inch hop; allowed to use hands to aid in stabilizing balance after landing

6. 36-inch hop with hands on hips while stabilizing balance after landing

7. 36-inch hop from a 6-inch platform.

3. Unanticipated Hop to Stabilization (3 sequences of numbers)

a. Subjects stood in the middle of a nine-marker grid (see figure c3).

b. A randomized, sequence of numbers will be displayed on a computer screen in front of the subjects.

c. Each number will correspond to a target position to which he/she will hop.

d. As the progression of numbers changes, subjects will hop to the new target position.

e. The hop to stabilization rules will apply for this activity; however, in this case, subjects will be allowed to use any combination of hops (AP, ML, AM/PL, or $\mathrm{AL} / \mathrm{PM}$ ) he/she desires to accomplish the goal of getting through the sequence error-free.

f. As a subject develops proficiency, the amount of time per move is reduced.

g. In each session, subjects will perform three sequences of numbers.

The levels of Unanticipated Hop to Stabilization is as follows:

1. Level 1; five seconds per move 
2. Level 2; three seconds per move

3. Level 3; one second per move

4. Level 4; if subject can progress to completion of all moves within one second without error, a foam pad will be placed on one of the numbers during the sequence. The subject will then continue the progression at the same level of intensity. If he/she cannot complete the course error-free, the time constraint will be increased to the level below

5. Level 5; if subject can progress to completion of all moves at level 3 within the foam pad error-free, a step will be added to an additional number

6. Level 6; if a subject progresses error-free, an additional foam pad will be added to one of the numbers, resulting in two foam pads and one step

7. Level 7; if a subject progresses error-free, an additional step will be included, resulting in two foam pads and two steps.

Errors will be determined by:

1. Touching down with the opposite limb

2. Excessive trunk motion $\left(>30^{\circ}\right.$ lateral flexion)

3. Removal of hands from hips during hand on hips activities

4. Bracing the nonstance limb against the stance limb

5. Missing the target.

4. Single-limb Stance (3 repetitions)

a. Each activity (eyes open and eyes closed) have seven levels of difficulty and is as follows:

b. Single-limb stance with eyes opened:

i. Arms across chest on hard floor for 60 seconds

ii. Arms across chest for 30 seconds on foam pad

iii. Arms across chest for 60 seconds on foam pad

iv. Arms across chest for 90 seconds on foam pad.

c. With ball toss on foam pad:

i. 30 seconds with arms across chest; 20 throws with 6-lb medicine ball

ii. 60 seconds with arms across chest; 20 throws with 6-lb medicine ball

iii. 90 seconds with arms across chest; 20 throws with 6-lb medicine ball. 
d. Single-limb stance with eyes closed:

i. Arms out on hard floor for 30 seconds

ii. Arms across chest on hard floor for 30 seconds

iii. Arms across chest on hard floor for 60 seconds

iv. Arms out on foam pad for 30 seconds

v. Arms across chest for 30 seconds on foam pad

vi. Arms across chest for 60 seconds on foam pad

vii. Arms across chest for 90 seconds on foam pad.

Errors will be determined by:

1. Touching down with opposite limb

2. Excessive trunk motion ( $>30^{\circ}$ lateral flexion)

3. Removal of arms from across chest during specified activities

4. Bracing the nonstance limb against the stance limb. 
Table C5: Traditional Rehabilitation Program ${ }^{34}$

1. Single-limb Stance

Each activity (eyes open and eyes closed) has seven levels of difficulty and is as follows: the following steps may be advanced when exercise is done error free.

a. Single-limb stance with eyes opened: (2 repetitions)

i. Arms across chest on hard floor for 60 seconds

ii. Arms across chest on hard floor for 60 seconds with eyes closed

iii. Arms across chest for 60 seconds adding light perturbations

b. Single leg stance with ball toss: (3 repetitions)

i. 10 throws with 6-lb medicine ball; single leg stance on hard floor

ii. 20 throws with 6-lb medicine ball; single leg stance on hard floor

iii. 20 throws with 6-lb medicine ball; single leg stance on foam pad

c. Single-limb stance opposite left kicking with resistance: (3 repetitions)

i. Green resistance band; 5 kicks in all 4 directions

ii. Blue resistance band; 5 kicks in all 4 directions

iii. Blue resistance band; 10 kicks in all 4 directions

d. Step downs with involved leg on step (2 repetitions)

i. 6 inch step; heel touches in 3 directions for 5 repetitions

ii. 6 inch step; foam pad; heel touches in 3 directions for 5 repetitions

iii. 10 inch step; foam pad; heel touches in 3 directions for 5 repetitions

Errors will be determined by:

2. Touching down with opposite limb

3. Excessive trunk motion $\left(>30^{\circ}\right.$ lateral flexion)

4. Removal of arms from across chest during specified activities

5. Bracing the nonstance limb against the stance limb. 


\section{APPENDIX D}

\section{ADDITIONAL RESULTS}

Table D1. Descriptive Statistics on Means and Standard Deviations for all Dependent Variables.

\begin{tabular}{|c|c|c|c|c|c|c|}
\hline \multirow{2}{*}{$\begin{array}{l}\text { Dependent } \\
\text { Variable }\end{array}$} & \multicolumn{2}{|c|}{ Control } & \multicolumn{2}{|c|}{ Traditional } & \multicolumn{2}{|c|}{ Dynamic } \\
\hline & Pre-Test & Post-Test & Pre-Test & Post-Test & Pre-Test & Post Test \\
\hline FAAM & $76.0 \pm 3.25$ & $76.38 \pm 2.72$ & $70.88 \pm 2.57$ & $73.11 \pm 2.09$ & $70.33 \pm 4.44$ & $74.67 \pm 4.15$ \\
\hline FAAM & $27.63 \pm 1.85$ & $27.75 \pm 1.91$ & $24.22 \pm 1.86$ & $26.44 \pm 1.59$ & $21.0 \pm 2.69$ & $22.89 \pm 3.02$ \\
\hline SPORT & & & & & & \\
\hline SEBT & & & & & & \\
\hline A & $85.06 \pm 3.06$ & $85.50 \pm 3.24$ & $83.93 \pm 5.71$ & $87.93 \pm 5.17$ & $87.43 \pm 4.39$ & $92.42 \pm 4.50$ \\
\hline PM & $97.52 \pm 5.65$ & $97.95 \pm 5.65$ & $95.8 \pm 6.71$ & $99.93 \pm 6.18$ & $97.98 \pm 4.36$ & $101.14 \pm 4.33$ \\
\hline PL & $88.01 \pm 2.57$ & $88.57 \pm 2.41$ & $89.31 \pm 5.21$ & $94.38 \pm 6.21$ & $88.96 \pm 3.50$ & $93.08 \pm 3.80$ \\
\hline JPS & & & & & & \\
\hline $\mathrm{DF}$ & $1.93 \pm .18$ & $1.90 \pm .17$ & $1.87 \pm .30$ & $1.58 \pm .30$ & $2.22 \pm .83$ & $1.89 \pm .68$ \\
\hline $\mathrm{PF}$ & $1.84 \pm .44$ & $1.78 \pm .49$ & $2.21 \pm .95$ & $1.67 \pm .73$ & $1.94 \pm .69$ & $1.67 \pm .54$ \\
\hline IV & $1.70 \pm .32$ & $1.70 \pm .34$ & $2.20 \pm .97$ & $1.88 \pm .68$ & $2.05 \pm .61$ & $1.67 \pm .32$ \\
\hline $\mathrm{EV}$ & $1.33 \pm .22$ & $1.17 \pm .22$ & $1.60 \pm .83$ & $1.39 \pm .28$ & $1.32 \pm .38$ & $1.25 \pm 0$ \\
\hline
\end{tabular}

Key: FAAM= Foot and Ankle Ability Measure; SEBT= Star Excursion Balance Test; $A=$ Anterior; $\mathrm{PM}=$ Posterior Medial; $\mathrm{PL}=$ Posterior Lateral; JPS= Joint Position Sense; $\mathrm{DF}=$ Dorsiflexion; $\mathrm{PF}=$ Plantarflexion; IV= Inversion; $\mathrm{EV}=$ Eversion.

Table D2. Two-way Repeated Measures ANOVA Results for FAAM and FAAM Sport

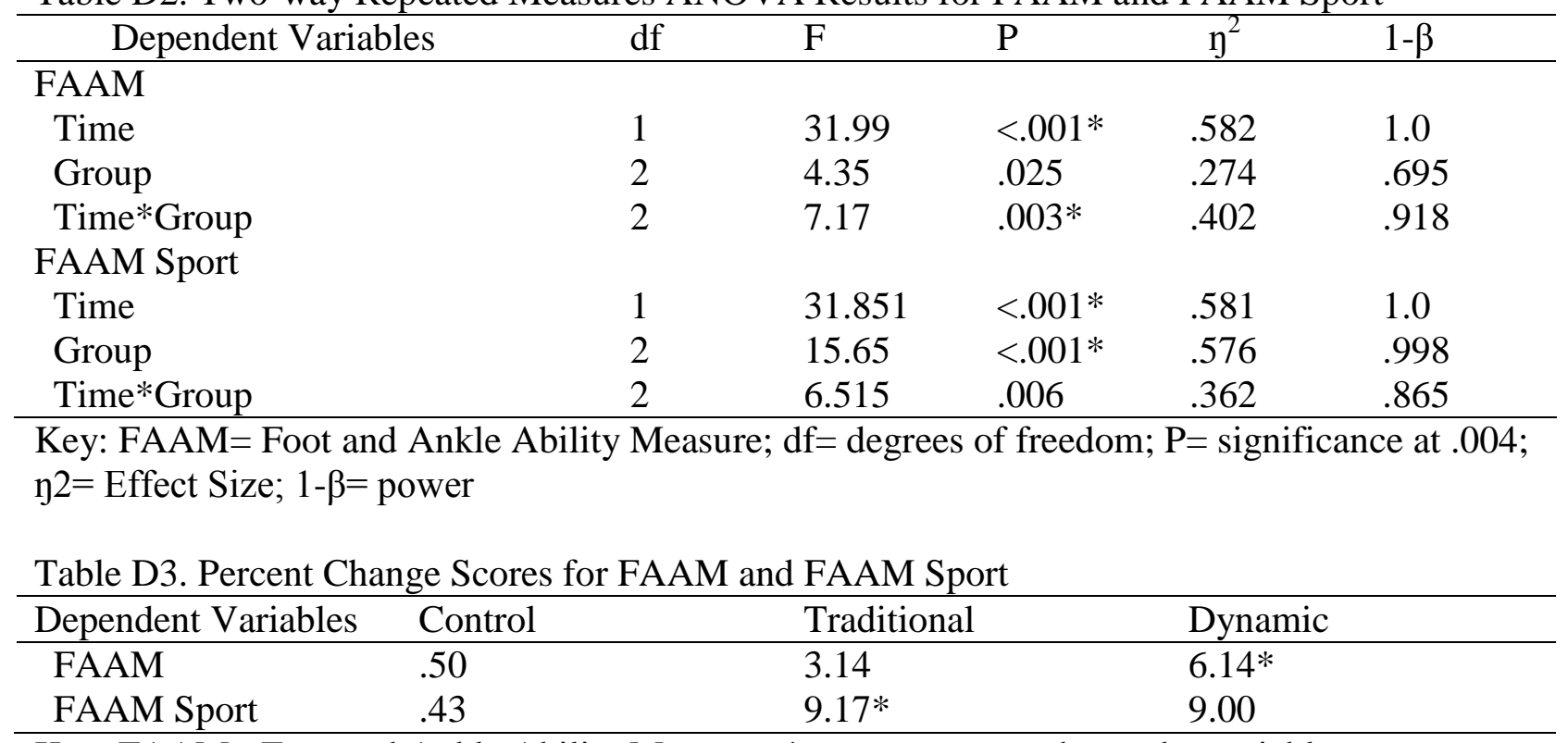

Key: FAAM= Foot and Ankle Ability Measure; * = most percent change by variable

Table D4. Two way Repeated Measures ANOVA Results for SEBT A, PM, and PL

\begin{tabular}{llllll}
\hline Dependent Variables & df & F & P & $\eta^{2}$ & $1-\beta$ \\
\hline SEBT A & & & & & \\
Time & 1 & 128.561 & $<.001^{*}$ & .848 & 1.00 \\
Group & 2 & 2.80 & .082 & .196 & .496 \\
Time*Group & 2 & 24.469 & $<.001 *$ & .680 & 1.00
\end{tabular}




\begin{tabular}{llllll} 
SEBT PM & & & & \\
$\quad$ Time & 1 & 108.216 & $<.001 *$ & .825 & 1.00 \\
$\quad$ Group & 2 & .301 & .743 & .025 & .092 \\
$\quad$ Time*Group & 2 & 19.461 & $<.001 *$ & .629 & 1.00 \\
SEBT PL & & & & & \\
$\quad$ Time & 1 & 149.251 & $<.001 *$ & .866 & 1.00 \\
$\quad$ Group & 2 & 1.65 & .215 & .125 & .311 \\
Time*Group & 2 & 25.764 & $<.001 *$ & .691 & 1.00 \\
\hline
\end{tabular}

Key: SEBT $=$ Star Excursion Balance Test; $\mathrm{A}=$ Anterior; $\mathrm{PM}=$ Posterior Medial; $\mathrm{PL}=$ Posterior Lateral; $\mathrm{df}=$ degrees of freedom; $\mathrm{P}=$ significance at $.004 ; \mathrm{\eta}^{2}=$ Effect Size; $1-\beta=$ power

Table D5: Percent Change Scores for SEBT- A, PM, PL

\begin{tabular}{llll}
\hline Dependent Variables & Control & Traditional & Dynamic \\
\hline SEBT A & .52 & 4.77 & $5.71^{*}$ \\
SEBT PM & .49 & $4.31^{*}$ & 3.23 \\
SEBT PL & .64 & $5.68^{*}$ & 4.60 \\
\hline
\end{tabular}

Key: SEBT= Star Excursion Balance Test; A= Anterior; PM= Posterior Medial; PL= Posterior Lateral; * ${ }^{*}$ most percent change by variable

Table D6. Two-way Repeated Measures ANOVA Results for JPS DF, PF,IV, EV

\begin{tabular}{|c|c|c|c|c|c|c|}
\hline Dependent Variables & & $\mathrm{df}$ & $\mathrm{F}$ & $\mathrm{P}$ & $\eta^{2}$ & $1-\beta$ \\
\hline \multicolumn{7}{|l|}{ JPS DF } \\
\hline \multicolumn{2}{|l|}{ Time } & 1 & 12.85 & $.002 *$ & .358 & .929 \\
\hline \multicolumn{2}{|l|}{ Group } & 2 & 1.116 & .345 & .088 & .222 \\
\hline \multicolumn{2}{|l|}{ Time*Group } & 2 & 2.334 & .119 & 169 & .424 \\
\hline \multicolumn{7}{|l|}{ JPS PF } \\
\hline \multicolumn{2}{|l|}{ Time } & 1 & 12.194 & $.002 *$ & .346 & .917 \\
\hline \multicolumn{2}{|l|}{ Group } & 2 & .096 & .889 & .01 & .066 \\
\hline \multicolumn{2}{|l|}{ Time*Group } & 2 & 2.661 & .091 & 188 & .475 \\
\hline \\
\hline \multicolumn{2}{|l|}{ Time } & 1 & 10.954 & $.003 *$ & .323 & .887 \\
\hline \multicolumn{2}{|l|}{ Group } & 2 & .729 & .493 & .06 & .158 \\
\hline \multicolumn{2}{|l|}{ Time*Group } & 2 & 2.659 & .091 & 188 & .475 \\
\hline \multicolumn{7}{|l|}{ JPS EV } \\
\hline \multicolumn{2}{|l|}{ Time } & 1 & 2.584 & .122 & .101 & .338 \\
\hline \multicolumn{2}{|l|}{ Group } & 2 & 1.253 & .304 & .098 & .245 \\
\hline \multicolumn{2}{|l|}{ Time*Group } & 2 & .207 & .814 & .018 & .079 \\
\hline \multicolumn{7}{|c|}{$\begin{array}{l}\text { Key: JPS= Joint Position Sense; } \mathrm{DF}=\text { Dorsiflexion; } \mathrm{PF}=\text { Plantarflexion; } \mathrm{IV}=\text { Inversion; } \mathrm{EV}= \\
\text { Eversion; } \mathrm{df}=\text { degrees of freedom; } \mathrm{P}=\text { significance at } .004 ; \mathrm{n}^{2}=\text { Effect Size; } 1-\beta=\text { power }\end{array}$} \\
\hline \multicolumn{7}{|c|}{ Table D7. Percent Change Scores for JPS- DF, PF, IV, EV } \\
\hline \multicolumn{3}{|c|}{ Dependent Variables Control } & \multicolumn{2}{|c|}{ Traditional } & \multicolumn{2}{|c|}{ Dynamic } \\
\hline \multirow{3}{*}{$\begin{array}{l}\text { DF } \\
\text { PF } \\
\text { IV }\end{array}$} & \multicolumn{2}{|l|}{1.55} & \multicolumn{2}{|c|}{$15.51 *$} & \multicolumn{2}{|c|}{14.86} \\
\hline & \multicolumn{2}{|l|}{3.26} & \multicolumn{2}{|l|}{$24.43 *$} & \multicolumn{2}{|c|}{13.92} \\
\hline & \multicolumn{2}{|l|}{0} & \multicolumn{2}{|l|}{14.50} & \multicolumn{2}{|c|}{$18.54^{*}$} \\
\hline EV & 12.03 & & $13.13 *$ & & 5.30 & \\
\hline
\end{tabular}

Key: JPS= Joint Position Sense; DF= Dorsiflexion; PF= Plantarflexion; IV= Inversion; EV= Eversion; * = most percent change by variable 
Table D8: Confidence Intervals for DV

\begin{tabular}{|c|c|c|c|c|}
\hline FAAM & Time & Mean & Lower Bound & Upper Bound \\
\hline \multirow[t]{2}{*}{ Dynamic } & 1 & 70.33 & 66.58 & 74.09 \\
\hline & 2 & 74.67 & 71.35 & 77.99 \\
\hline \multirow[t]{2}{*}{ Traditional } & 1 & 70.89 & 67.14 & 74.64 \\
\hline & 2 & 73.11 & 69.78 & 76.64 \\
\hline \multirow[t]{2}{*}{ Control } & 1 & 76.00 & 72.02 & 79.98 \\
\hline & 2 & 76.38 & 72.84 & 79.91 \\
\hline \multicolumn{5}{|c|}{ FAAM Sport } \\
\hline \multirow[t]{2}{*}{ Dynamic } & 1 & 21.00 & 18.68 & 23.33 \\
\hline & 2 & 22.89 & 20.47 & 25.31 \\
\hline \multirow[t]{2}{*}{ Traditional } & 1 & 24.22 & 21.89 & 26.55 \\
\hline & 2 & 26.44 & 24.02 & 28.87 \\
\hline \multirow[t]{2}{*}{ Control } & 1 & 27.63 & 25.16 & 30.09 \\
\hline & 2 & 27.75 & 25.18 & 30.31 \\
\hline \multicolumn{5}{|c|}{ SEBT Anterior } \\
\hline \multirow[t]{2}{*}{ Dynamic } & 1 & 87.43 & 82.55 & 92.29 \\
\hline & 2 & 92.43 & 87.71 & 97.14 \\
\hline \multirow[t]{2}{*}{ Traditional } & 1 & 83.93 & 79.01 & 88.80 \\
\hline & 2 & 87.93 & 83.21 & 92.64 \\
\hline \multirow[t]{2}{*}{ Control } & 1 & 85.09 & 79.92 & 90.25 \\
\hline & 2 & 85.49 & 80.49 & 90.49 \\
\hline \multicolumn{5}{|c|}{ SEBT Posteriomedial } \\
\hline \multirow[t]{2}{*}{ Dynamic } & 1 & 97.98 & 91.96 & 104.01 \\
\hline & 2 & 101.14 & 95.35 & 106.94 \\
\hline \multirow[t]{2}{*}{ Traditional } & 1 & 95.80 & 89.78 & 101.83 \\
\hline & 2 & 99.93 & 94.13 & 105.72 \\
\hline \multirow[t]{2}{*}{ Control } & 1 & 97.54 & 91.13 & 103.92 \\
\hline & 2 & 97.95 & 91.80 & 104.09 \\
\hline SEBT Poste & & & & \\
\hline Dynamic & 1 & 88.96 & 84.73 & 93.18 \\
\hline & 2 & 93.08 & 88.29 & 97.88 \\
\hline Traditional & 1 & 89.31 & 85.08 & 93.54 \\
\hline & 2 & 94.38 & 89.58 & 99.17 \\
\hline Control & 1 & 88.01 & 83.53 & 92.49 \\
\hline & 2 & 88.57 & 83.48 & 93.65 \\
\hline JPS Dorsifle & & & & \\
\hline Dynamic & 1 & 2.22 & 1.66 & 2.79 \\
\hline & 2 & 1.89 & 1.41 & 2.37 \\
\hline Traditional & 1 & 1.87 & 1.30 & 2.43 \\
\hline & 2 & 1.59 & 1.11 & 2.07 \\
\hline Control & 1 & 1.93 & 1.33 & 2.53 \\
\hline & 2 & 1.89 & 1.39 & 2.41 \\
\hline JPS Plantar & & & & \\
\hline Dynamic & 1 & 1.94 & 1.16 & 2.73 \\
\hline & 2 & 1.67 & 1.03 & 2.31 \\
\hline Traditional & 1 & 2.21 & 1.42 & 2.99 \\
\hline & 2 & 1.67 & 1.03 & 2.31 \\
\hline Control & 1 & 1.84 & 1.01 & 2.67 \\
\hline & 2 & 1.78 & 1.10 & 2.46 \\
\hline JPS Inversic & & & & \\
\hline Dynamic & 1 & 2.05 & 1.29 & 2.80 \\
\hline & 2 & 1.67 & 1.15 & 2.18 \\
\hline Traditional & 1 & 2.20 & 1.45 & 2.96 \\
\hline & 2 & 1.88 & 1.37 & 2.39 \\
\hline Control & 1 & 1.70 & .90 & 2.50 \\
\hline & 2 & 1.70 & 1.16 & 2.25 \\
\hline JPS Eversio & & & & \\
\hline Dynamic & 1 & 1.32 & .73 & 1.91 \\
\hline & 2 & 1.25 & 1.03 & 1.47 \\
\hline Traditional & 1 & 1.59 & 1.01 & 2.19 \\
\hline & 2 & 1.39 & 1.17 & 1.61 \\
\hline Control & 1 & 1.33 & .70 & 1.95 \\
\hline & 2 & 1.17 & .94 & 1.4 \\
\hline
\end{tabular}

Key: 1=pre, $2=$ post, SEBT $=$ Star excursion balance test, JPS=joint position sense 
Figure D1. FAAM and FAAM Sport Means and Standard Deviations

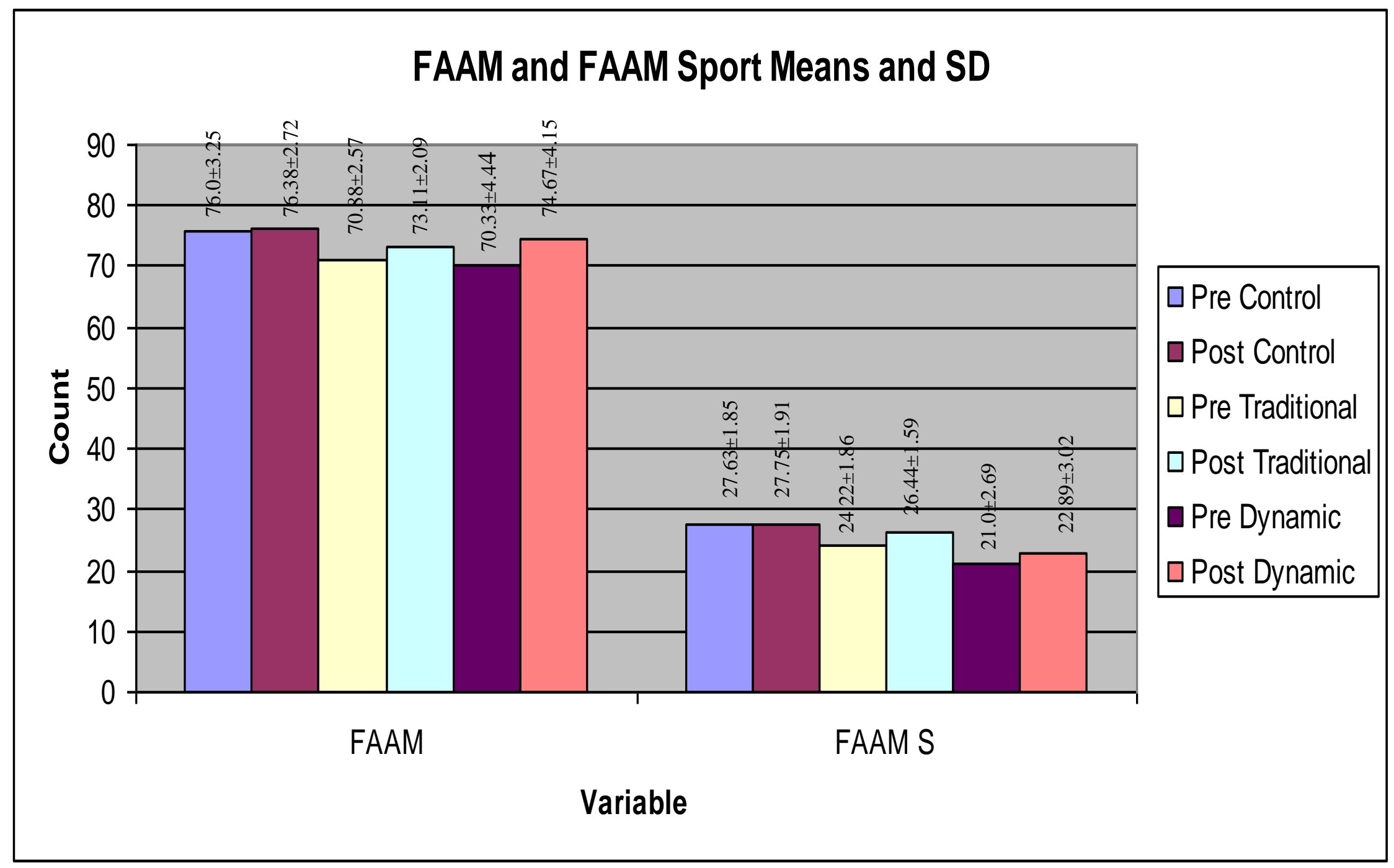

Key: FAAM= Foot and Ankle Ability Measure 
Figure D2. SEBT Means and Standard Deviations

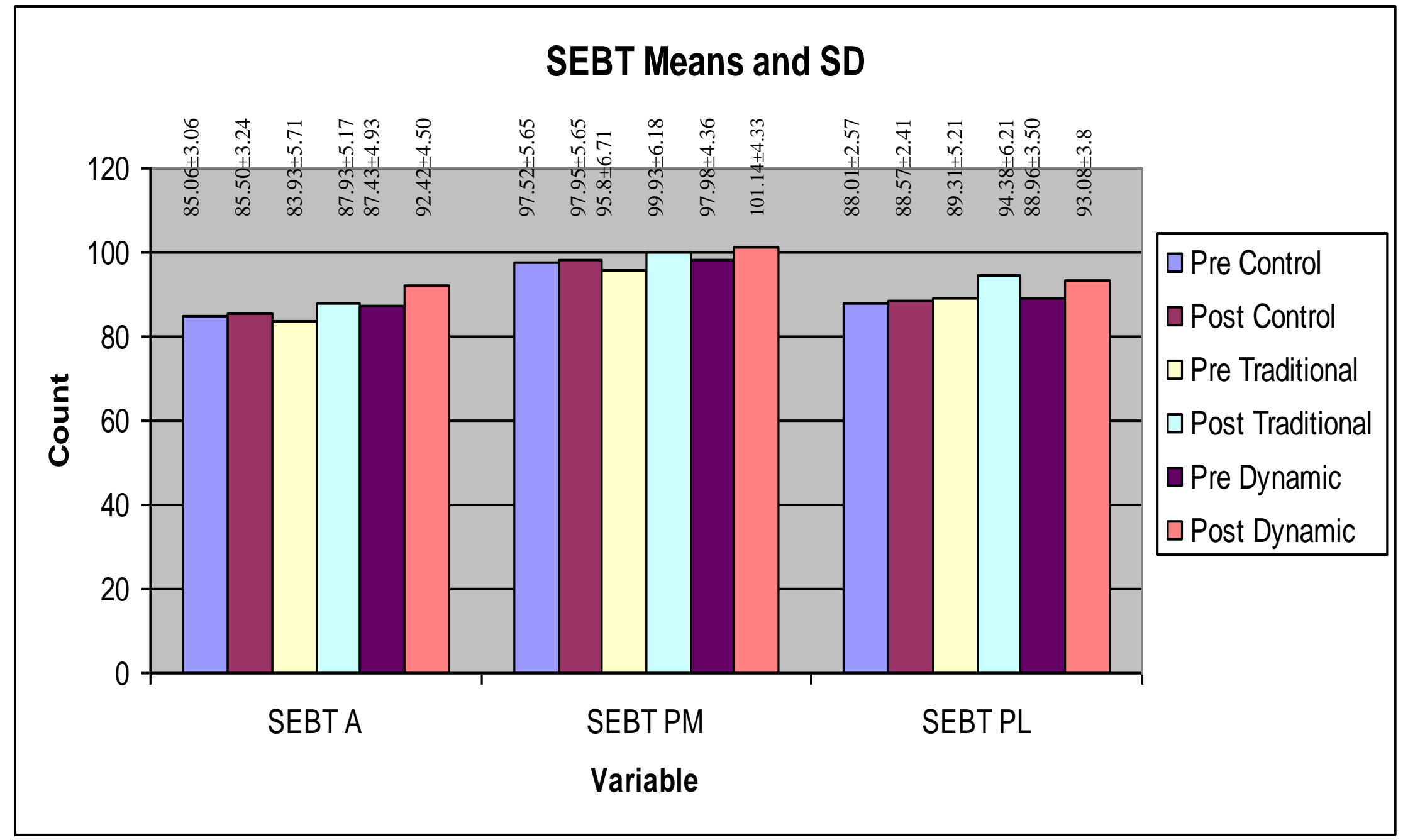

Key: SEBT= Star Excursion Balance Test, A=Anterior, PM=Posterior Medial, PL=Posterior Lateral 


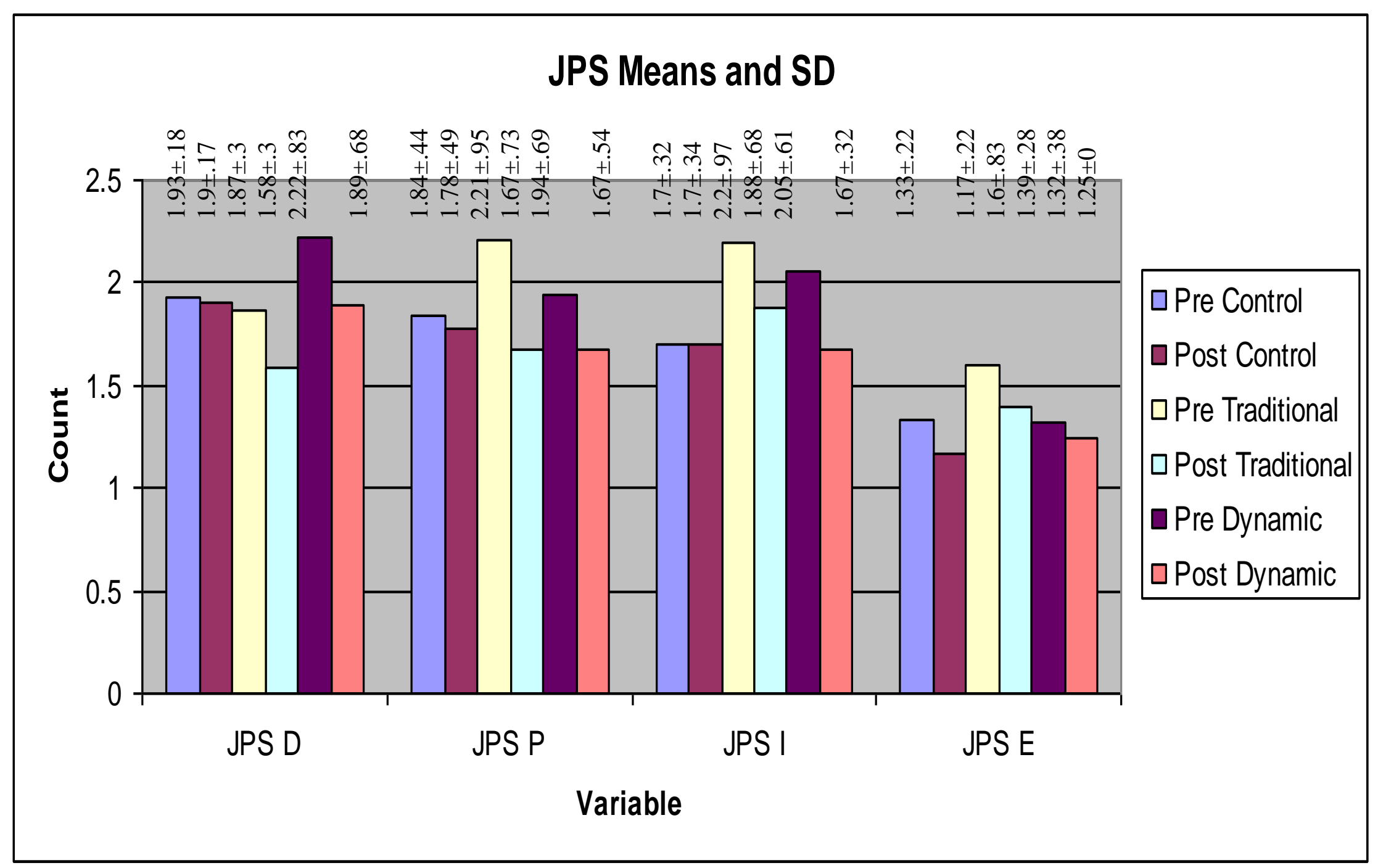

Key: JPS= Joint Position Sense, D= Dorsiflexion, $\mathrm{P}=\mathrm{Plantarflexion,} \mathrm{I}=$ Inversion, $\mathrm{E}=$ Eversion 


\section{APPENDIX E \\ RECOMMEDATIONS FOR FUTURE RESEARCH}

1. Conduct the study during the spring or summer when there are fewer activities at the school and where school cancellations would not be an issue due to weather.

2. Increase the number of researchers collecting data to two or four to aid in data entry and treatment.

3. Increase the length of the study to six or eight weeks to potentially see if differences between groups are evident.

4. Increase the number of subjects per experimental groups to 30 to 45 to increase significance, power, and effect size.

5. Use a multiple sites for subjects for data collection to increase the number of participants and provide a more heterogeneous subject population.

6. Conduct the study using recreational, collegiate, high school, and youth athletes.

7. Conduct the study using non-physically active subjects with chronic ankle instability.

8. Conduct the study on athletes who are not conditioning with out of season workouts.

9. Conduct the study in a controlled laboratory setting or an undisturbed, restrained area.

10. Conduct a prospective study as a pre-season injury prevention program each year, and then perform a longitudinal study to look at the injury rates for this season, and successive years. 


\section{ADDITIONAL REFERENCES}

36 Hertal J, Denegar, CR, Monroe MM, Stokes WL. Talocrural and subtalar joint instability after lateral ankle sprains. Med Sci Sport Exerc. 1999;31(11):1501-1508

37 Safran MR, Benedetti RS, Bartolozzi AR, Manselbaum BR. Lateral ankle sprains: a comprehensive review part 1: etiology, pathoanatomy, histopathologies, and diagnosis. Med Sci Sport Exerc. 1999;31(7):S429-S437

38 Hopkins JT, Palmeri R. Effects of Ankle Joint Effusion on Lower Leg Function. Clinical Journal of Sport Medicine. January 2004;14(1):1-7

39 Young CC, Neidfeldt MW, Morris GA, Eerkes KJ. Clinical Examination of the foot and ankle. Prim Care Clin Offic Pract. 2005;32:105-132

40 Hale S, Hertel J. Reliability and Sensitivity of the Foot and Ankle Disability Index in Subjects with Chronic Ankle Instability. J Athl Train. January 2005;40(1):35-40.

41 Kynsburg Á, Halasi T, Tállay A, Berkes I. Changes in joint position sense after conservatively treated chronic lateral ankle instability. Knee Surgery, Sports Traumatology, Arthroscopy. December 2006;14(12):1299-1306.

42 Starkey C, Ryan J. Evaluation of Orthopedic and Athletic Injuries. $2^{\text {nd }}$ ed. Philadelphia, PA: F.A Davis Company. 2002; 158,159

43 Willems T, Witvrouw E, Verstuyft J, Vaes P. Proprioception and muscle strength in subjects with a history of ankle sprains and chronic instability. J Athl Train. 2002;37(4):361-366

44 Zoch C, Fialka-Moser V, Quittan M. Rehabilitation of ligamentous ankle injuries: a review of recent studies. Br J Sports Med. 2003;37;291-295

45 Melham TJ, Sevier TL, Malnofski MJ, Wilson JK, Robert HJ. Chronic pain and fibrosis successfully treated with new no augmentated soft tissue mobilization technique(ASTM): a case report. Med Sci Sport Exerc. 1998;30(6):801-804

46 Miller CA, Bosco JA. Lateral ankle and subtalar instability. Bull Hosp Jt Dis. 2001-2002; 60(3-4):143-9

47 Morrison KE, Kaminski TW. Foot characteristics in association with inversion ankle injury. J Athl Train. 2007;42(1):135-142

48 Ross SE, Guskiewicz KM, Gross MT. Assessment tools for identifying functional limitations associated with functional ankle instability. J Athl Train. 2008;43(1):44-50 
49 Boyce SH, Quigley MA, Campbell S. Management of ankle sprains: a randomized controlled trial of the treatment of inversion injuries using elastic support bandage or aircast ankle braces. Br J Sports Med. 2005;39:91-96

50 Hertal J. Functional anatomy, pathomechanics and pathophysiology of lateral instability. J Athl Train. 2002;37(4):364-375

51 Levangie PK, Norkin CC. Joint Structure and Function: A Comprehensive Analysis. 3ed. Philadelphia, PA: F.A. Davis; 2001:2,372-376

52 Nordin M, Frankel VH. Basic Biomechanics of Musculoskeletal Systems. 3 ed. Baltimore, MD: Lippincott Williams \& Wikins; 2001:251

53 Hertal J, Denegar CR, Monroe MM, Stokes WL. Talocrural and subtalar joint instability after lateral ankle sprain. Med Sci Sport Exerc. 1999;31(11):1501-1508.

54 Prentice WE. Rehabilitation techniques for sports medicine and athletic training. $4^{\text {th }}$ ed. New York, NY. Mc Graw-Hill Companies, Inc. 2004;28-30,40-47,600-684

55 Prentice WE. Arnheim's principles of athletic training a competency based approach $12^{\text {th }}$ ed. New York, NY. Mc Graw-Hill Companies, Inc. 2006:272-292,560-597

56 Moore KL, Dalley AF. Clinically Oriented Anatomy. $5^{\text {th }}$ ed. Baltimore, MD: Lippincott, Williams \& Wilkins;2006, 551-555, 577, 583, 588, 589

57 Rockar PA. The subtalar joint: anatomy and joint potion. J Orthop Sports Phys Ther. 1995;21(6):361-372

58 Hetal J. Sensimotor deficits with ankle sprains and chronic ankle instability. Clin Sports Med. 2008;27:353-370

59 Forkin DM, Koczur C, Battle R, Newton RA. Evaluation of kinesthetic deficits indicative of balance control in gymnasts with unilateral chronic ankle sprains. J Orthop Sports Phys Ther. 1996:23(4):245-250

60 Garrison JG, Hart JM, Palmeiri RM, Kerrigan DC, Ingersoll CD. Lower extremity EMG in male and female college soccer players during single leg landing. J Sport Rehabil. $2005 ; 14: 48-57$

61 Hopkins JT, Palmeri R. Effects of Ankle Joint Effusion on Lower Leg Function. Clinical Journal of Sport Medicine. January 2004;14(1):1-7

62 Taser F, Shafiq Q, Ebraheim NA. Anatomy of lateral ankle ligaments and their relationship to bony landmarks. Surg radiol Anat 2006;28:391-397 
63 Hootman JM, Dick R, Agel J. Epidemiology of collegiate injuries for 15 sports: summary and recommendations for injury prevention initiatives. J Athl Train. 2007;42(2):311-9

64 Kaminski TW, Hartsell HD. Factors contributing to chronic ankle instability: a strength perspective. J Athl Train. 2002:37(4):394-405

65 Beynnon BD, Murphy DF, Alsoa DM. Predictive Factors for the lateral ankle sprain: a literature Review. J Athl Train. 2002;37(4):376-380

66 Beynnon BD, Vacek PM, Murphy D, Alosa D, Paller D. First-time inversion ankle ligament trauma: the effects of sex, level of competition, and sport on the incidence of injury. Am J Sports Med. 2005;33:1485-1491

67 Karlsson J, Brandersson S, Jerre R. Ligament injuries of the ankle joint. Curr Opin Orthop. 1999;10:143-9

68 Van Dijk C, Mol B, Lim L, Marti R, Bossuyt R. Diagnosis of ligament rupture of the ankle joint. Acta Orthop Scand. 1996;67(6):566-570

69 Vela L, Tourville TW, Hertel J. Physical examination of acutely injured ankles: an evidence based approach. Athl Ther Today. 2003;8(5):13-19

70 Hertel J, Hale SA, Olmstead LC. The effect of a 4-week comprehensive rehabilitation program on postural control and lower extremity function in individuals with chronic ankle instability. J Orthop Sports Phys Ther. 2007;37(6):303-11

71 Hertal J, Denegar CR. A rehabilitation paradigm for restoring neuromuscular control following athletic injury. Athl Ther Today. 1998;3(5):12-16

72 Bleakley CM, McDonough SM, MacAuley DC. Cryotherapy for acute ankle sprains: a randomized controlled study for two different icing protocols. Br J Sports Med. 2006; $40: 700-705$

73 Enwemeka, CS, Allen C, Avila P, Bina J, Konrade J, Munns S. Soft tissue thermodynamics before, during and after cold pack therapy. Med Sci Sport Exerc. 2002;34(1):45-50

74 Kovaleski JE, Norrell PM, Heitman RJ, Hollis JM, Pearsall AW. Knee and ankle position, anterior drawer laxity and stiffness of the ankle complex. J Athl Train. 2008; 43(3):242-8 